SAND89-1343

TTC 1015

DE91 009852

Unlimited Distribution

Printed December 1990

\title{
EVALUATION OF IMPACT \\ LIMITER PERFORMANCE DURING \\ END-ON AND SLAPDOWN DROP TESTS OF \\ A ONE-THIRD SCALE MODEL STORAGE/TRANSPORT \\ CASK SYSTEM*
}

H. R. Yoshimura, D. R. Bronowski, and W. L. Uncapher

Transportation System Development Department

Sandia National Laboratories**

Albuquerque, NM 87185

S. W. Attaway

Engineering Analysis Department

Sandia National Laboratories

Albuquerque, NM 87185

V. I. Bateman, T. G. Carne, and D. L. Gregory

Experimental Mechanics Department

Sandia National Laboratories

Albuquerque, NM 87185

M. Huerta

Southwest Engineering Associates

E1 Paso, TX 79925

*This work was performed at Sandia National Laboratories, Albuquerque, New Mexico, supported by the United States Department of Energy under Contract DE-AC04-76DP00789.

$* *$ A United States Department of Energy Facility. 


\section{DISCLAIMER}

This report was prepared as an account of work sponsored by an agency of the United States Government. Neither the United States Government nor any agency Thereof, nor any of their employees, makes any warranty, express or implied, or assumes any legal liability or responsibility for the accuracy, completeness, or usefulness of any information, apparatus, product, or process disclosed, or represents that its use would not infringe privately owned rights. Reference herein to any specific commercial product, process, or service by trade name, trademark, manufacturer, or otherwise does not necessarily constitute or imply its endorsement, recommendation, or favoring by the United States Government or any agency thereof. The views and opinions of authors expressed herein do not necessarily state or reflect those of the United States Government or any agency thereof. 


\section{DISCLAIMER}

Portions of this document may be illegible in electronic image products. Images are produced from the best available original document. 
This report describes drop testing of a one-third scale model shipping cask system. Two casks were designed and fabricated by Transnuclear, Inc., to ship spent fuel from the former Nuclear Fuel Services West Valley reprocessing facility in New York to the Idaho National Engineering Laboratory for a long-term spent fuel dry storage demonstration project. As part of the NRC's regulatory certification process, one-third scale model tests were performed to obtain experimental data on impact limiter performance during impact testing. The objectives of the testing program were to (1) obtain deceleration and displacement information for the cask and impact limiter system, (2) obtain dynamic force-displacement data for the impact limiters, (3) verify the integrity of the impact limiter retention system, and (4) examine the crush behavior of the limiters. Two 30-ft (9-m) drop tests were conducted on a mass model of the cask body and scaled balsa and redwood-filled impact limiters. In the first test, the cask system was tested in an end-on configuration. In the second test, the system was tested in a slapdown configuration where the axis of the cask was oriented at a 12.4-degree angle with the horizontal. Slapdown occurs when one end of the cask impacts the target at an angle, resulting in a primary and secondary impact. This report describes the results of both tests in terms of measured decelerations, posttest deformation measurements, and the general structural response of the system. 
1.0 INTRODUCTION $\ldots \ldots \ldots \ldots \ldots \ldots \ldots \ldots \ldots \ldots \ldots \ldots \ldots \ldots \ldots$

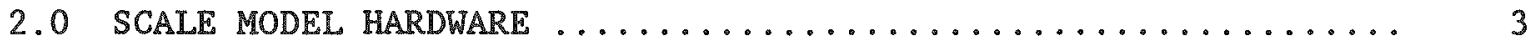

3.0 TEST PROCEDURE/INSTRUMENTATION $\ldots \ldots \ldots \ldots \ldots \ldots \ldots \ldots \ldots$

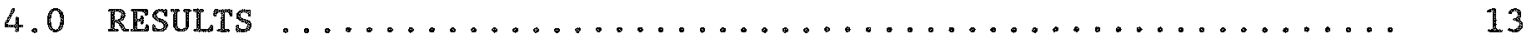

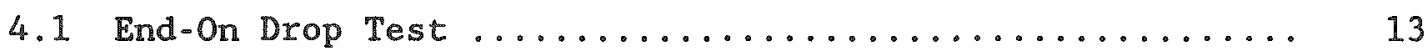

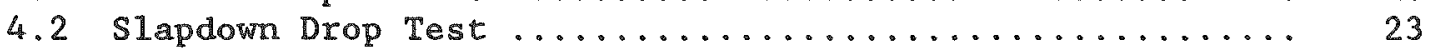

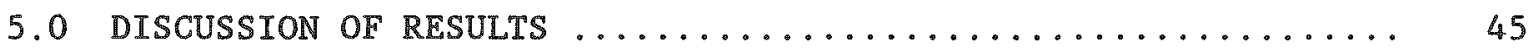

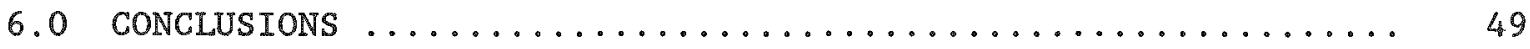

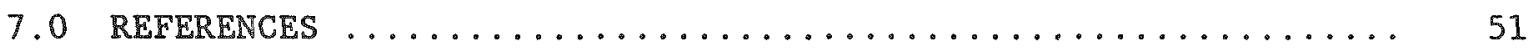

APPENDIX A FABRICATION DRAWINGS FOR THE MODEL CASK AND IMPACT
LIMITERS $\ldots \ldots \ldots \ldots \ldots \ldots \ldots \ldots \ldots \ldots \ldots \ldots \ldots \ldots \ldots \ldots \ldots$

APPENDIX B INSTRUMENTATION SPEGIFICATIONS $\ldots \ldots \ldots \ldots \ldots \ldots \ldots \ldots$ B-1

APPENDIX $c$ POSTTEST MEASUREMENTS $\ldots \ldots \ldots \ldots \ldots \ldots \ldots \ldots \ldots \ldots \ldots \ldots$

APPENDIX D MICROGRAPHS OF BOLT FAILURE SURFACES AND A DISCUSSION OF BOLT FAILURE MECHANISM ............... D 1

APPENDIX E DERIVATION OF FORCE-DISPLACEMENT CURVES FOR IMPACT LIMITERS FROM ACCELEROMETER AND FILM DATA ......... E-1

APPENDIX F DETAILS OF THE SUM OF WEIGHTED ACCELERATIONS AND DECONVOLUTION TECHNIQUES 
Table

C-1 Dimensional Differences for the Top End Impact Limiter After the End-On Drop Test ...................... C-5

C-2 Dimensional Differences for the Top Impact Limiter After the Slapdown Drop Test .................... C-6

C-3 Dimensional Differences for the Bottom Impact Limiter After the Slapdown Drop Test .................... C-7

E-1 Force-Displacement Results for the End-On Drop Test ...... E-3

E-2 Displacement and Rotation of the Center of Gravity of the Cask During the Slapdown Drop Test ............... E-8

E-3 Calculated Impact Limiter Forces and Displacements for the Slapdown Drop Test ........................... E-9 


\section{FIGURES}

Figure

Page

1 Schematic of the Model Cask ..................... 4

2 Schematic of the Impact Limiters $\ldots \ldots \ldots \ldots \ldots \ldots \ldots \ldots$

3 Impact Limiter with the End Cover Plates Removed ......... 6

4 The Test System Before the End-On Drop Test $\ldots \ldots \ldots \ldots \ldots \ldots$

5 Schematic of the Instrumentation for the End-On Drop Test ... 9

6 Schematic of the Instrumentation for the Slapdown Drop Test .. 11

7 Schematic of the Impact Limiter Bolt Instrumentation ....... 12

8 The Test System in Position for the End-On Drop Test ....... 14

9 Sequence From High-Speed Film of the End-On Drop Test ...... 15

10 The Test System After the End-On Drop Test ............ 18

11 Deformation Pattern in the Impact Limiter Gusset Plates After the End-On Drop Test ...................... 19

12 Vertical Displacement vs. Time for a Point on the Cask and on the Impact Limiter During the End-On Drop Test ....... 20

13 Vertical Velocity vs. Time for a Point on the Cask and on the Impact Limiter During the End-On Drop Test .......... 21

14 Acceleration vs. Time for the End-On Drop Test .......... 22

15 The Test System Before Impacting the Target in the

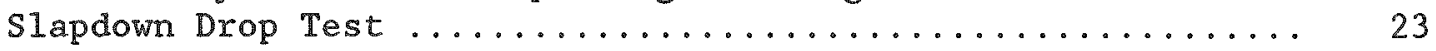

16 Sequence From High-Speed Film of the Slapdown Drop Test .... 24

17 The Test System After the Slapdown Drop Test ............ 29

18 Deformations Sustained by Impact Limiters in the Slapdown Drop Test ........................... 30

19 Failed Impact Limiter Retaining Bolts .............. 31

20 Vertical Displacement vs. Time for the Center of Gravity of the Cask During the Slapdown Drop Test ............. 32

21 Cask Attitude vs. Time for the Cask During the Slapdown Drop

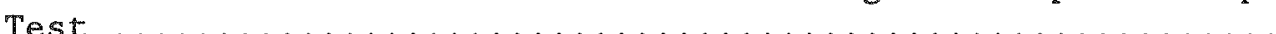


FIGURES

(continued)

Figure

Page

22 Vertical Velocity of the Center of Gravity of the Cask vs.

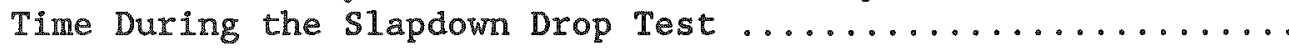

23 Angular Velocity of the Cask vs. Time During the Slapdown

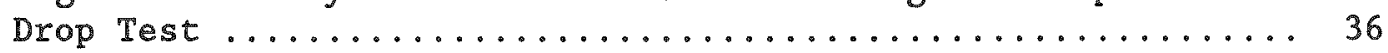

24 Acceleration vs. Time From Accelerometers on the First Plane Measured During the Slapdown Drop Test .............

25 Acceleration vs. Time From Accelerometers on the Third Plane Measured During the Slapdown Drop Test ............ 38

26 Acceleration vs. Time From Accelerometers on the Fourth Plane Measured During the Slapdown Drop Test ............. 39

27 Acceleration vs. Time From Accelerometers on the Fifth

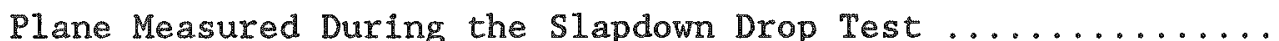

28 Acceleration in Axial Direction vs. Time From Accelerometers on the Third Plane During the Slapdown Drop Test ......... 42

29 Microstrain Signals From Instrumented Bolts SB5 and SB8 Measured During the Slapdown Drop Test ................

30 Microstrain Signals From Instrumented Bolts SB6 and SB7

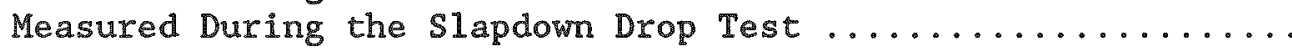
44

31 Force vs. Displacement for the Impact Limiter From the End-On Drop Test .............................. 46

32 Force vs. Displacement for the Impact Limiter From the Slapdown Drop Test ......................... 48

B-1 Data Sheet for an Endevco 2262-1000 Piezoresistive Accelerometer ............................ B 4

B-2 Data Sheet for an Endevco 2264 Piezoresistive

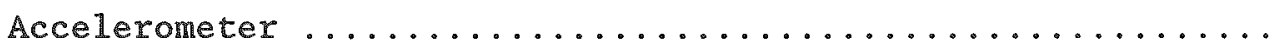

B-3 Data Sheet for an Endevco 7270A Piezoresistive Accelerometer ........................... B 6

B-4 Schematic of a Soft-Mounted Endevco 7270A-2K Piezoresistive

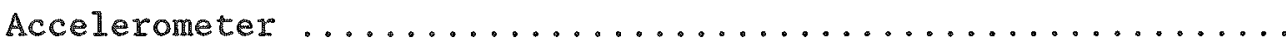

B-5 Shaker Calibration of a Soft-Mounted Endevco 7270A

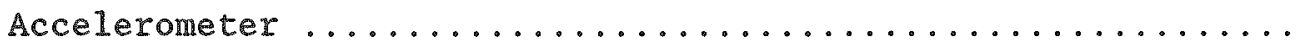


FIGURES

(continued)

Figure

$\underline{\text { Page }}$

B-6 Centrifuge Calibration of a Soft-Mounted Endevco 7270A

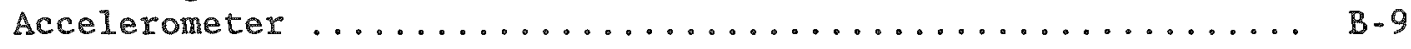

B-7 Shaker Calibration of an Endevco 7270A Accelerometer ....... B-10

B-8 Centrifuge Calibration of an Endevco 7270A Accelerometer .... B-11

B-9 Force Calibration Test for an SDH-QB-1/2-13NC $\times 21 / 2 \mathrm{Lg}$

Strainsert Bolt .............................

C-1 Schematic of Measurements From the Impact Limiter ......... C-4

C-2 Lateral Deformations Sustained by the Impact Limiters ..... C-8

D-1 Micrographs of Fracture Surface of Upper Bolt $\ldots \ldots \ldots \ldots \ldots$ D-4

D-2 Micrographs of Fracture Surface of Lower Bolt .......... D-5

D-3 Velocity Conditions of the Cask at Time of Bolt Failure .... D-6

D-4 Forces Acting on Limiter at Time of Bolt Failure ........ D 7

E-1 Accelerometer Trace Used to Estimate Force for End-On

Drop Test .............................. E

E-2 SWAT Data Used to Estimate Forces on Cask During Slapdown Drop Test ........................... E-6

E-3 Geometric Relationships Used to Calculate Displacement at End of Cask Relative to the Center of Gravity ......... E-7

F-1 Accelerometer Placement to Measure Axial Force Component..... F-5

F-2 Accelerometer Placement to Measure Lateral Force Component... F-7

F-3 Accelerometer Locations and Assumed Input Force Points for DECON ........................... F 9

F-4 Reconstructed Lateral Force for Slapdown Test Using SWAT .... F-12

F-5 Reconstructed Moment for Slapdown Test Using SwAT ........ F-13

F-6 Reconstructed Angular Velocity for Slapdown Test.......... F-14

F-7 Force Reconstruction fox Primary End Using DECON ......... F-15

F-8 Force Reconstruction for Secondary End Using DECON ....... F-15 


\section{FIGURES}

(concluded)

Figure

Page

F-9 Comparison of Reconstructed Forces From SWAT and DECON..... F-16

F-10 Comparison of Normalized SWAT and $1500 \mathrm{~Hz}$ Filtered Accelerometer Data ............................ F-17

F-11 Comparison of Reconstructed Forces From SWAT and DECON with Force Estimated by Conventional Filter Technique ....... F-17 


\subsection{INTRODUCTION}

This report describes drop tests of a one-third scale model storage/transport cask system. Two casks were designed and fabricated by Transnuclear, Inc., to transport spent fuel from the former Nuclear Fuel Services West Valley reprocessing facility to the Idaho National Engineering Laboratory for a long-term dry storage project. As part of the NRC's regulatory certification process, scale model tests were performed to obtain experimental data on impact limiter performance during impact tests. Two $30-\mathrm{ft}(9-\mathrm{m})$ drop tests were conducted in accordance with regulatory requirements. In the first series, the system was tested in an end-on drop orientation; the second series of tests involved a slapdown orientation with the cask axis at a nominal angle of 10 degrees to the horizontal. Slapdown occurs when one end of the cask impacts the target at an angle, resulting in a primary and a secondary impact.

These test series were designed to obtain deceleration and displacement information for the system as well as dynamic force-displacement data for the impact limiters. The tests also allow evaluation of the crush behavior of the impact limiters and the performance of the limiter retention system.

In both test series, the cask was instrumented with numerous accelerometers and the tests were photographed with high-speed cameras. Instrumented bolts attached an impact limiter to the cask body.

Test results are described in terms of measured decelerations and the observed structural response of the system. Also included are estimates of the dynamic force-displacement characteristics of the impact limiters. All accelerometer traces are provided on microfiche inside the back report cover. 


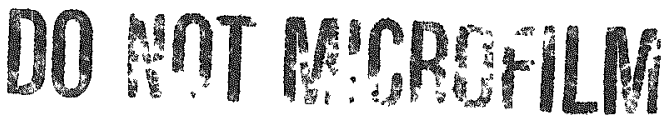 \\ This Phis}




\subsection{SCALE MODEL HARDWARE}

The cask system was designed for the transport and storage of spent fuel elements (Nolan et al., 1986). The cask body is a thick-walled steel cylinder with an integrally welded forged bottom closure. The full-scale system incorporates a flanged and bolted forged top lid. The one-third scale model that was tested had welded plates at each end of the cylindrical body and did not simulate the bolted closure of the prototype. The scaled cask body acted only as an equivalent mass and was not intended to model the full-scale cask in detail. Each end of the cask had four attachment bolts as well as four unthreaded holes to accept shear pins on the limiters. The model cask weighed $78501 \mathrm{~b}$. Figure 1 is a schematic of the fabrication features of the model cask.

Figure 2 illustrates the construction of the 360-1b impact 1imiters. The impact limiters used redwood and balsa encased in sheet metal plating. The steel plating on the outer surface of the model limiter was $0.090 \mathrm{in}$. thick. Internally, the limiters featured 0.060-in. gusset plates running radially. Figure 3 illustrates how the wood was placed in the steel shell. Each wood piece in the model was scaled down from the prototype. All cut lines of the prototype limiters were reflected in the model. Fabrication drawings for the cask and limiters are included in Appendix A. 


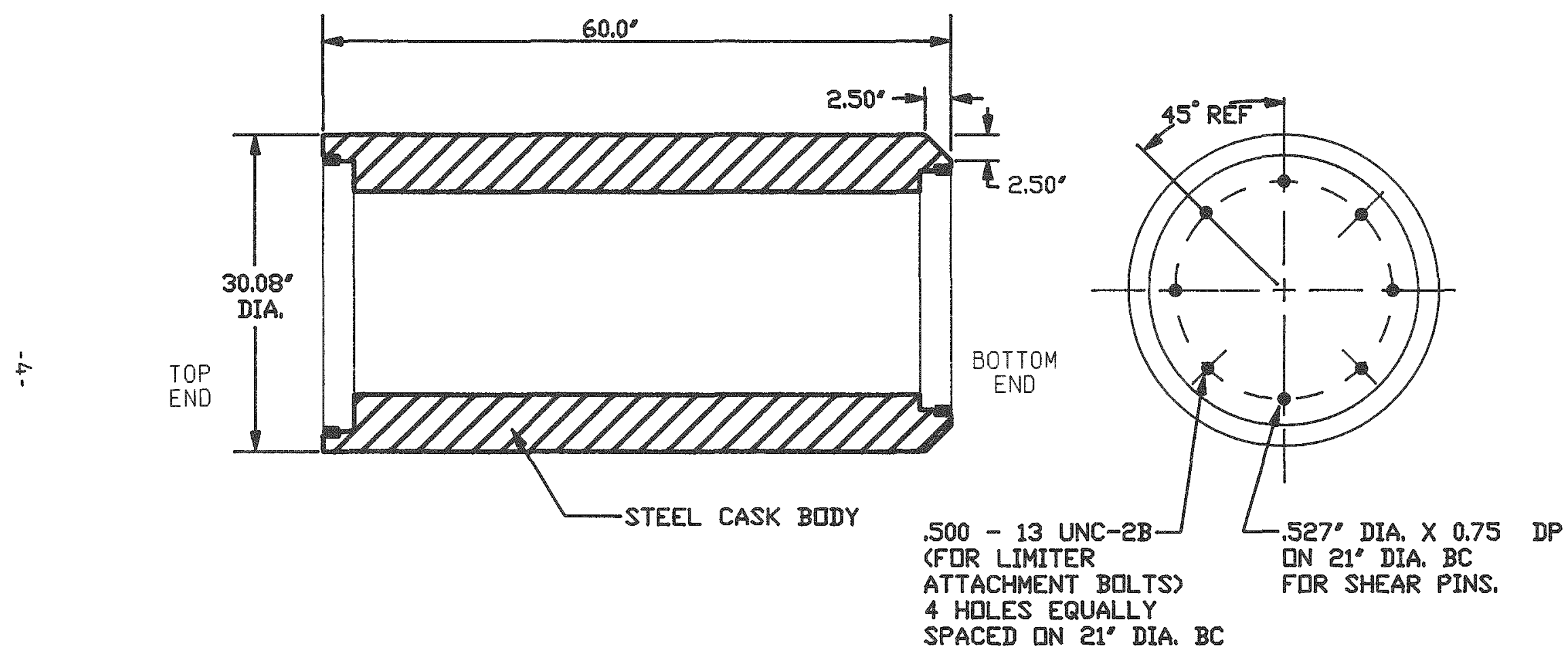

Figure 1. Schematic of the Model Cask 


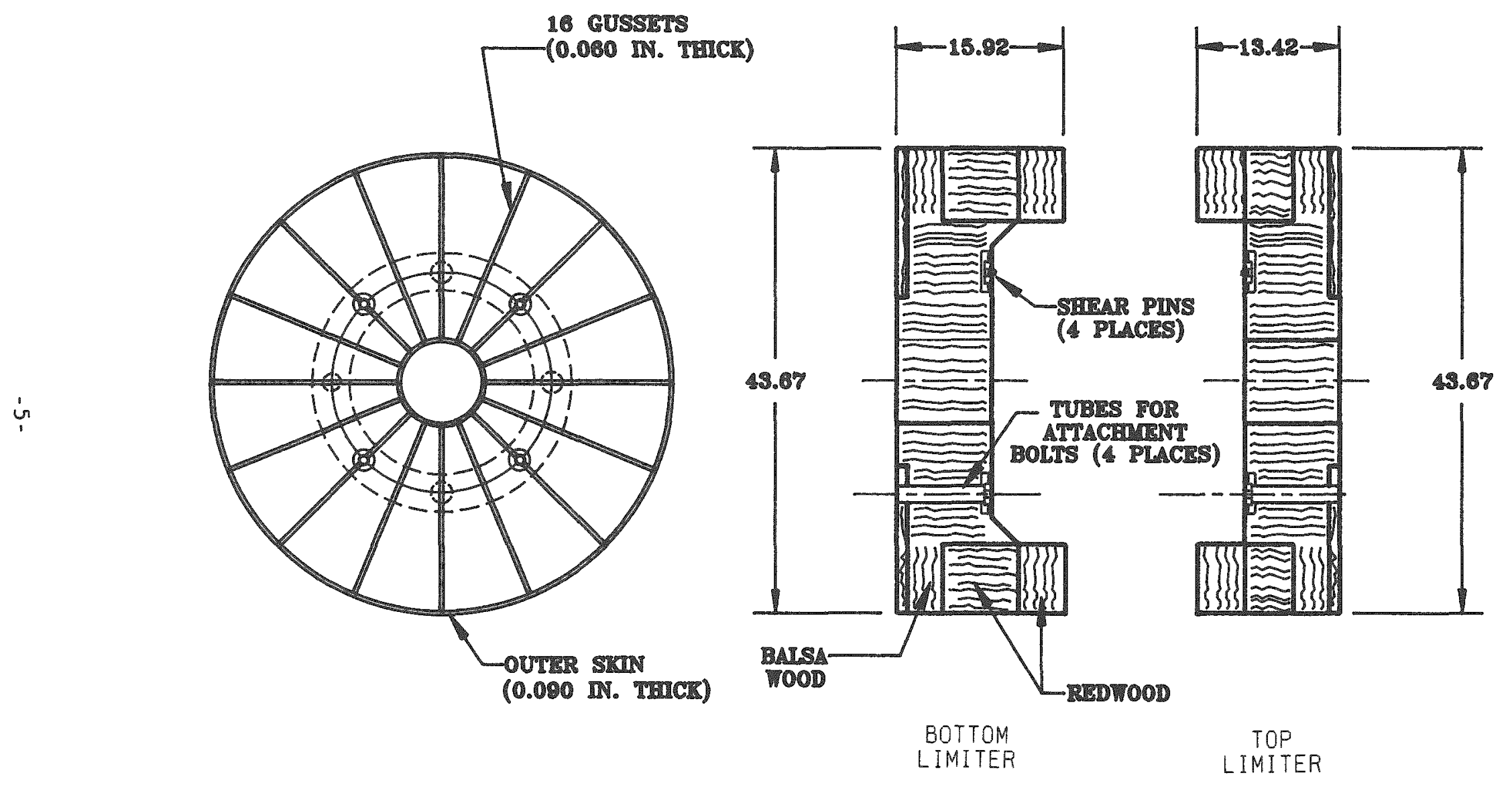

Figure 2. Schematic of the Impact Limiters 


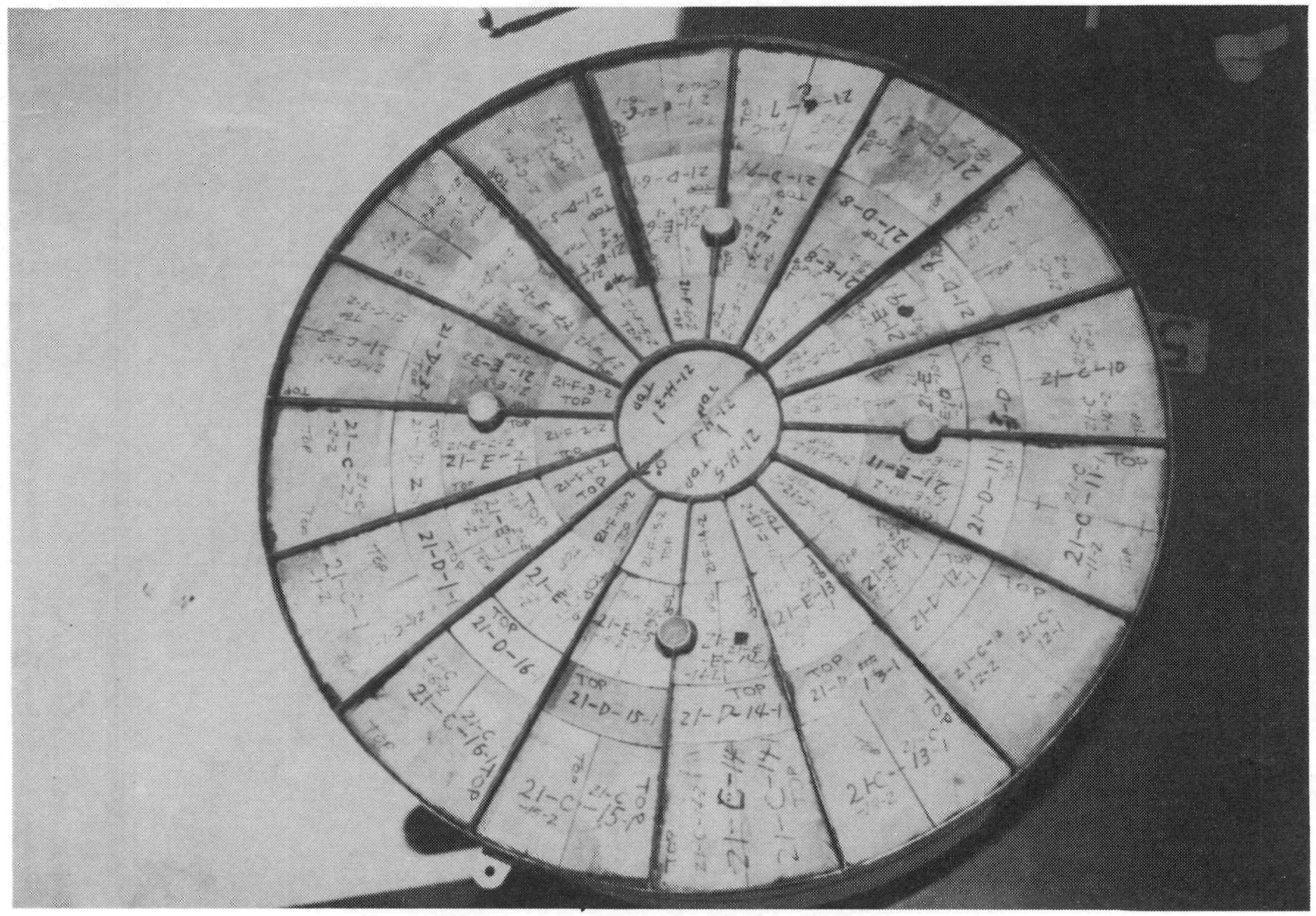

Figure 3. Impact Limiter With the End Cover Plates Removed 


\subsection{TEST PROCEDURE/INSTRUMENTATION}

The tests described in this report were conducted at the Coyote Test Facility of Sandia National Laboratories. The target at the facility meets International Atomic Energy Agency critexia for being essentially unyielding. It consisted of a block of reinforced concrete weighing about 225 metric tons $(500,000 \mathrm{1b})$ covered with a $10-\mathrm{cm}-(4-$ in.-) thick armor plating.

In each test the system was suspended from a beam using wire rope. Explosive cutters were fitted to each supporting rope to allow the cask to drop onto the target.

In the first test, the cask was tested in an end-on orientation, impacting the top or square end. Figure 4 shows the cask before the first test and a close-up view of an accelerometer block mounted on the cask body at mid-plane. Only one impact limiter (top end) was used in this test; an impact limiter mock-up was fabricated and fitted to the bottom (tapered) end of the cask. The mock-up was used to prevent damage to the costly scaled impact limiter should the cask topple over during the test. The 360-1b mock-up impact limiter consisted of a steel plate and several circular layers of plywood. Like the actual impact limiter which is secured by four retaining bolts the mock-up was bolted to the tapered end of the cask.

For the slapdown drop test, the mock-up impact limiter was replaced with an actual limiter. The impact limiter used in the end-on drop was left on the cask for the slapdown drop test. This impact limiter was crushed in the area adjacent to the end of the cask. The annular portion of the limiter was not crushed. Thus the limiter was judged to be adequate for use in the slapdown test. The cask was suspended from the rigging beam at a 10-degree angle to the horizontal. The top (square) end of the cask impacted the target first. The tapered end which had the undamaged limiter was subjected to the secondary impact. 


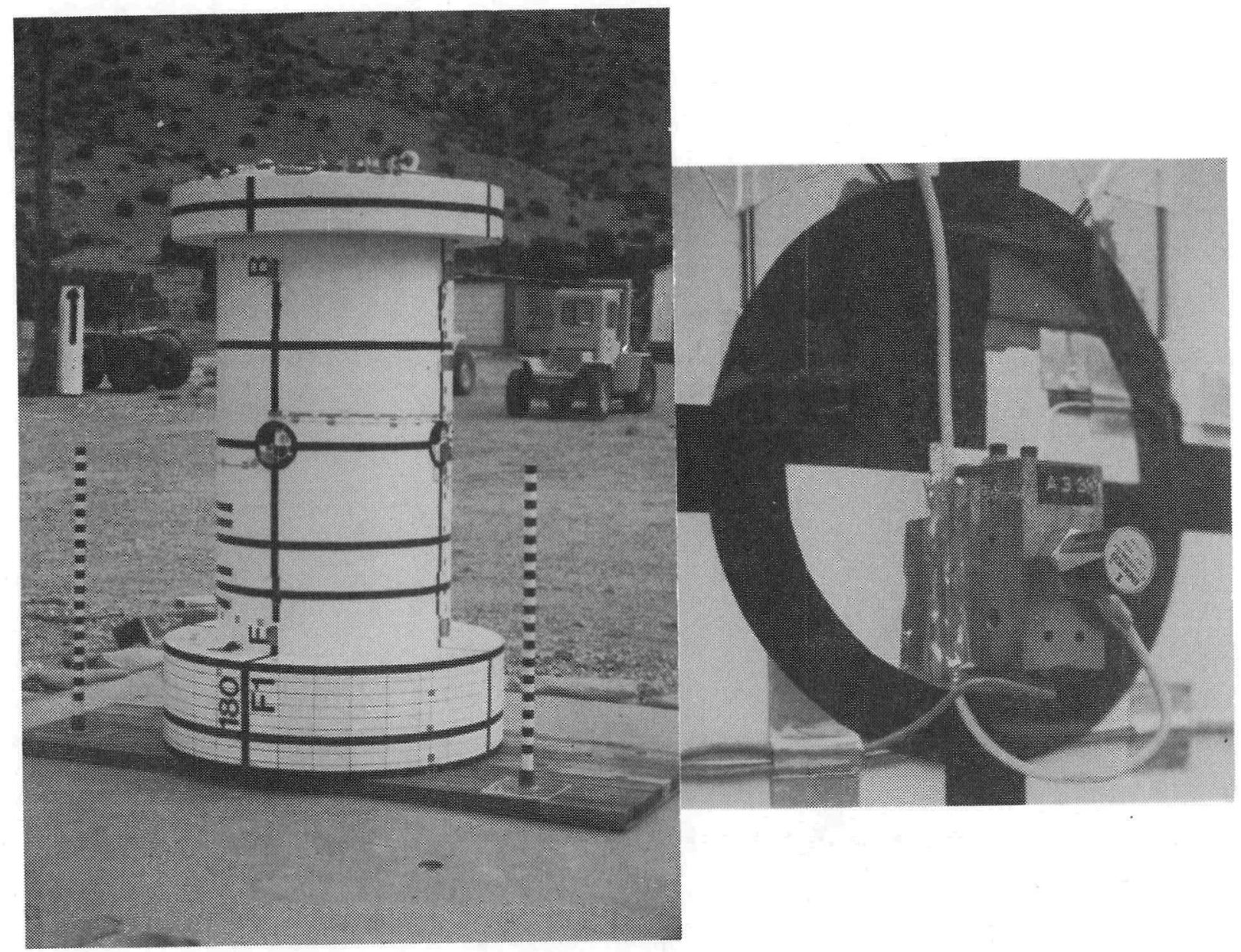

Figure 4. The Test System Before the End-On Drop Test

Numerous accelerometers were used to monitor the response of the cask during each test. Figure 5 is a schematic of the accelerometer layout for the end-on drop test. Three Endevco models (Appendix A) were installed in three planes at different axial positions on the cask. Each unit was given a designation beginning with the letter "A" followed by two numbers and a letter indicating the direction of alignment. Designations ending with ' $R$ ' represent a redundant transducer at that location. Figure 5 shows the superimposed coordinate system. The first number of the designation indicates the plane in which the unit was located, and the second number indicates the circumferential location on the cask body. For the end-on drop tests, most of the units were aligned 


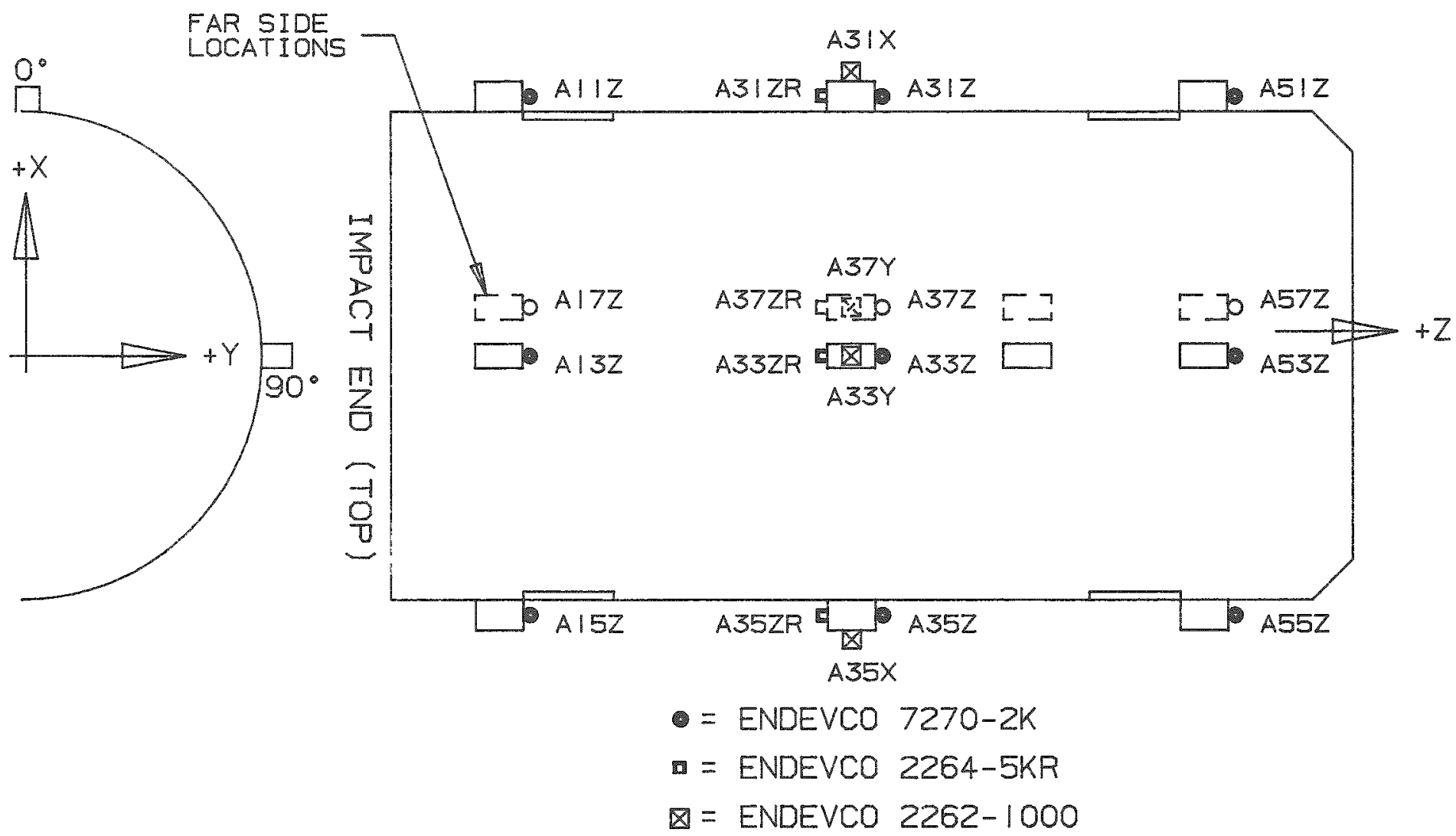

Figure 5. Schematic of the Instrumentation for the End-On Drop Test 
in the $\mathrm{Z}$ direction, which was the direction of impact. The model was dropped on the top end.

Figure 6 illustrates the accelerometer locations for the slapdown drop test. In this test, accelerometers were installed at four different planes located at different axial positions on the cask. Four different Endevco models were used (Appendix B). A number of them were soft mounted using a thin layer of an elastomeric material, as described in Appendix $\mathbf{B}$. The soft mounting was used to dampen frequencies above $3000 \mathrm{~Hz}$, which were observed in the end dxop test. For this test the significant acceleration readings were predominantly in the $X$ direction. Accelerometer results were digitized and filtered to levels of 500, 750, 1000,1500 , and $2000 \mathrm{~Hz}$.

Figure 7 illustrates the instrumented bolt channels and their fit in the system. The bolts were 0.5 inch diameter strainsert in internally gauged bolts selected to exceed the strength of the bolts that would normally be used (Appendix A). The instrumentation wires were run through the bolt installation tubes and attached to connection strips on the cask body. Instrumented bolts were used only on the bottom end of the cask. These channels were designated SB5-SB8. Regular bolts retained the top impact limiter. The shear pins indicated in Figure 7 were 0.5 inch in diameter and were fabricated from high-strength steel (ASME SA-540). Sacrificial strain gages were installed near the corners of the impact limiters to signal the times of contact.

The tests were recorded by high-speed motion-picture cameras, including Milliken cameras (400 frames/sec), Nova cameras (2000 frames/sec), and a streak camera. The films were digitized to obtain displacement and velocity data. 


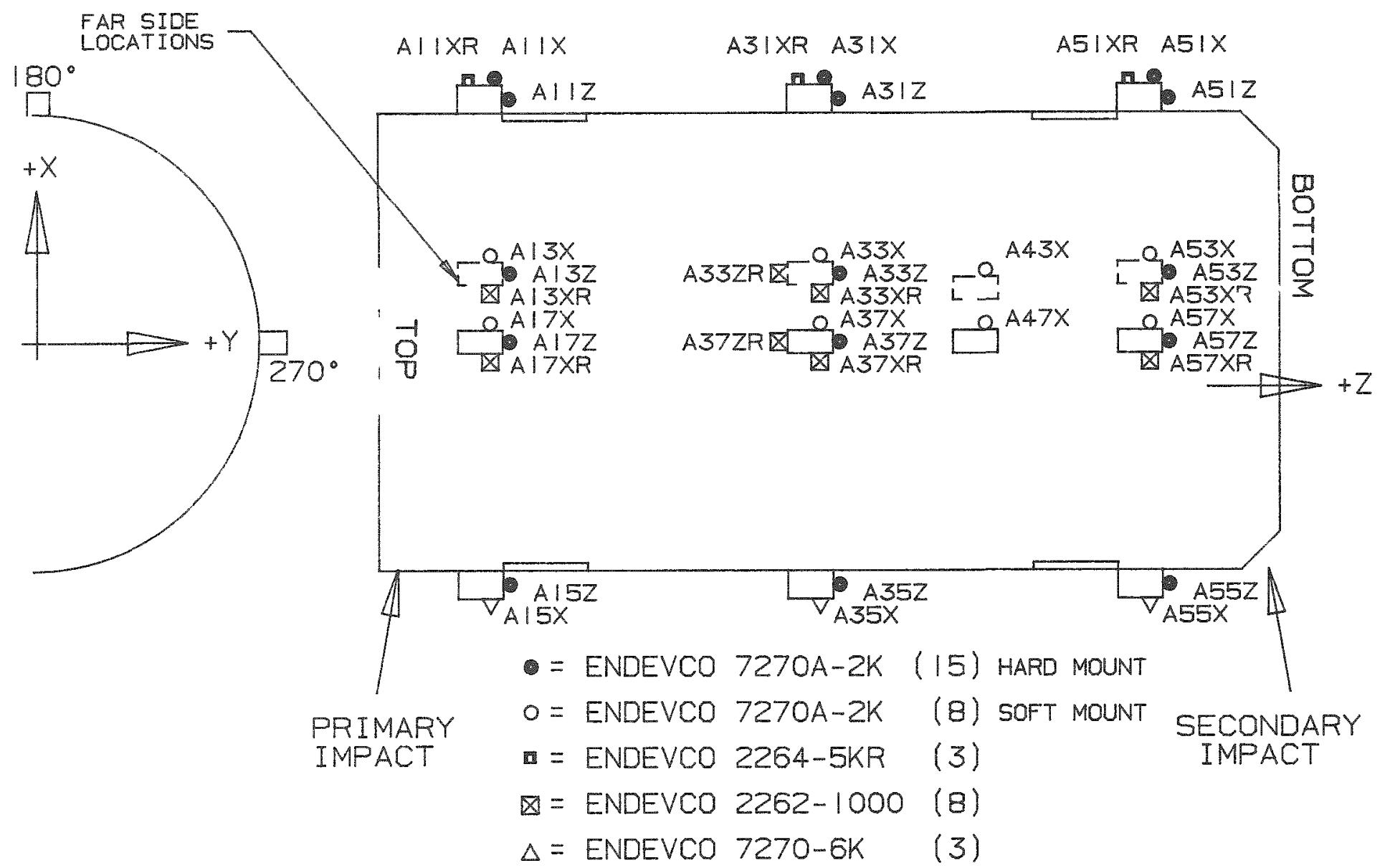

Figure 6. Schematic of the Instrumentation for the Slapdown Drop Test 


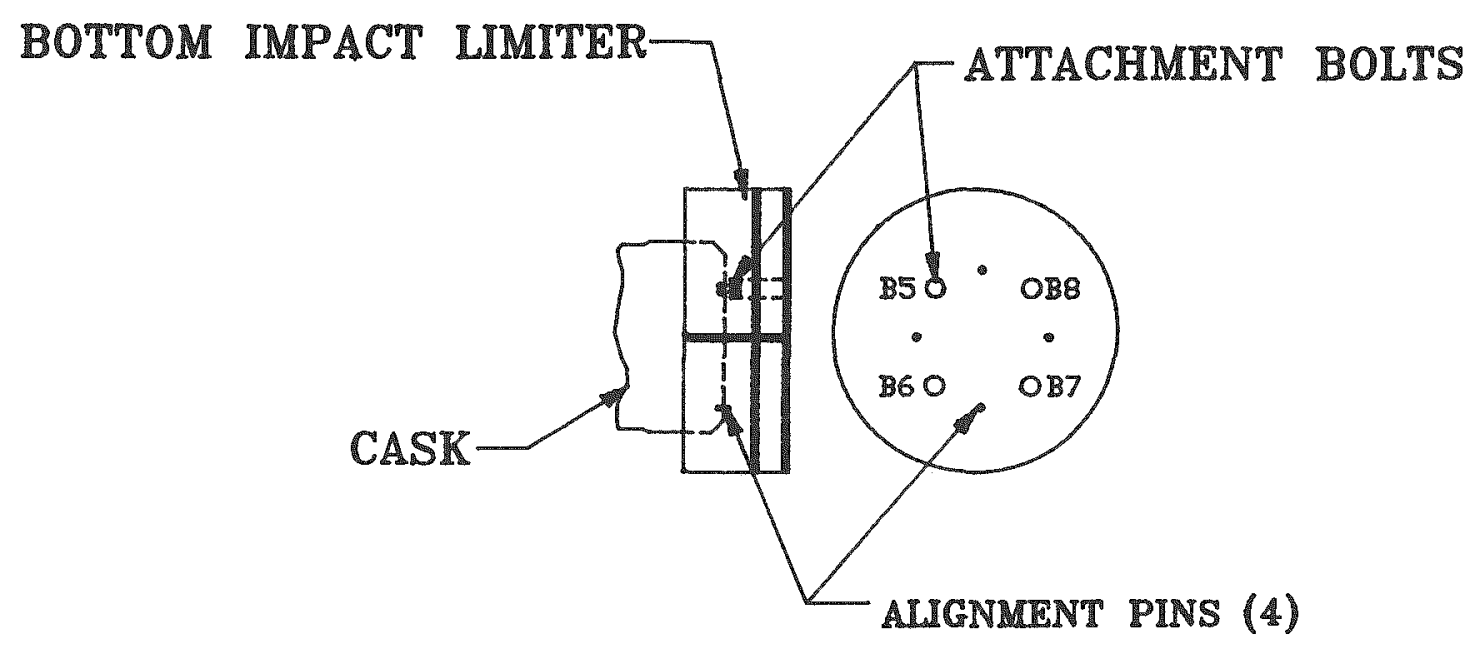

BOLT AND SHEAR PIN PATTERN

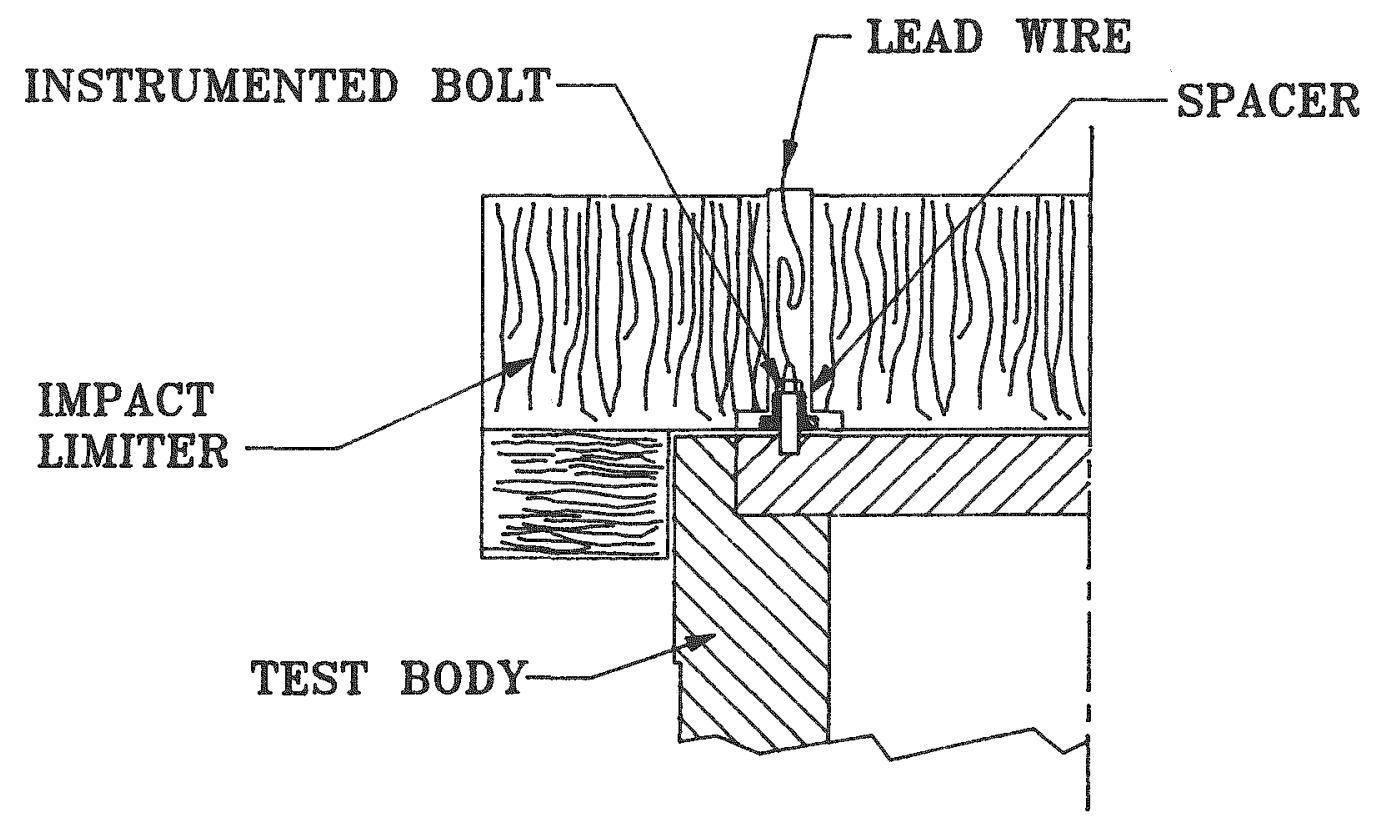

INSTRUMENTED BOLT DETAIL

Figure 7. Schematic of the Impact Limiter Bolt Instrumentation 


\subsection{RESULTS}

\subsection{End-On Drop Test}

The system was dropped from $30 \mathrm{ft}$ and impacted the target in an almost perfect orientation at $44 \mathrm{ft} / \mathrm{sec}$. Figure 8 shows the cask system, just before the test, suspended on the cross beam above the target. Figure 9 is a sequence of photographs taken from a high-speed film recording of the event focusing on the impact end of the cask. The duration of the impact was about $13.4 \mathrm{~ms}$. During the impact, the cask body punched into the impact limiter about 3 in. The limiter did not crush at the limiter/target interface. (A more detailed description of damage sustained by the system can be found in Appendix C.) The motion of the cask moving into the limiter can be observed in Figure 9 by noting the displacement of the stripes on the cask relative to the impact limiter. Figure 10 is a photograph taken at the end of the impact just as the cask had come to rest. The system remained in an upright position and the damage sustained was not readily apparent.

Disassembly of the system was complicated by the collapse of the tubes which allow access to the bolts. The damage sustained by the limiter was observed by cutting away a portion of the limiter end plate to allow access to the wood. A portion of the wood was then removed to observe the damage. Damage to the structure consisted of some tearing of sheet metal and buckling of gusset plates and tubes. Figure 11 includes a photograph showing a buckled tube and gusset plate and a sketch of the approximate deformation pattern of the gusset plate. Note that the gusset plates were severly buckled under the cask body whereas portions of the gusset plates extending along the sides of the cask body did not undergo significant buckling.

The vertical motion of the cask and limiter was observed by digitizing high-speed film recording and plotting the vertical displacement and velocity results as a function of time. Figure 12 is a plot of the cask and impact limiter displacement. These displacement results indicate that the external surface of the limiter stopped almost 


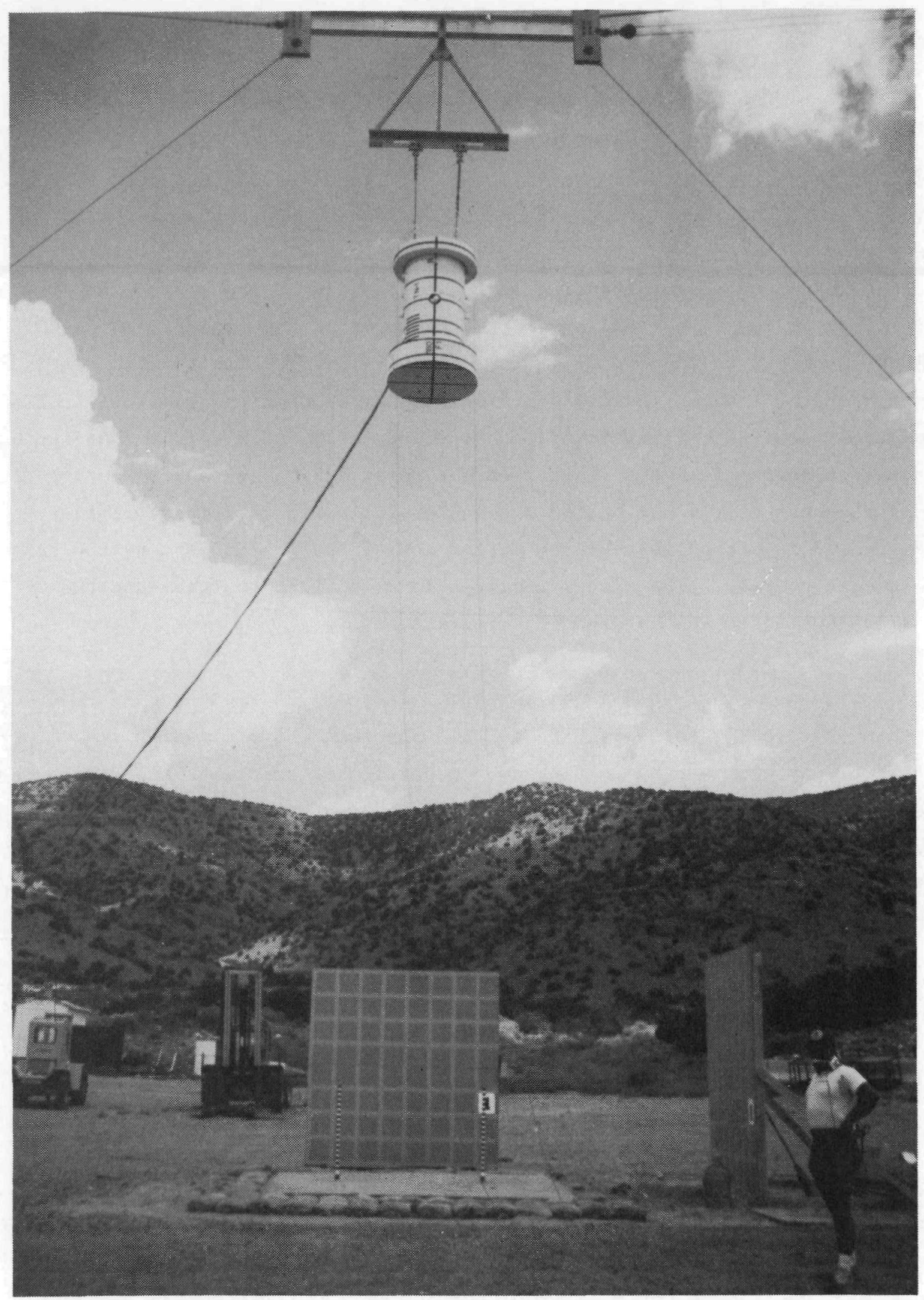

Figure 8. The Test System in Position for the End-On Drop Test 


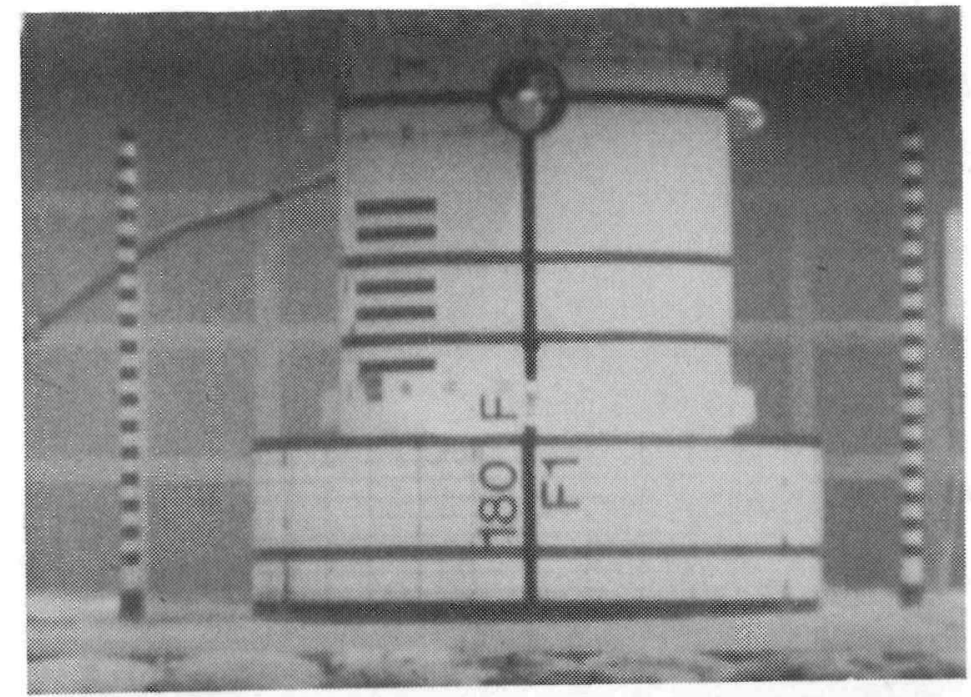

\section{TIME \\ (SEC)}

$t=0.0$

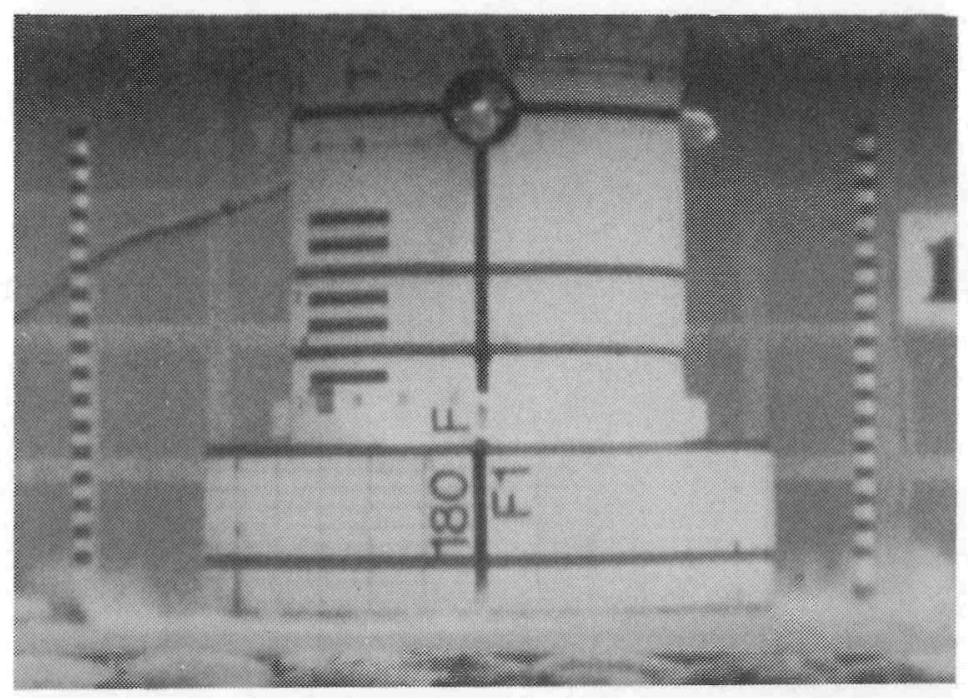

\section{$t=0.002$}

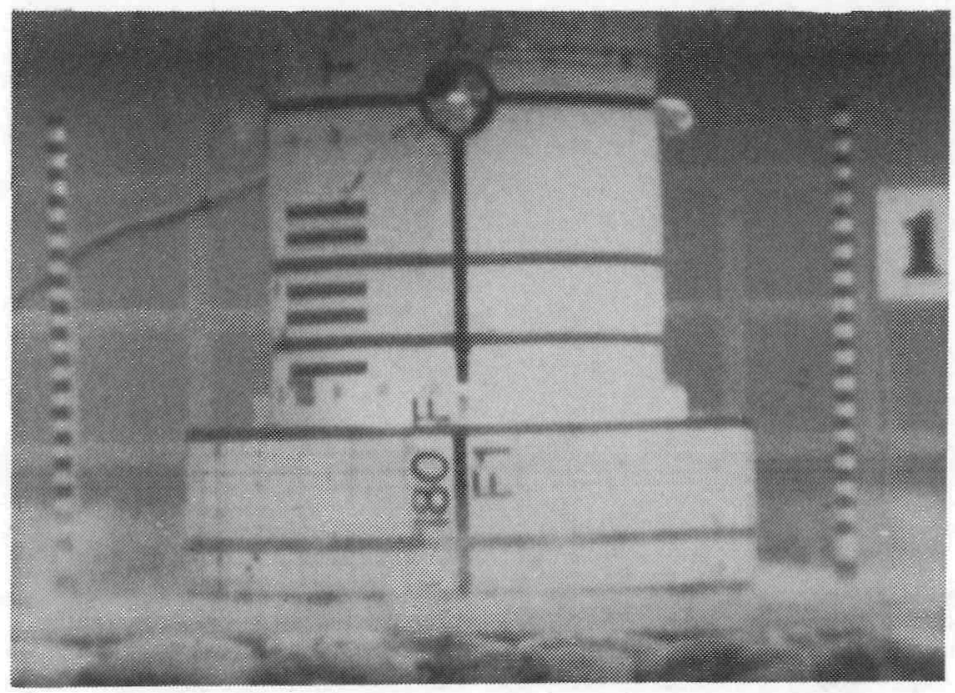

\section{$t=0.004$}

Figure 9. Sequence From High-Speed Film of the End-On Drop Test 


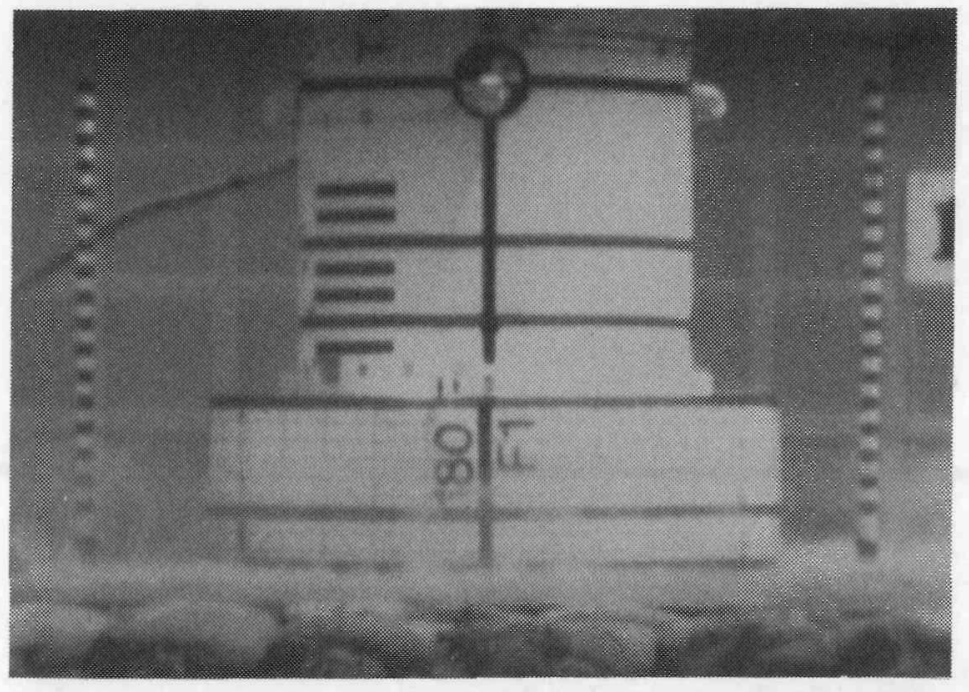

\section{TIME (SEC)}

\section{$\mathrm{t}=0.006$}

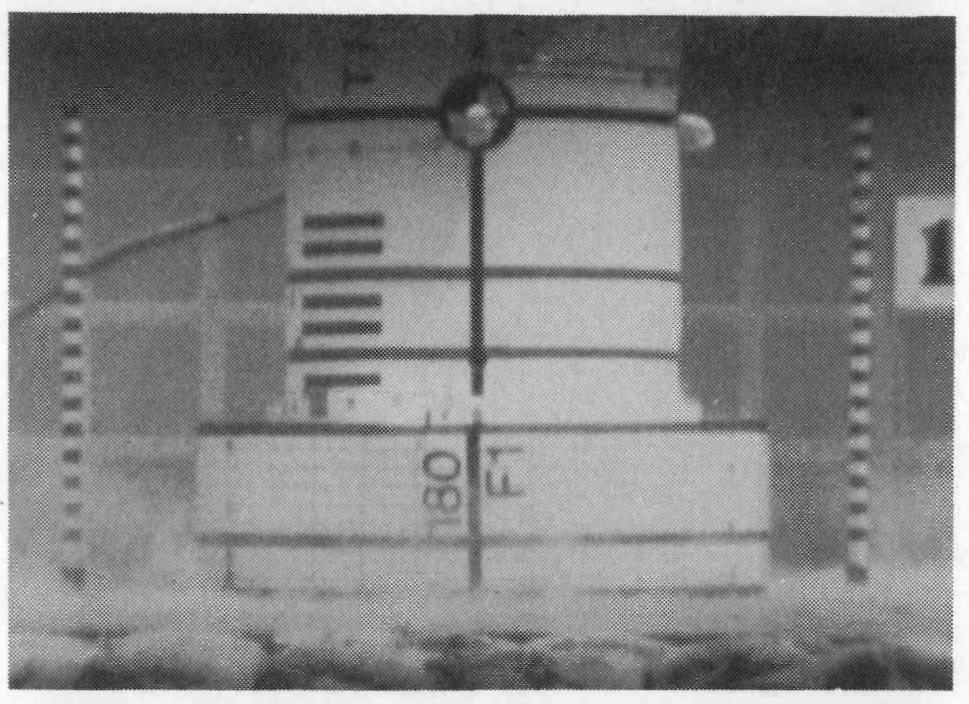

\section{$t=0.008$}

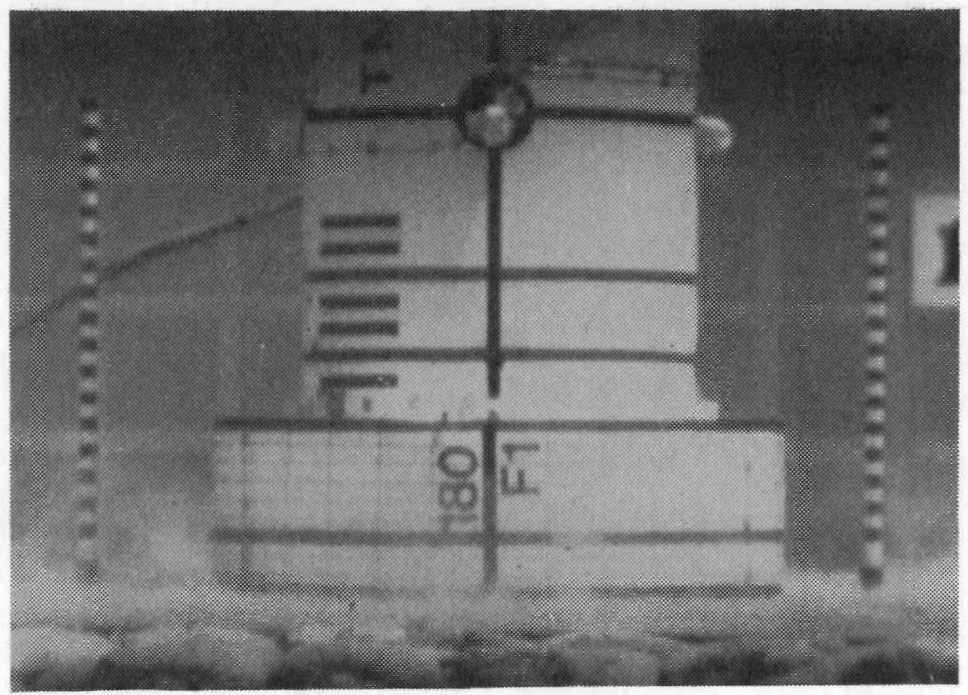

$t=0.010$

Figure 9. Sequence From High-Speed Film of the End-On Drop Test (continued) 


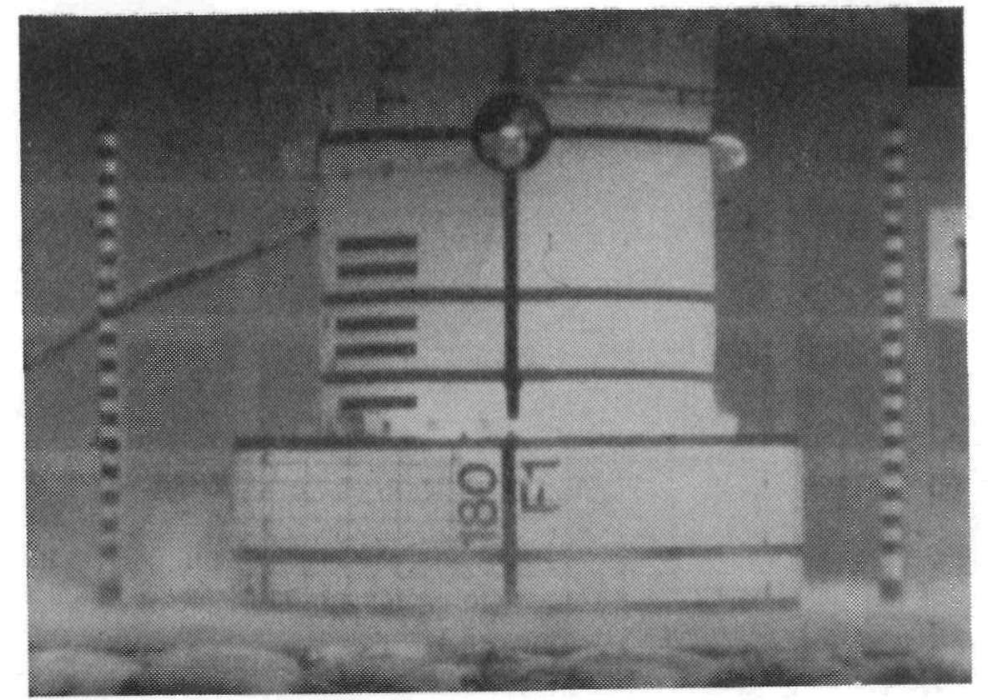

\section{TIME \\ (SEC)}

\section{$t=0.012$}

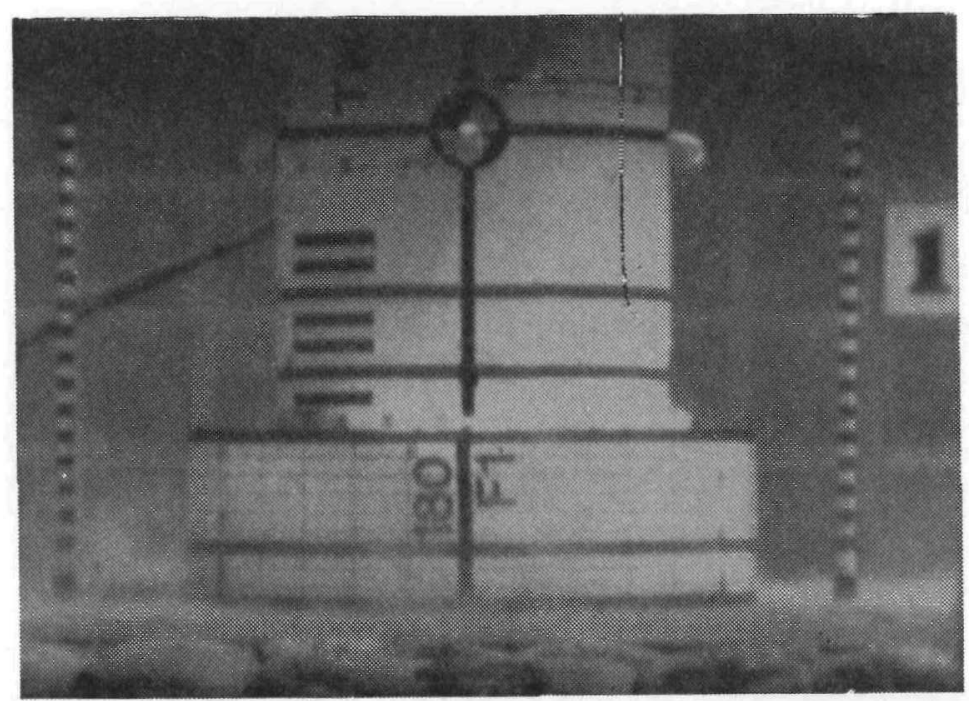

$t=0.014$

Figure 9. Sequence From High-Speed Film of the End-On Drop Test (concluded) 


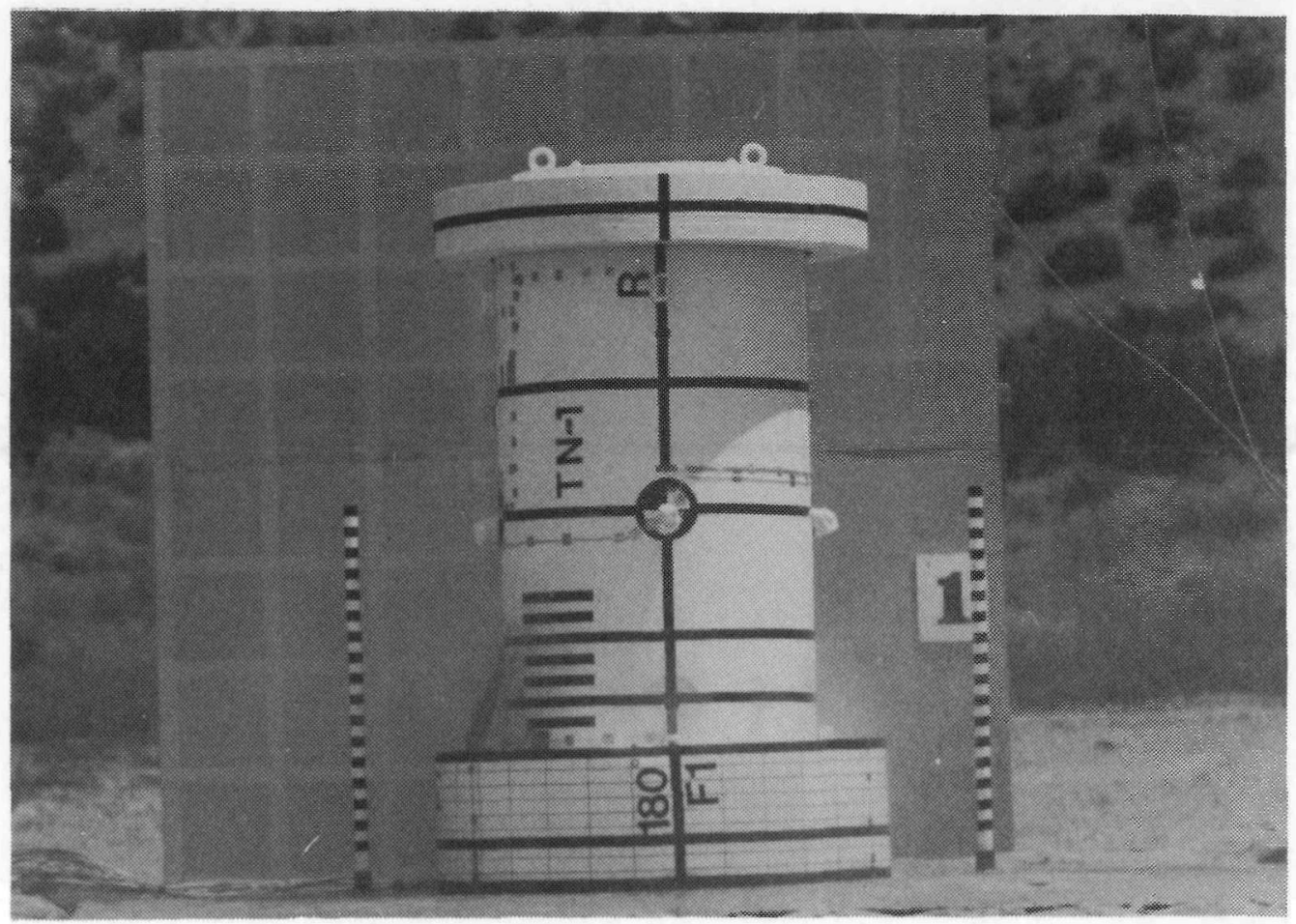

Figure 10. The Test System After the End-On Drop Test

instantly after contacting the target surface. The cask body kept moving and punched into the limiter, causing the damage described above. The velocity differences between the dynamics of the cask and limiter are more dramatic. Figure 13 illustrates the velocity-time histories of the cask and impact limiter. The gradual slowdown of the cask and the abrupt stopping of the impact limiter can be seen clearly in this figure. These results indicate that the system had a rebound velocity of approximately $4 \mathrm{ft} / \mathrm{sec}$. Fitting a straight line to the velocity-time history of the cask results in an average deceleration of about $100 \mathrm{~g}$.

The accelerometer results from this test were disappointing in that most traces were not usable; a very high frequency content caused the units to "ring," thus rendering the data unusable. However, two units mounted on the reverse side of the instrumentation blocks did yield credible results. Figure 14 is a deceleration trace from a unit mounted at the approximate midpoint of the cask. (A complete data set on microfiche is included inside the back cover of this report.) This 

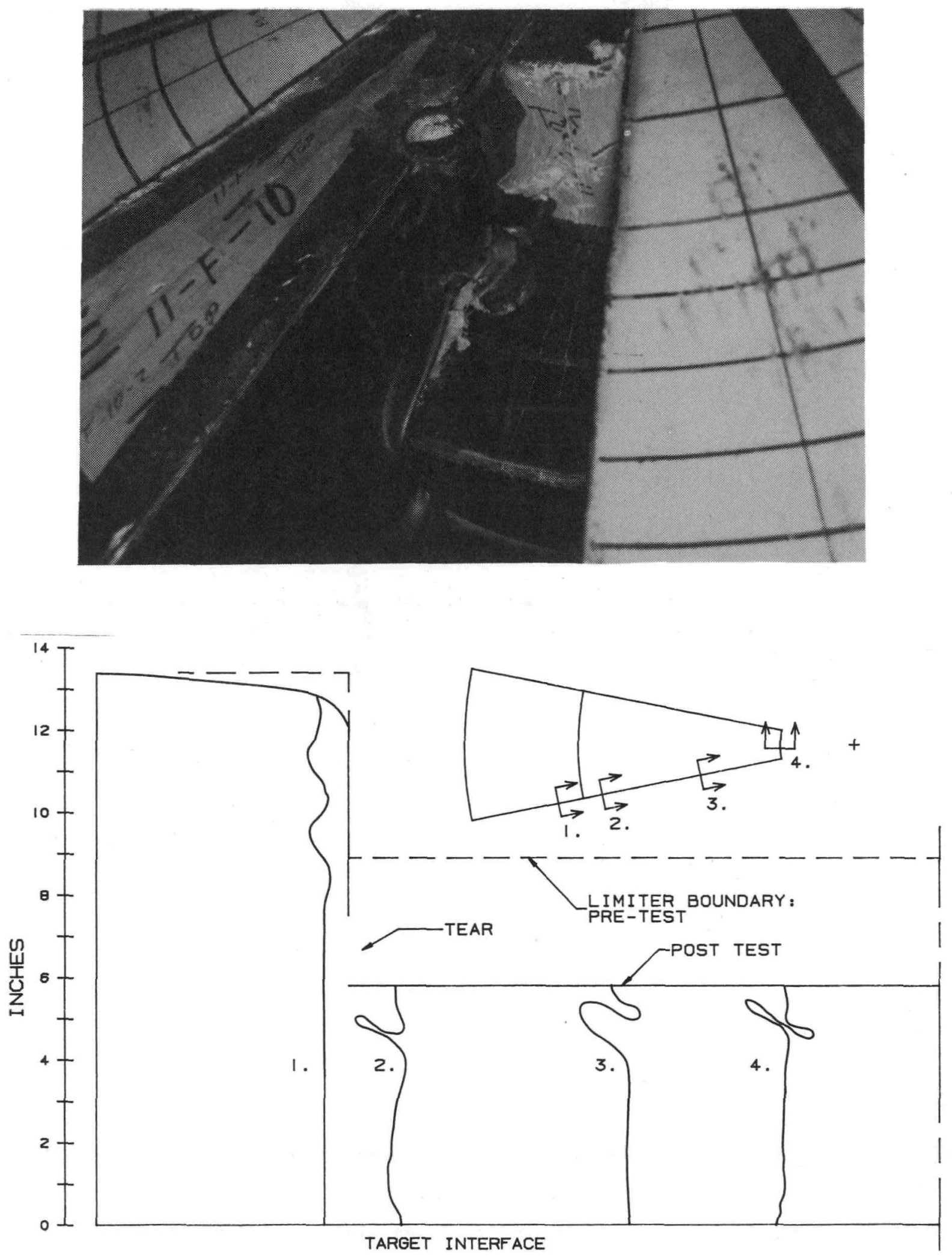

Figure 11. Deformation Pattern in the Impact Limiter Gusset Plates After the End-On Drop Test 


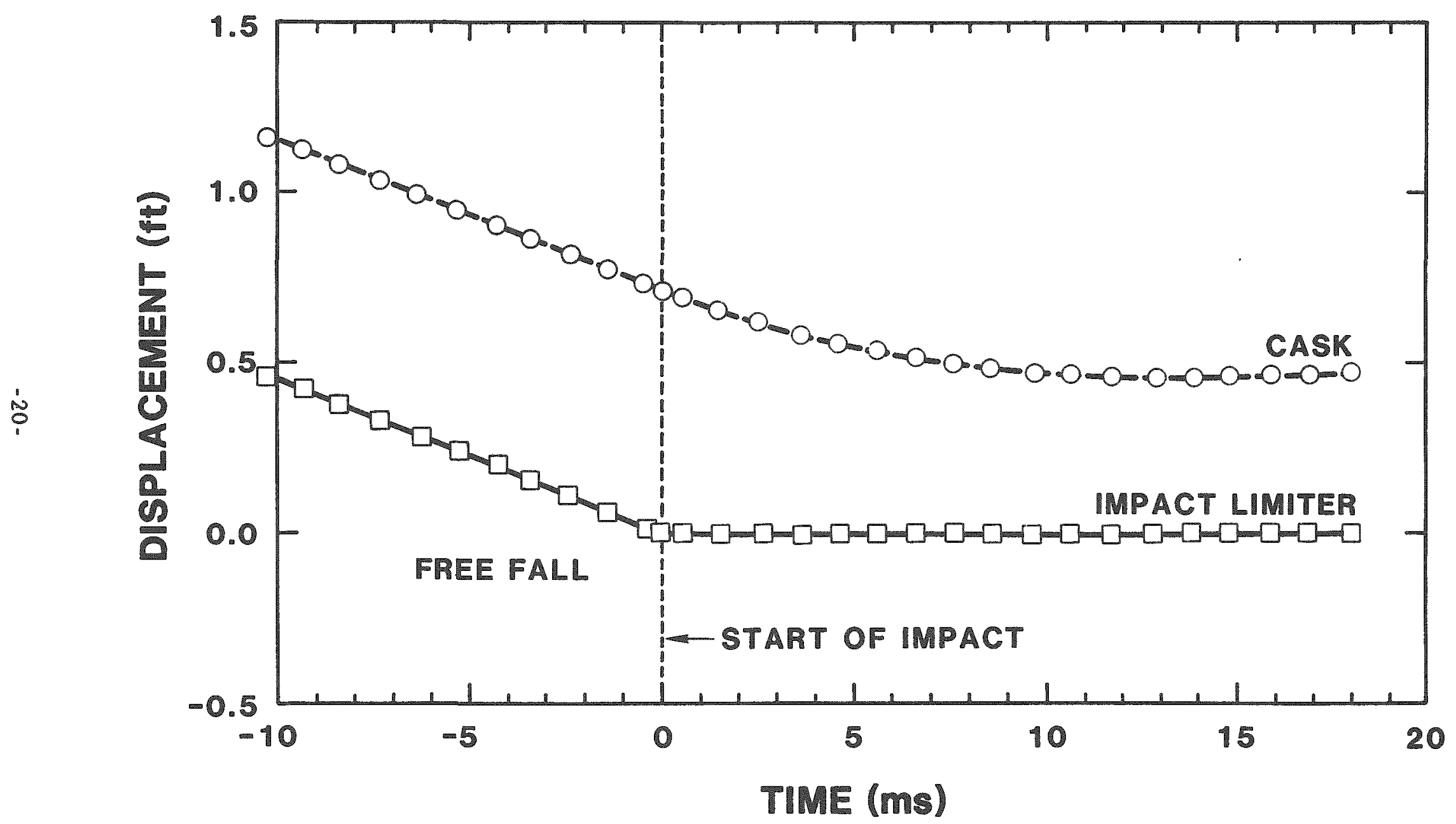

Figure 12. Vertical Displacement Vs. Time for a Point on the Cask and on the Impact Limiter During the End-On Drop Test 


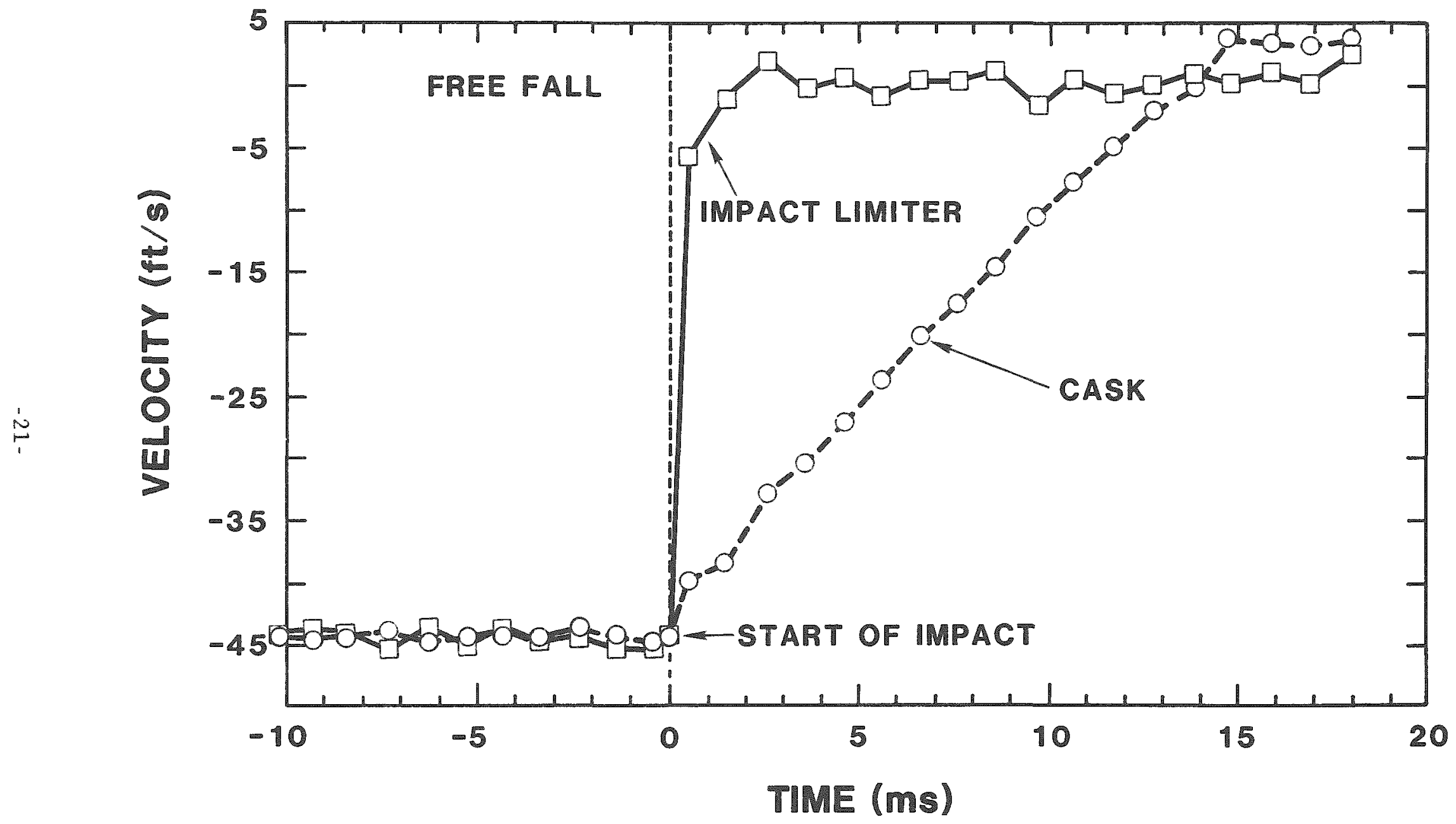

Figure 13. Vertical Velocity vs. Time for a Point on the Cask and on the Impact Limiter During the End-On Drop Test 


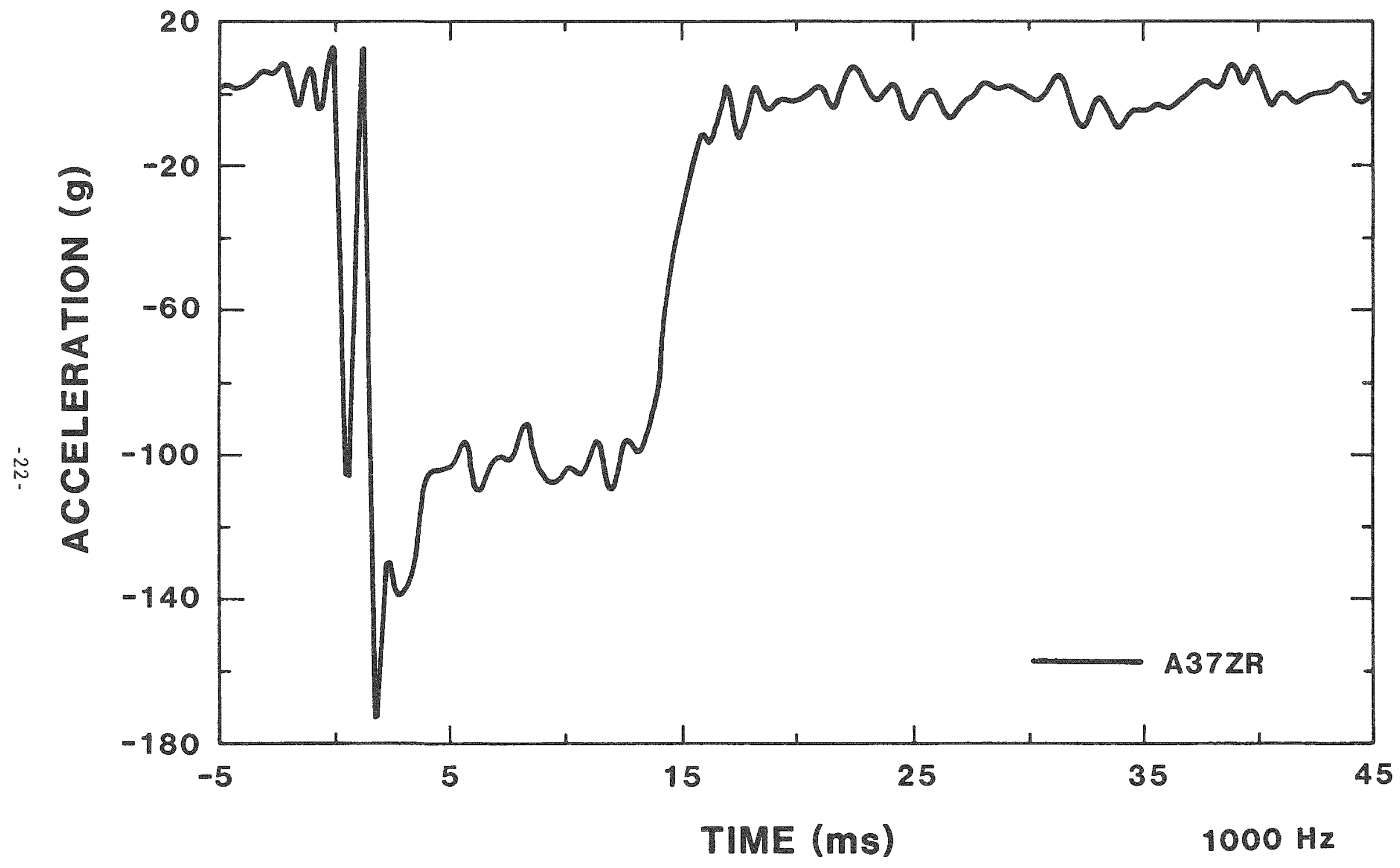

Figure 14. Acceleration vs. Time for the End-On Drop Test 
trace, filtered to $1000 \mathrm{~Hz}$, indicates a deceleration spike to approximately $180 \mathrm{~g}$ and a leveling-off at about $100 \mathrm{~g}$. It also indicates a pulse duration of about $13 \mathrm{~ms}$.

\subsection{Slapdown Drop Test}

The cask system was successfully dropped and impacted the target at an angle of 12.4 degrees. Figure 15 shows the cask system just before contacting the target. Figure 16 is a sequence of photographs taken during the impact. The duration of this impact was approximately $40 \mathrm{~ms}$. After impacting at $44 \mathrm{ft} / \mathrm{sec}$, the system translated vertically, without rotating, for about $8 \mathrm{~ms}$, crushing the corner of the impact limiter on the top end. The system then began rotating while continuing to crush the impact limiter. At $20.6 \mathrm{~ms}$ into the impact, the cask had rotated sufficiently for the bottom impact limiter to contact the target. The bottom impact limiter crushed about 6 in. as the cask came to a stop. Figure 17 shows the system on the target after the test. The rotation of the cask system during impact caused the corner of the top limiter to come

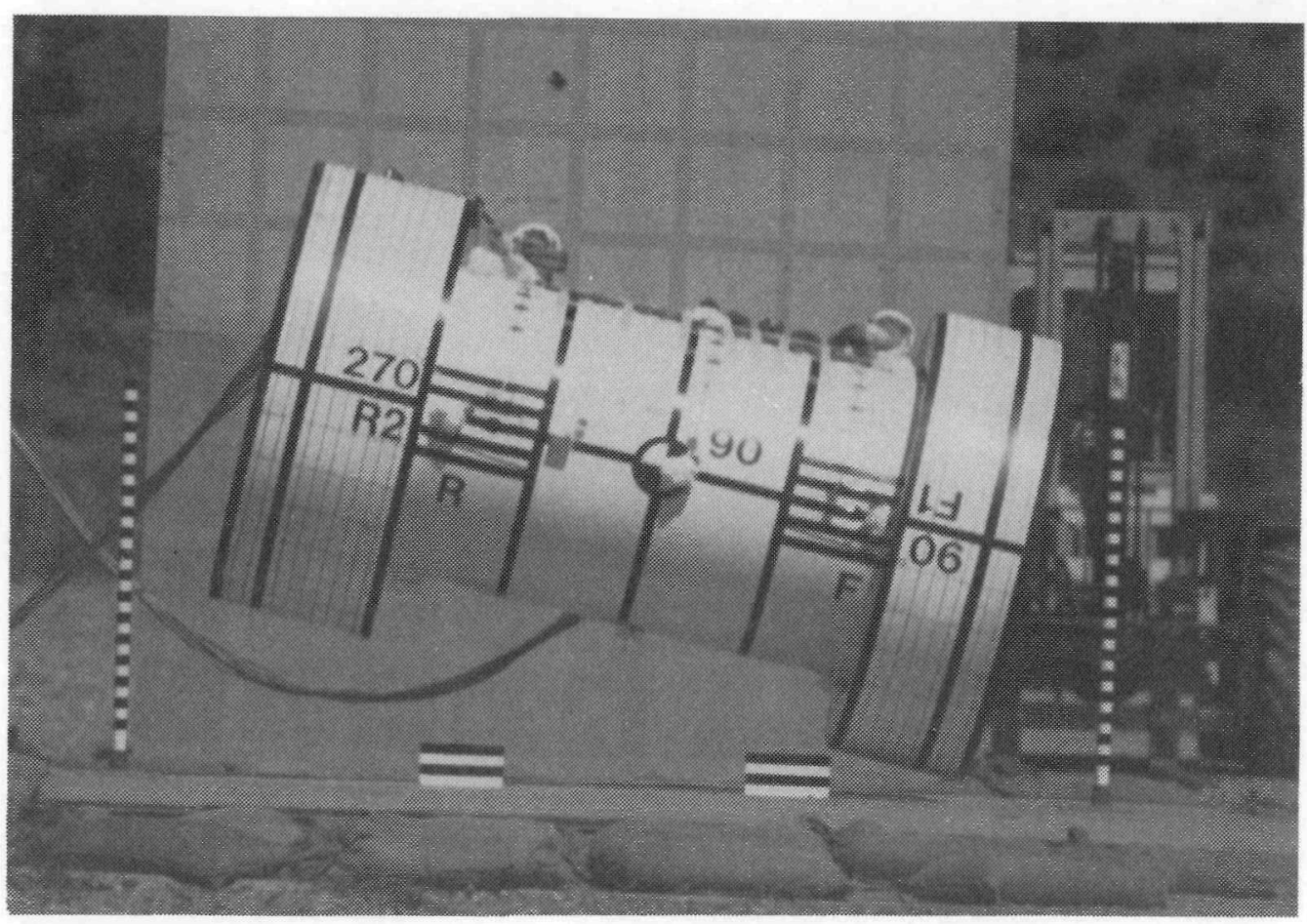

Figure 15. The Test System Before Impacting the Target in the Slapdown Drop Test 


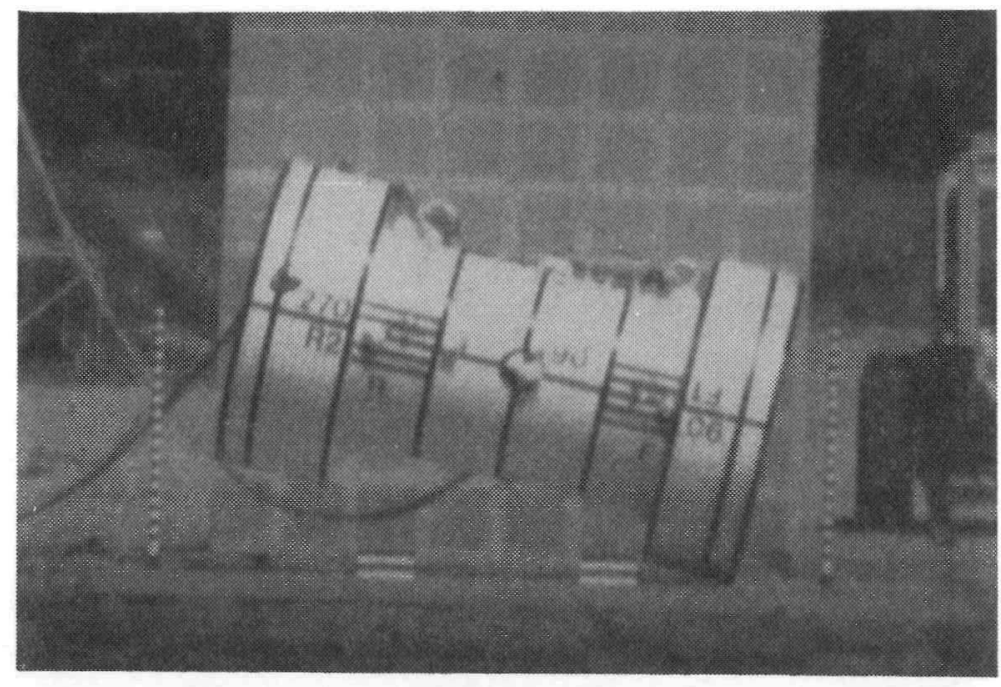

\section{TIME \\ (SEC)}

$$
\mathrm{t}=0.0
$$

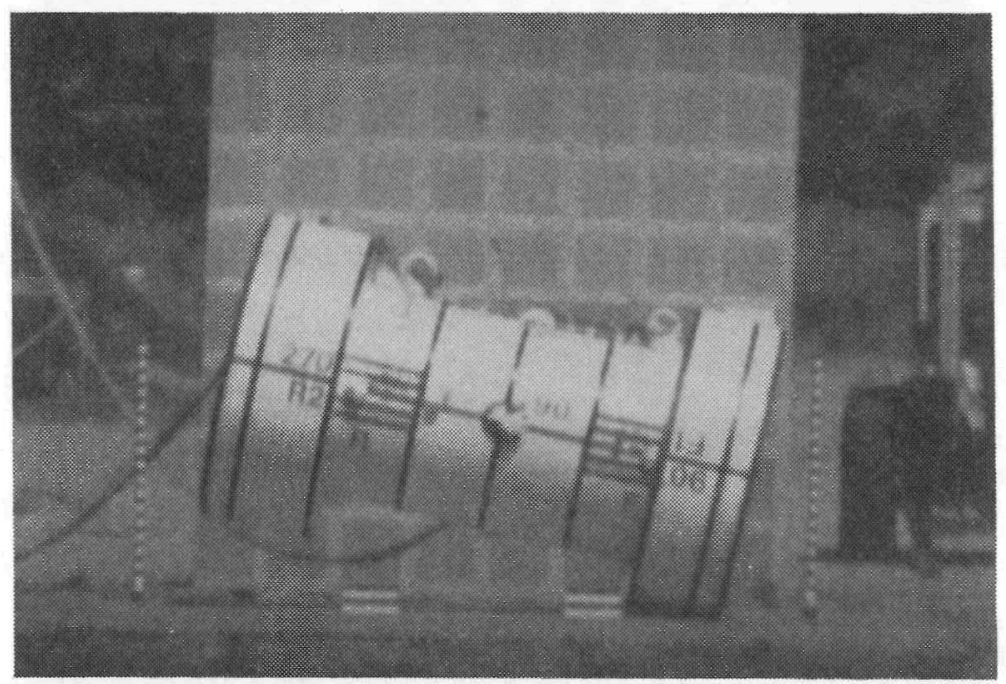

\section{$t=0.005$}

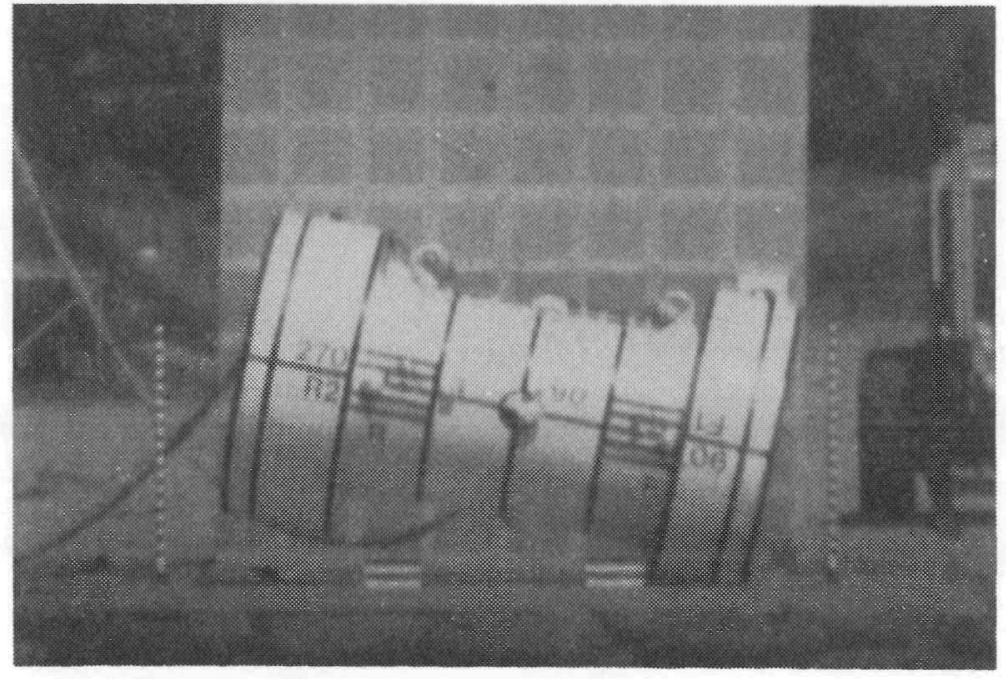

$t=0.010$

Figure 16. Sequence From High-Speed Film of the Slapdown Drop Test 


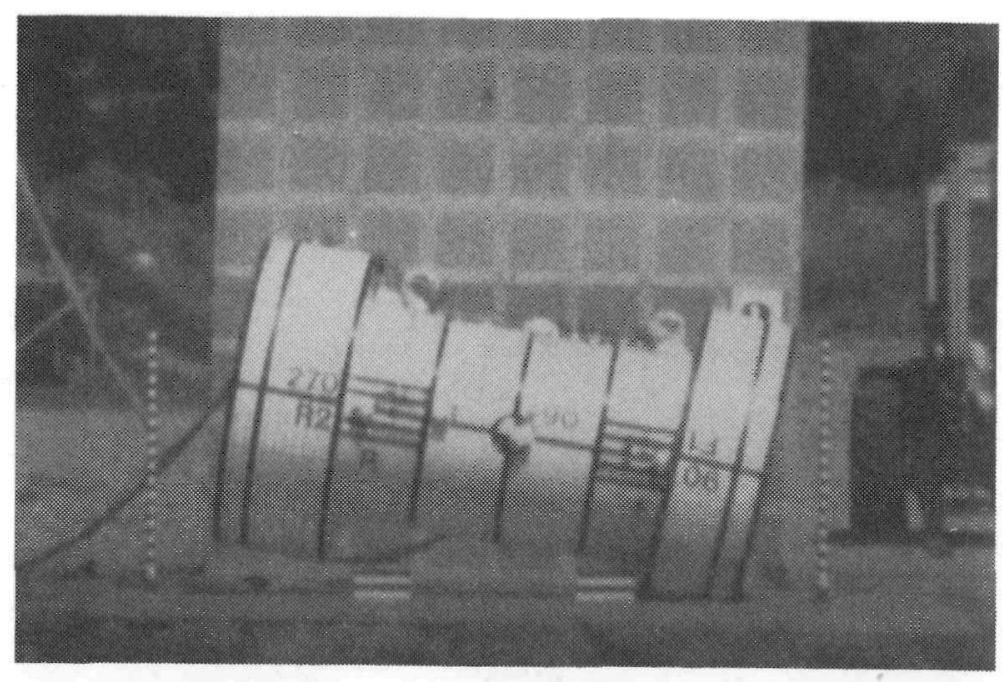

\section{TIME \\ (SEC)}

\section{$t=0.015$}

\section{$t=0.020$}

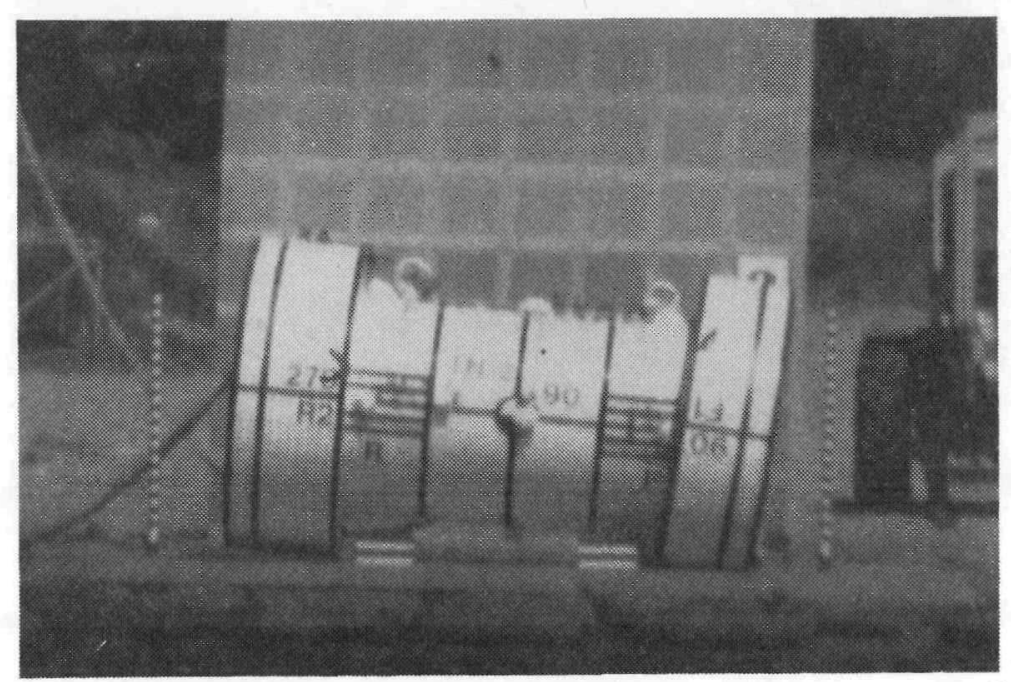

\section{$t=0.025$}

Figure 16. Sequence From High-Speed Film of the Slapdown Drop Test (continued) 


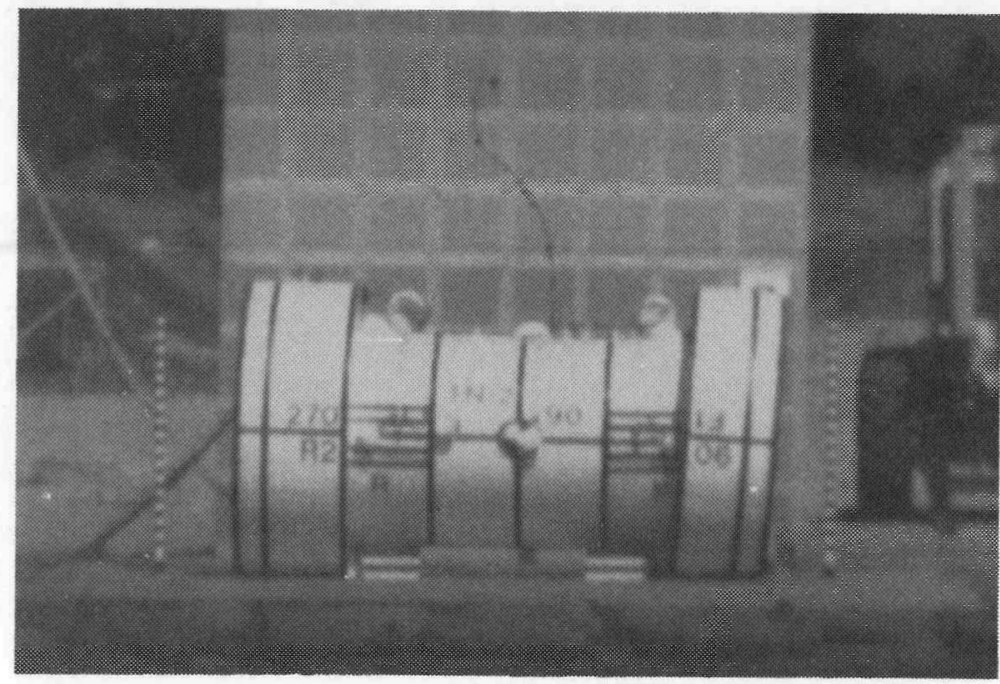

\section{TIME \\ (SEC)}

\section{$t=0.030$}

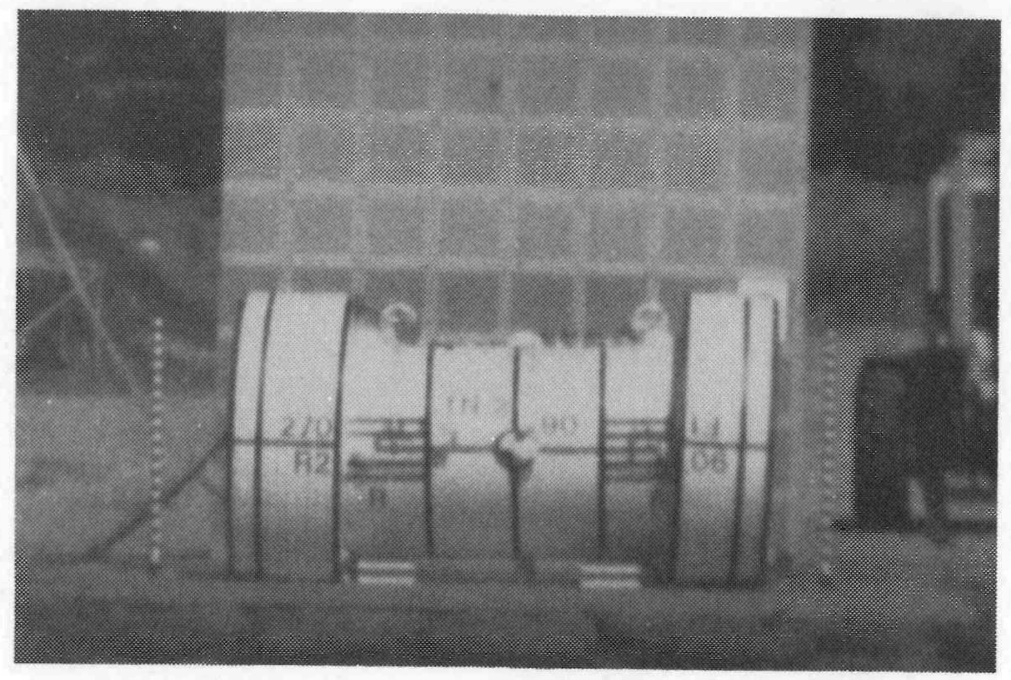

$t=0.040$

Figure 16. Sequence From High-Speed Film of the Slapdown Drop Test (continued) 


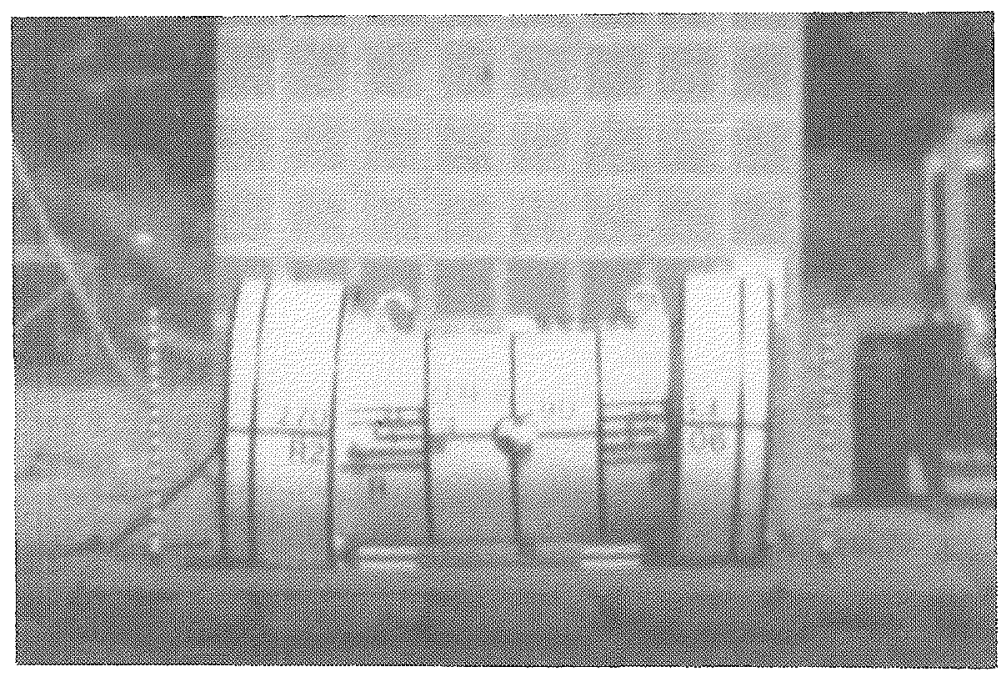

\section{TIME \\ (SEC)}

\section{$t=0.045$}

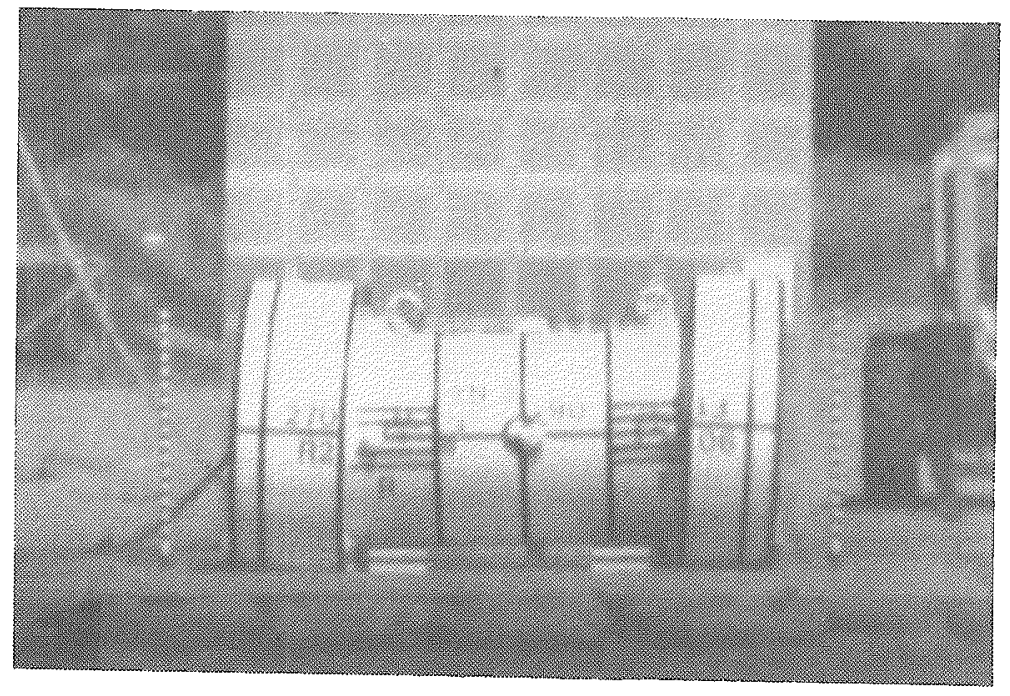

$t=0.050$

Figure 16. Sequence From High-Speed Film of the Slapdown Drop Test (concluded) 
to rest approximately 2-1/2 in. off the target surface (Figure 17, lower photograph). Some tearing of the impact limiter skin in the crushed areas was evident. Scuff marks on the target surface indicated the system slid approximately 6 in. in the direction of the bottom end of the cask. It was also immediately evident that the limiter retaining bolts on the bottom end of the cask had failed, allowing the limiter to move outward slightly. Measurements of the distance between the cask body and the target indicated that near the bottom limiter the cask came to rest $2-7 / 8$ in. from the target surface. A similar measurement near the top limiter indicated a clearance of $3-7 / 8$ in. Figure 18 shows the crushed surfaces on both impact limiters. The flattened surfaces were about 22 in. wide. Detailed deformation measurements are included in Appendix $C$.

Figure 19 shows the fractured bottom impact limiter bolts. The bolts shown in the upper photograph of Figure 19 were placed at the upper locations and the bolts shown in the lower photograph of Figure 19 were in the lower (impact side) locations. The upper bolts failed in a mode that was almost purely shear. The fallure surface was nearly perpendicular to the bolt axis. The lower bolts appeared to have failed in a combined. tensile and bending mode; the fracture surface was angled. The inclined failure surface was composed of ductile fracture dimples. Roots of threads were stretched on the top surface, indicating tensile loading. There was no evidence of flaws, which could have initiated fracture, in any of the bolts and there was no evidence of brittle fracture modes. Micrographs of the fracture surface and a more detailed discussion of the bolt failures are included in Appendix $D$.

As in the first test, high-speed film recordings were digitized to study the motion of the cask during the impact. These studies concentrated on following the $C G$ of the cask, measuring vertical and horizontal displacement and the attitude of the cask body.

Figure 20 illustrates the vertical displacement of the CG of the cask as a function of time. The CG displaced approximately 11 in. downward after the top corner of the system contacted the target. 

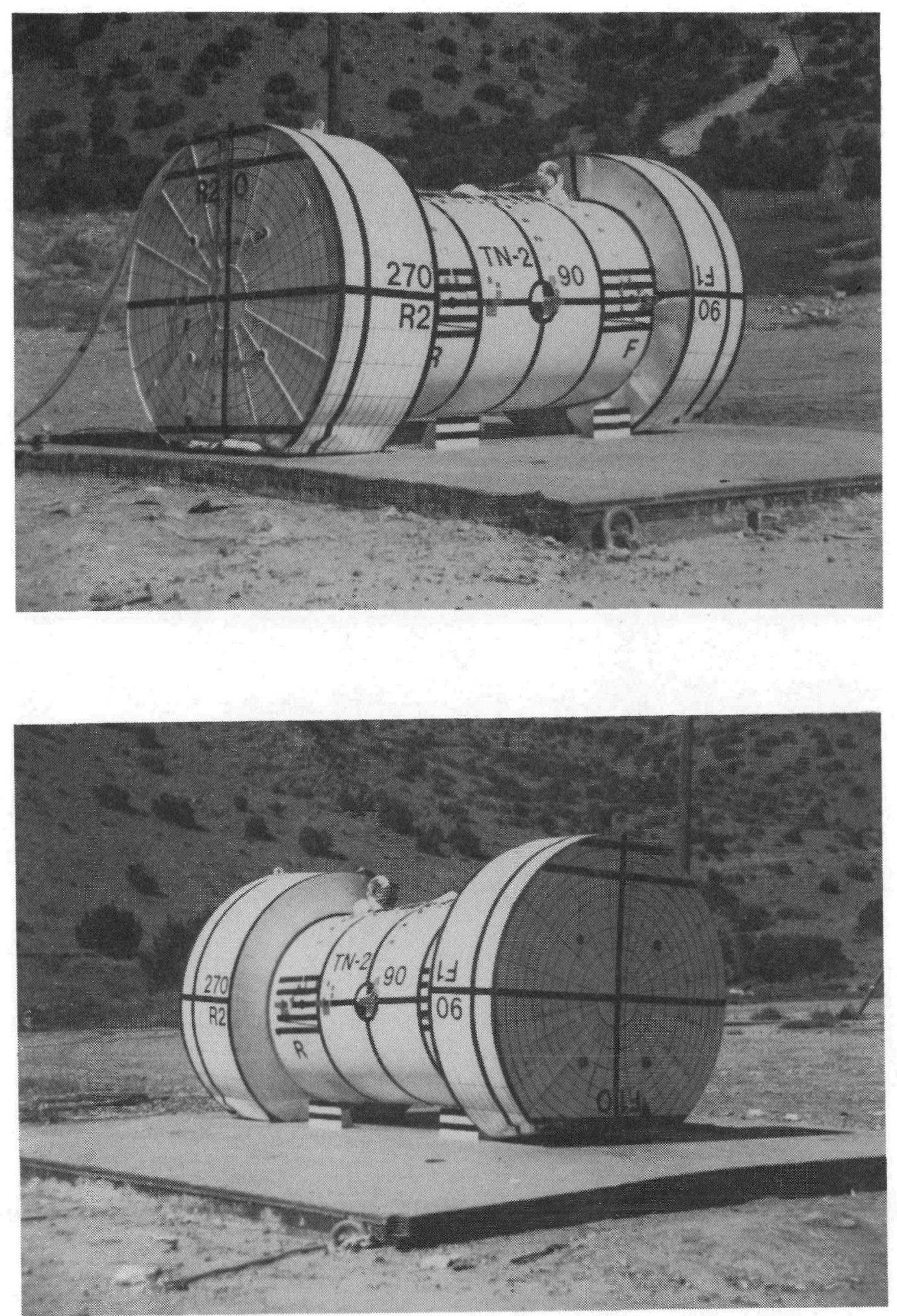

Figure 17. The Test System After the Slapdown Drop Test 

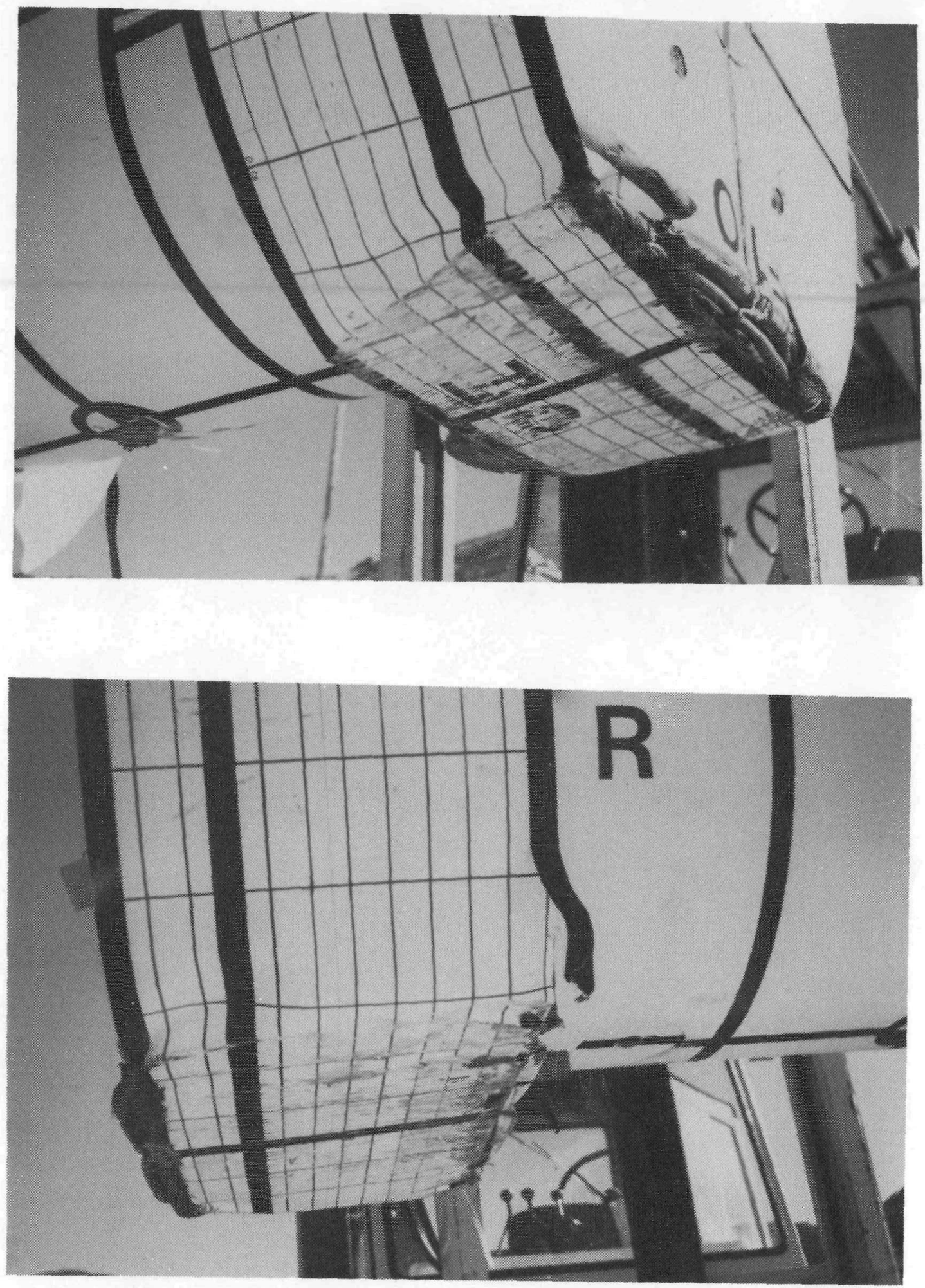

Figure 18. Deformations Sustained by Impact Limiters in the Slapdown
Drop Test 

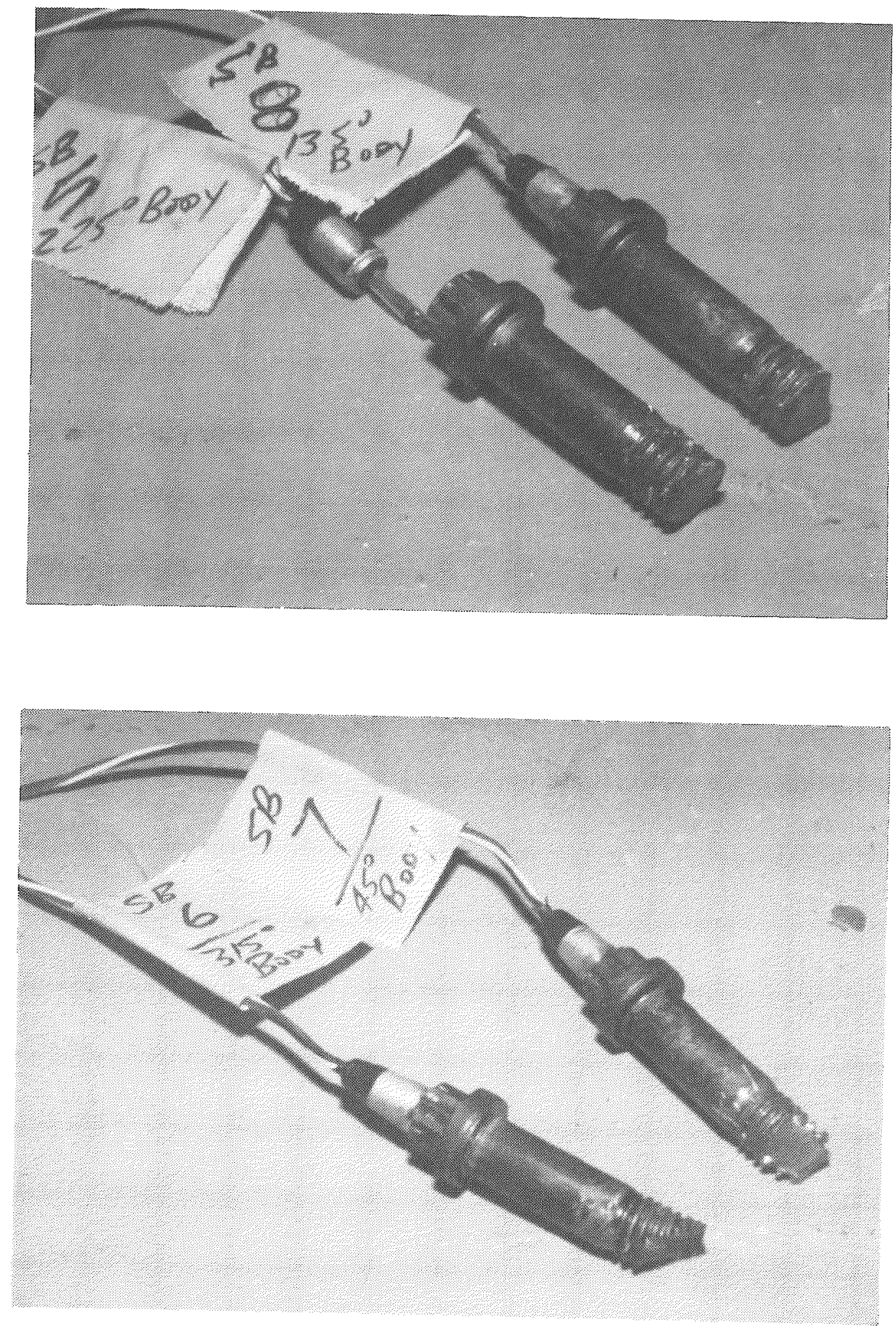

Figure 19. Failed Impact Limiter Retaining Bolts 


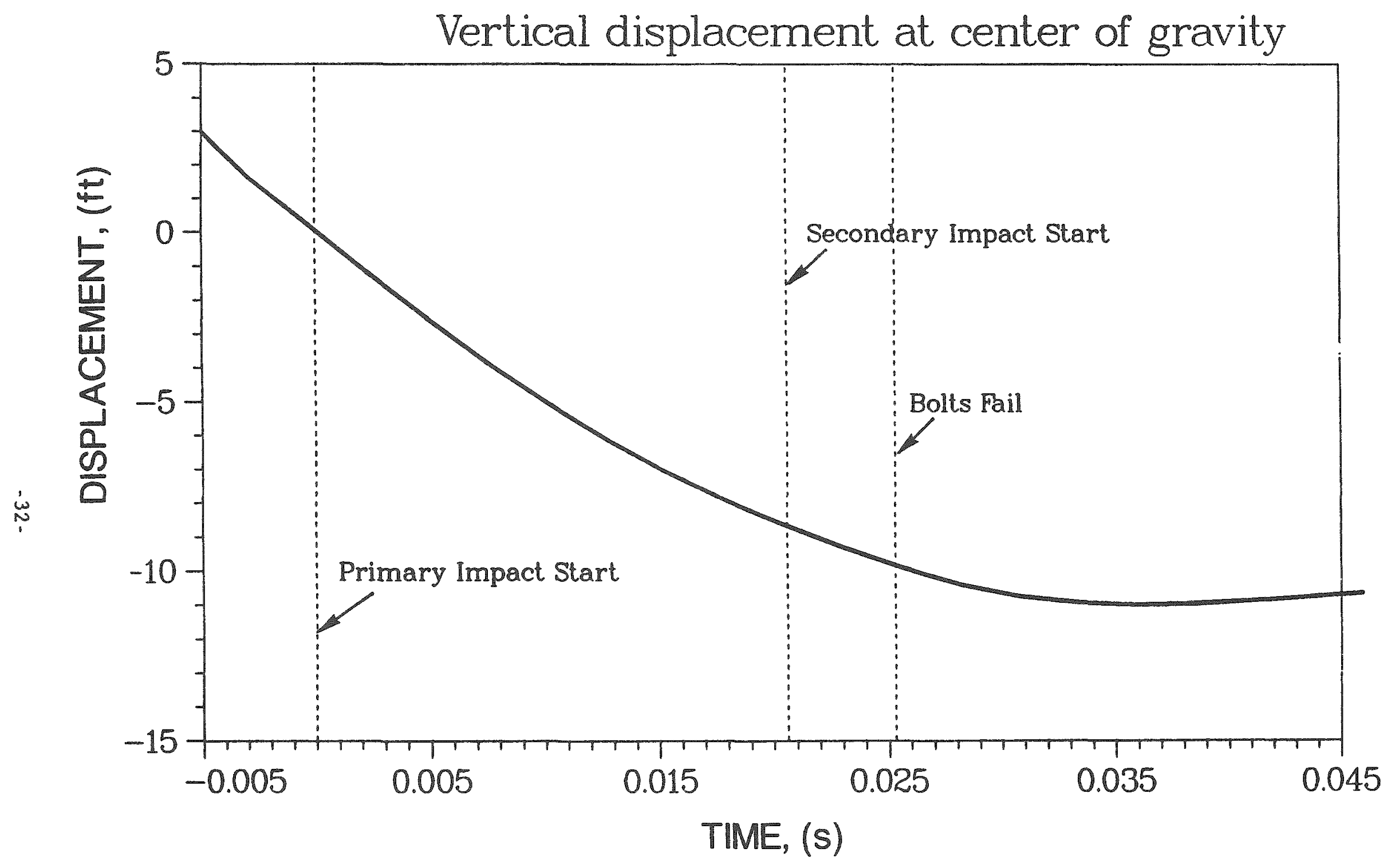

Figure 20. Vertical Displacement vs, Time for the Center of Gravity of the Cask During the Slapdown Drop Test 
Superimposed on these results are dotted lines indicating points in time for the primary and secondary impacts and the point in time when the bolts failed. Figure 21 illustrates the cask attitude as a function of time during the impact. The cask rotated very slightly during the first $8 \mathrm{~ms}$ of the impact. The system then rotated about 12 degrees in the following $17 \mathrm{~ms}$. The displacement data of Figure 20 with the rotational data of Figure 21 can be used to determine the displacement of each point on the cask as a function of time.

Figure 22 illustrates the velocity-time results obtained for the CG from the digitized film data. These results were obtained by differentiating the displacement data. The CG decelerated from the impact velocity of $44 \mathrm{ft} / \mathrm{sec}$ to rest in about $35 \mathrm{~ms}$. This represents an average deceleration of about $40 \mathrm{~g}$.

Figure 23 illustrates angular velocity results for the CG from the digitized film data. These results were obtained by differentiating the cask attitude data. The maximum rotational velocity is about $13 \mathrm{rad} / \mathrm{s}$ at $22 \mathrm{~ms}$ after start of impact.

The accelerometer data were digitized and filtered to different levels. The results presented here are for a filtering level of $1000 \mathrm{~Hz}$. The results were grouped according to the plane of the accelerometer location. (A complete data set on microfiche is included inside the back cover of this report.) Results for the top end (first plane) are included in Figure 24. The accelerometer results were quite consistent, indicating a pulse that corresponds to crushing the top impact limiter. The duration of the pulse is about $15 \mathrm{~ms}$ and the deceleration level is approximately $100 \mathrm{~g}$. The secondary pulse is not discernible. Figure 25 includes results from accelerometers located at the approximate center of the cask (third plane). Both the primary and secondary impact pulses are evident in these data. Three of four accelerometers at this location yielded consistent results. The pulses for both the primary and secondary impacts appear to be approximately equivalent at this location. The peak deceleration levels indicated by the pulses were about $50 \mathrm{~g}$. Figure 26 includes results from an accelerometer located between the 


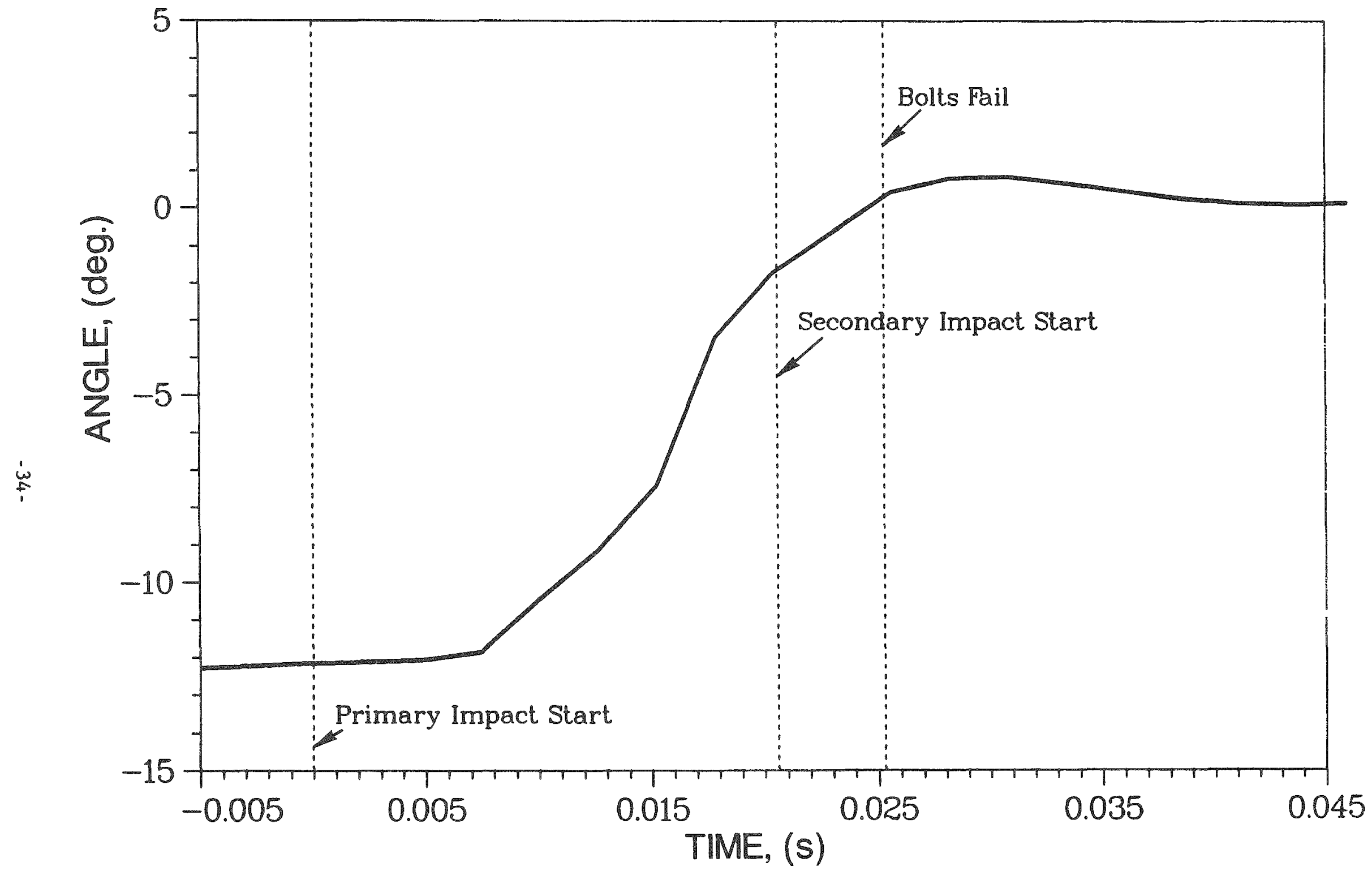

Figure 21. Cask Attitude vs. Time for the Cask During the Slapdown Drop Test 


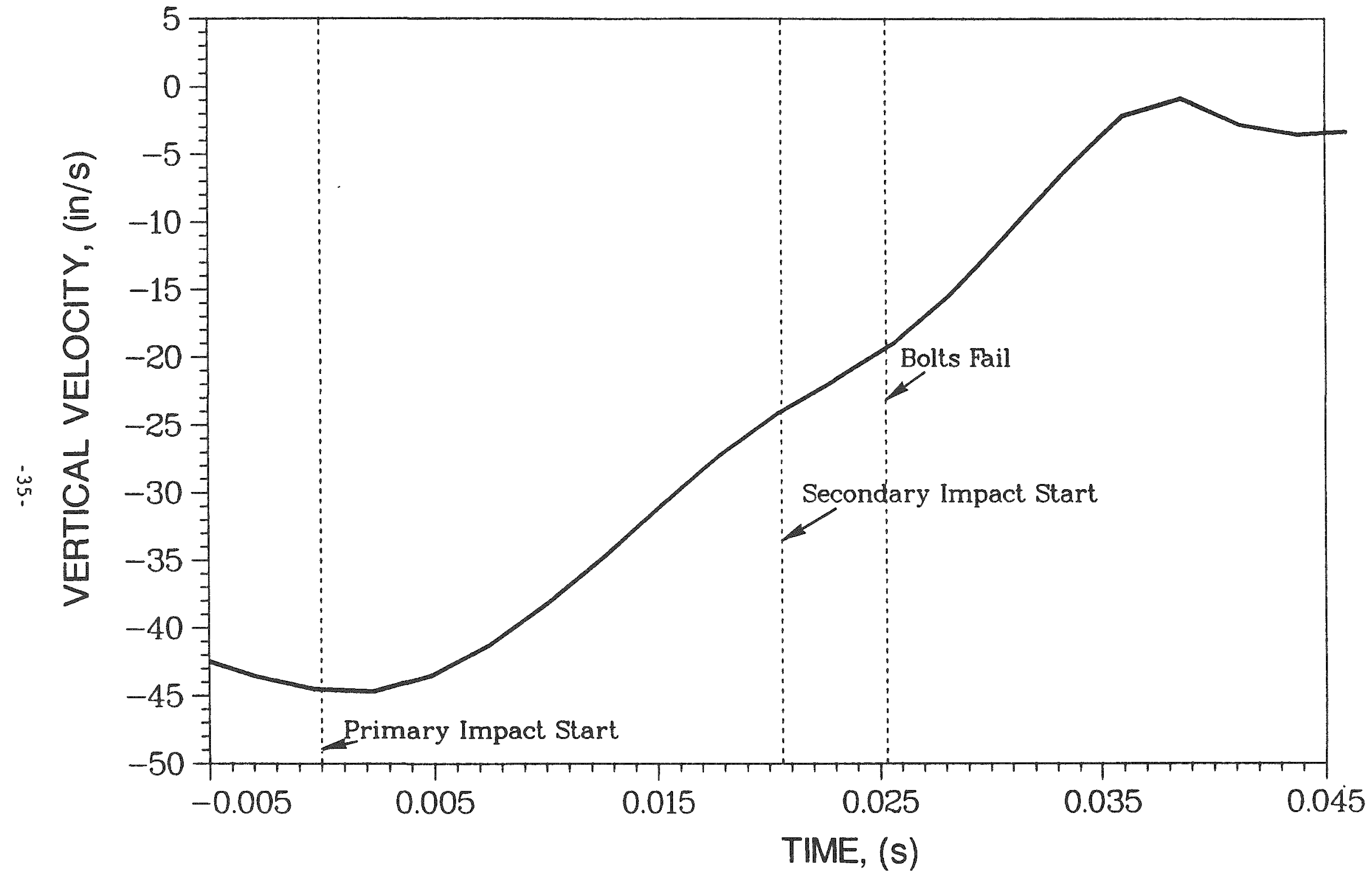

Figure 22. Vertical Velocity of the Center of Gravity of the Cask vs. Time During the Slapdown Drop Test 


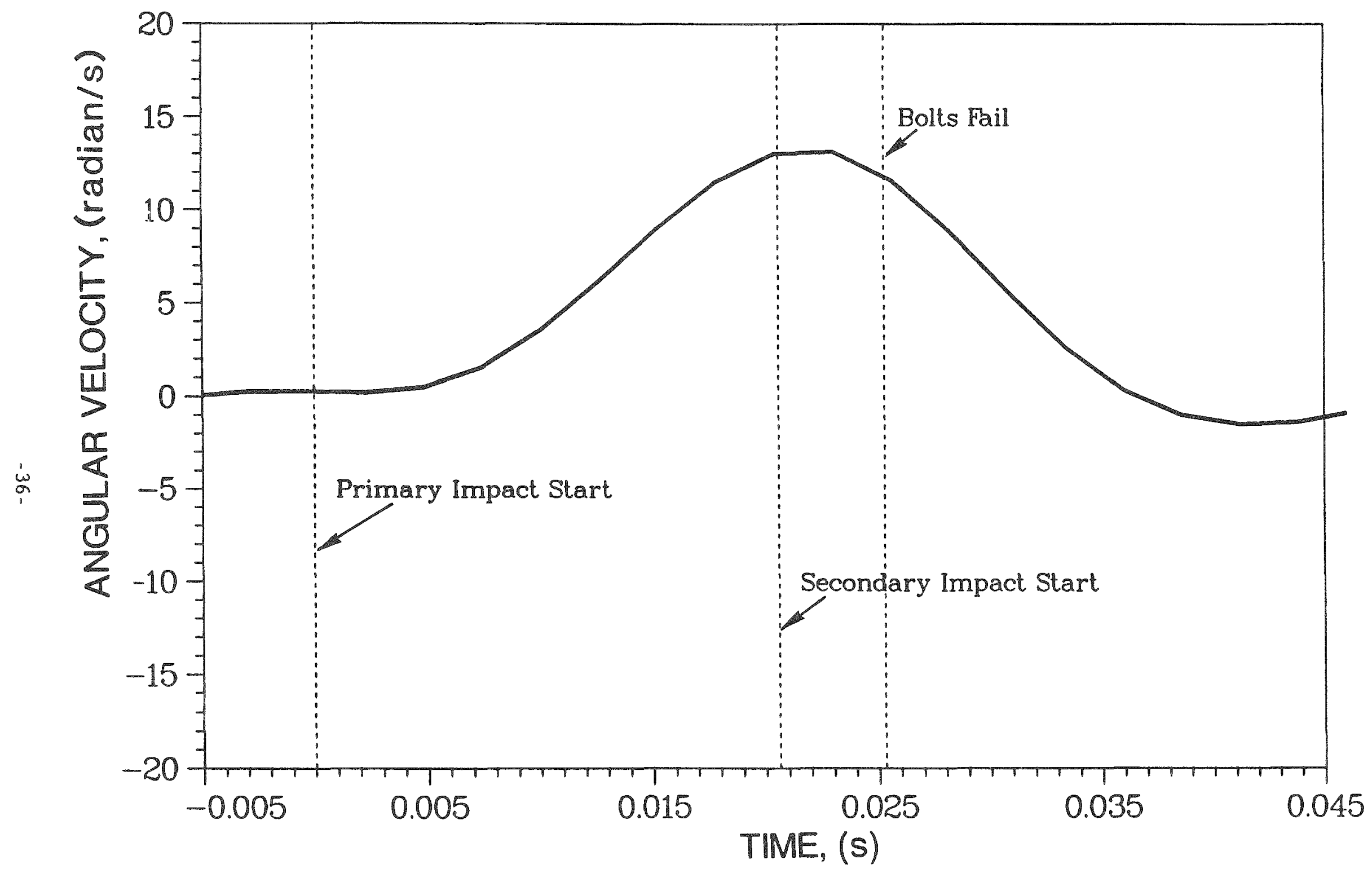

Figure 23. Angular Velocity of the Cask vs. Time During the Slapdown Drop Test 


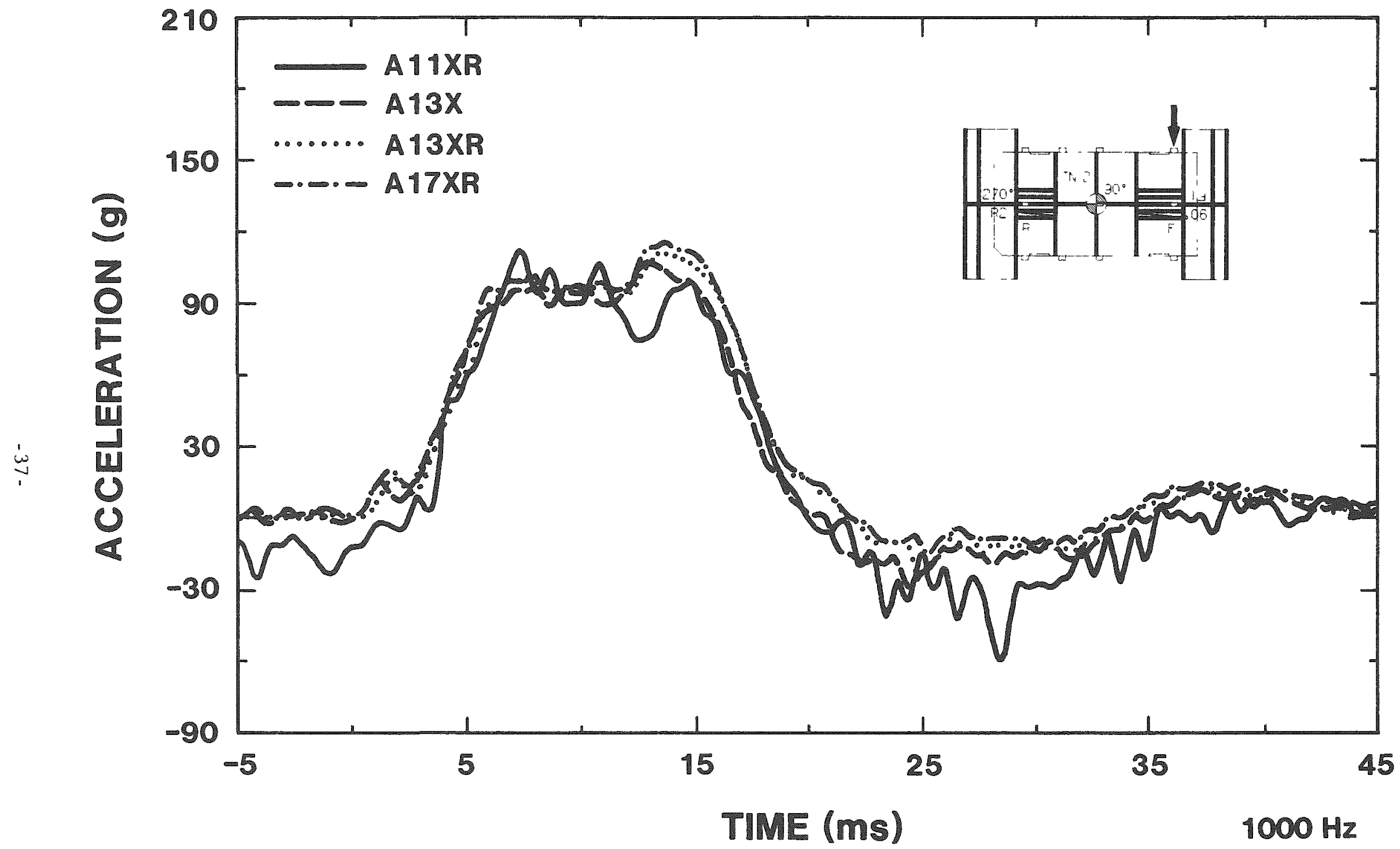

Figure 24. Acceleration vs. Time From Accelerometers on the First Plane Measured During the Slapdown Drop Test 


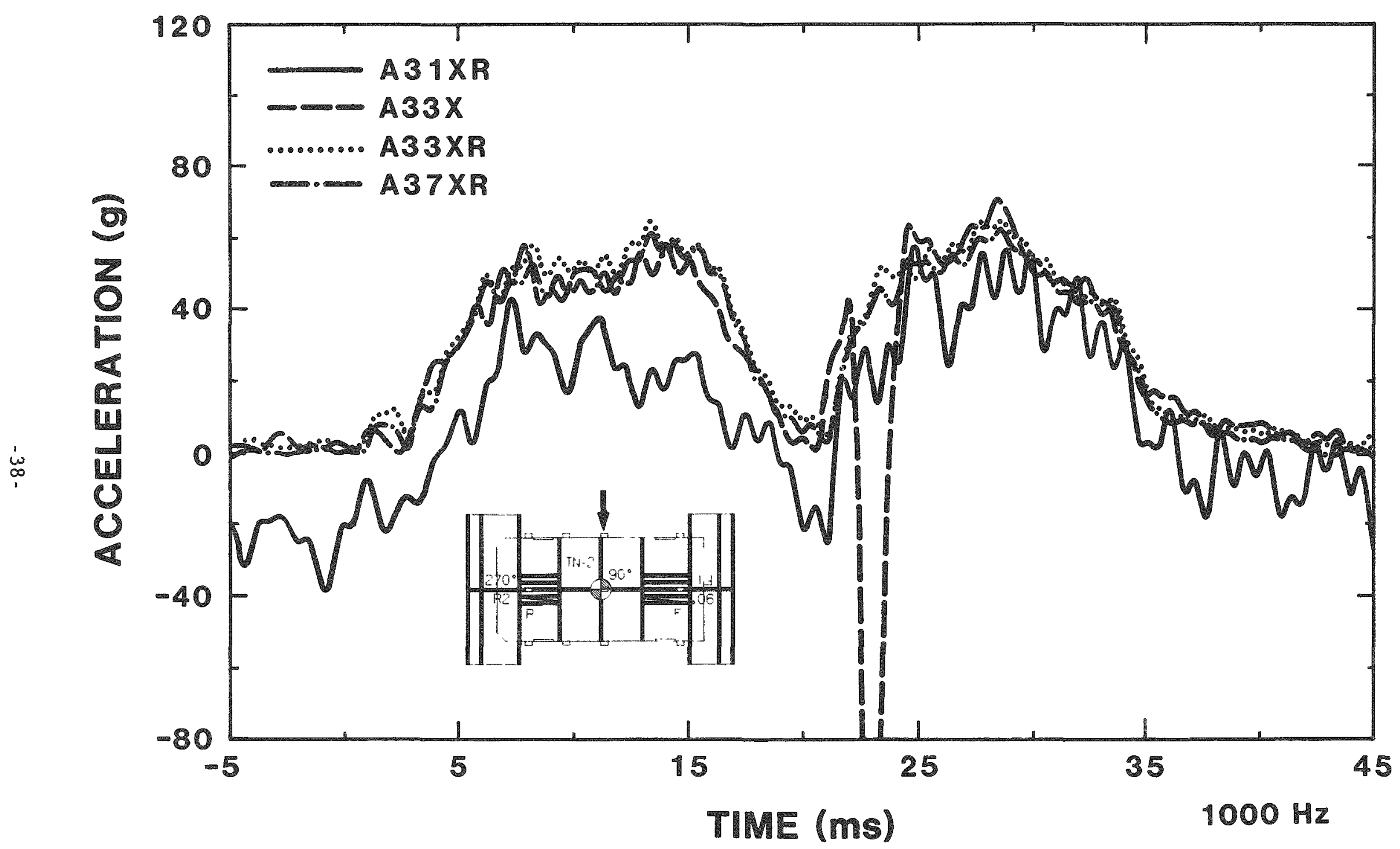

Figure 25. Acceleration vs. Time From Accelerometers on the Third Plane Measured During the Slapdown Drop Test 


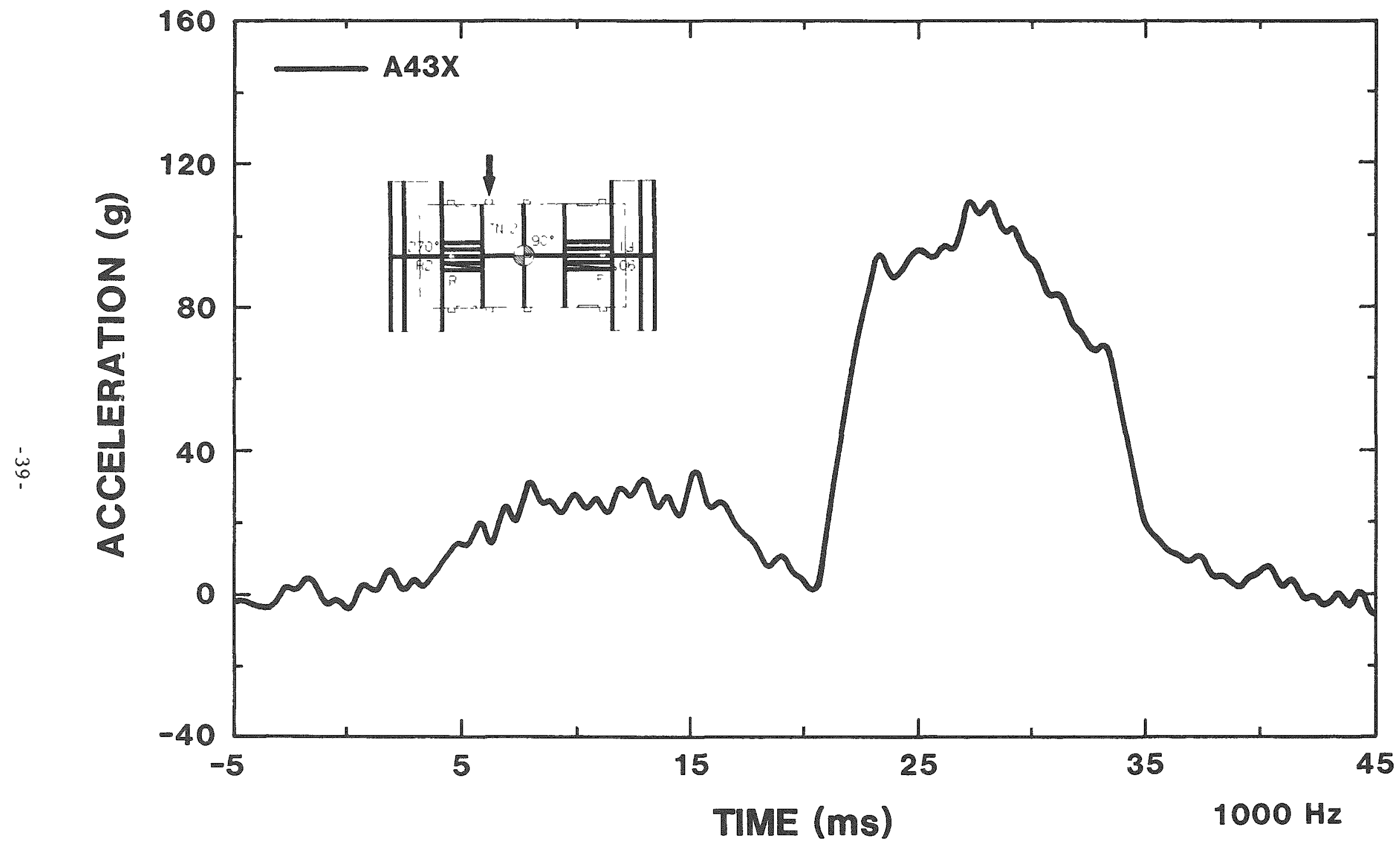

Figure 26. Acceleration vs. Time From Accelerometers on the Fourth Plane Measured During the Slapdown Drop Test 
center and bottom end of the cask (fourth plane). These results indicate much less sensitivity to the primary pulse and more sensitivity to the secondary pulse. Levels for the secondary pulse were about $100 \mathrm{~g}$ for this location. Figure 27 includes results from accelerometers located at the bottom end of the cask (fifth plane). These accelerometers predominantly read the secondary impulse. The results from these units were quite consistent and indicated a peak deceleration level for the pulse of about $140 \mathrm{~g}$. Acceleration levels recorded for the axial direction of the cask were low. The maximum levels were recorded during the primary impact. Figure 28 includes results from axial accelerometers located at the approximate center of the cask. These units indicated maximum values on the order of $15 \mathrm{~g}$.

Microstrain signals from the instrumented bolts indicated a sharp rise in strain at the time of the secondary impact. The upper bolts (SB5 and SB8) indicated strain levels that rose sharply at the point of contact and peaked at about $23 \mathrm{~ms}$ into the impact (Figure 29). Strain levels in the lower bolts (SB6 and SB7) peaked at about $25 \mathrm{~ms}$ into the impact (Figure 30). 


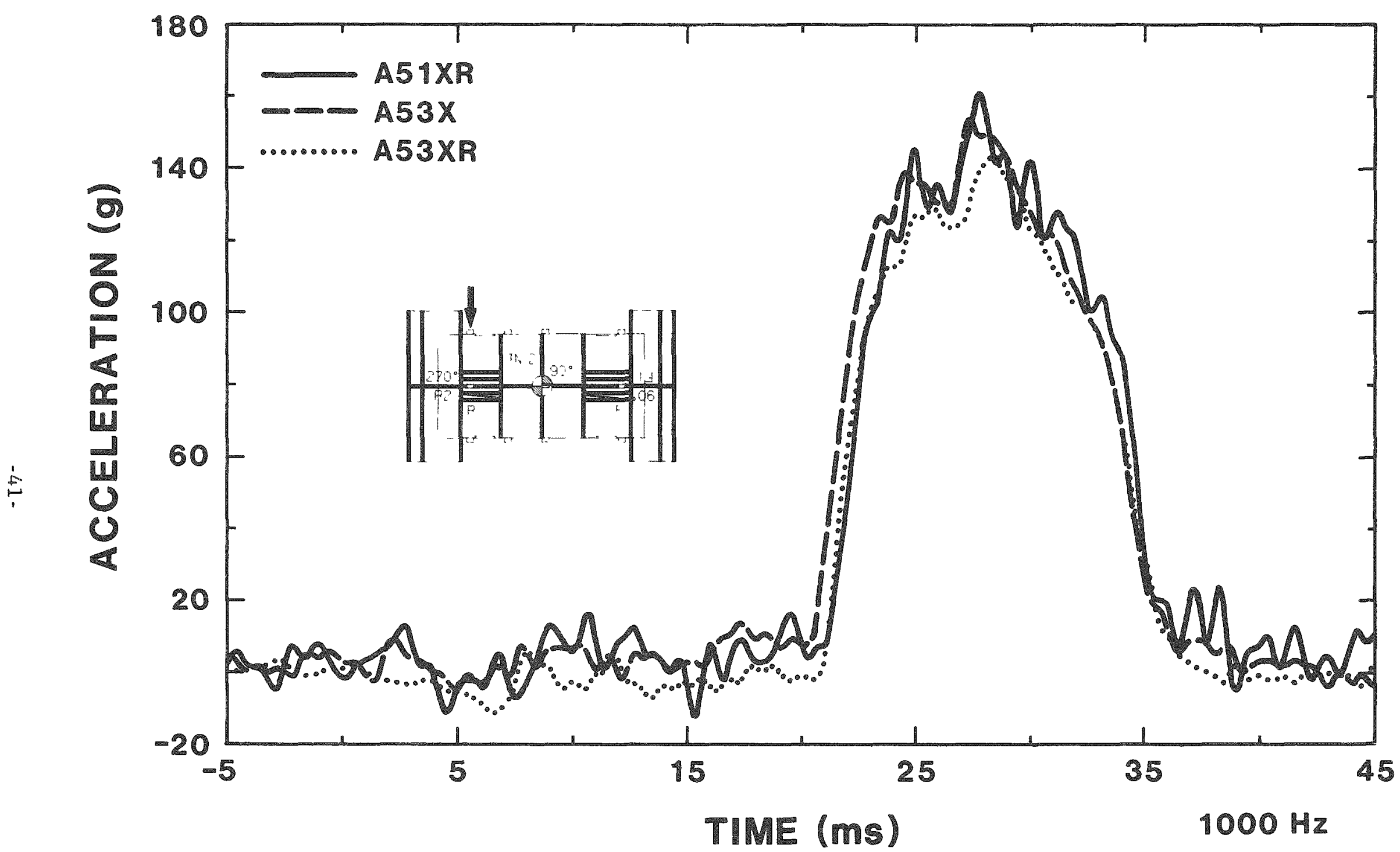

Figure 27. Acceleration vs. Time From Accelerometers on the Fifth Plane Measured During the Slapdown Drop Test 


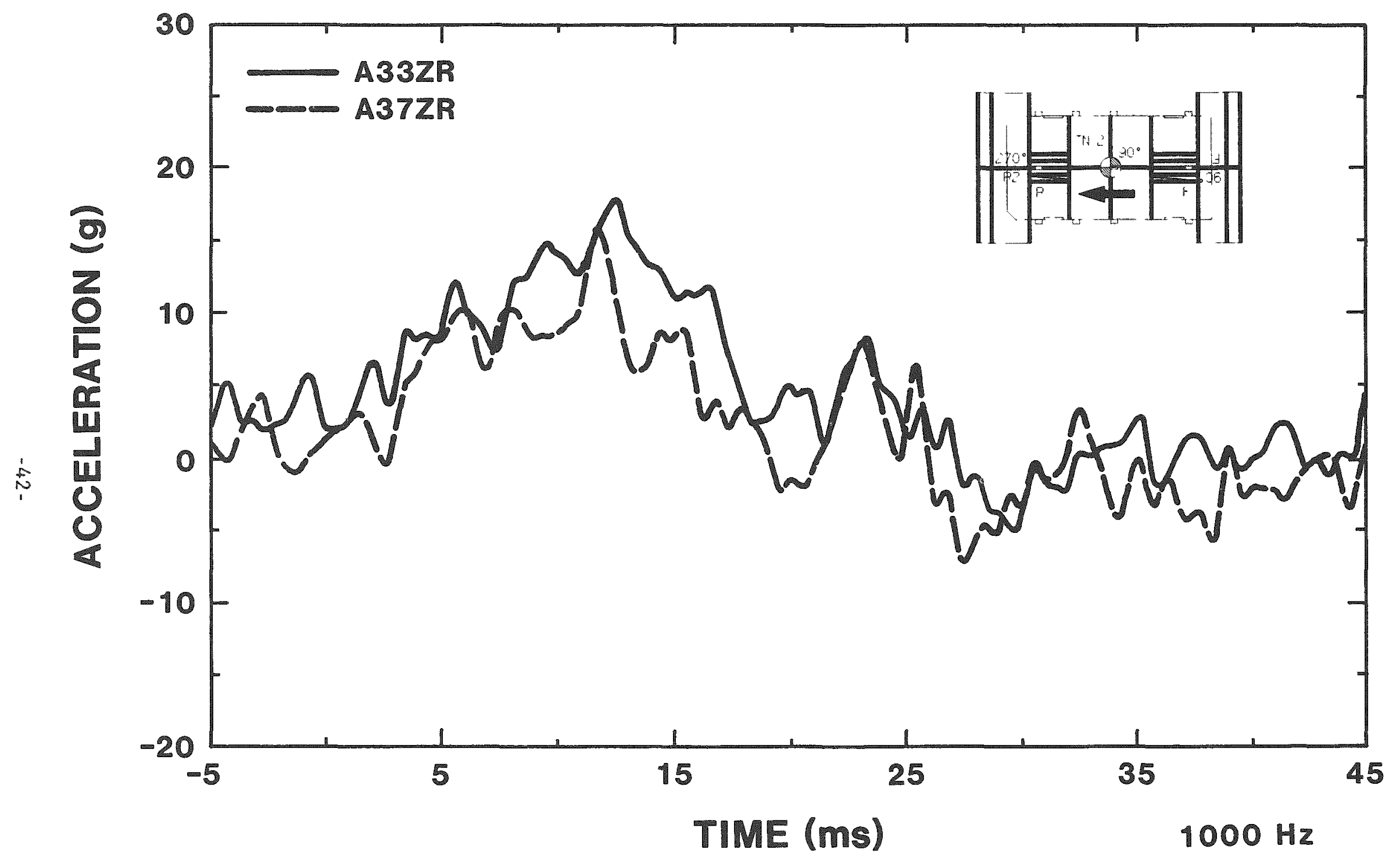

Figure 28. Acceleration in Axial Direction vs. Time From Accelerometers on the Third Plane During the Slapdown Drop Test 


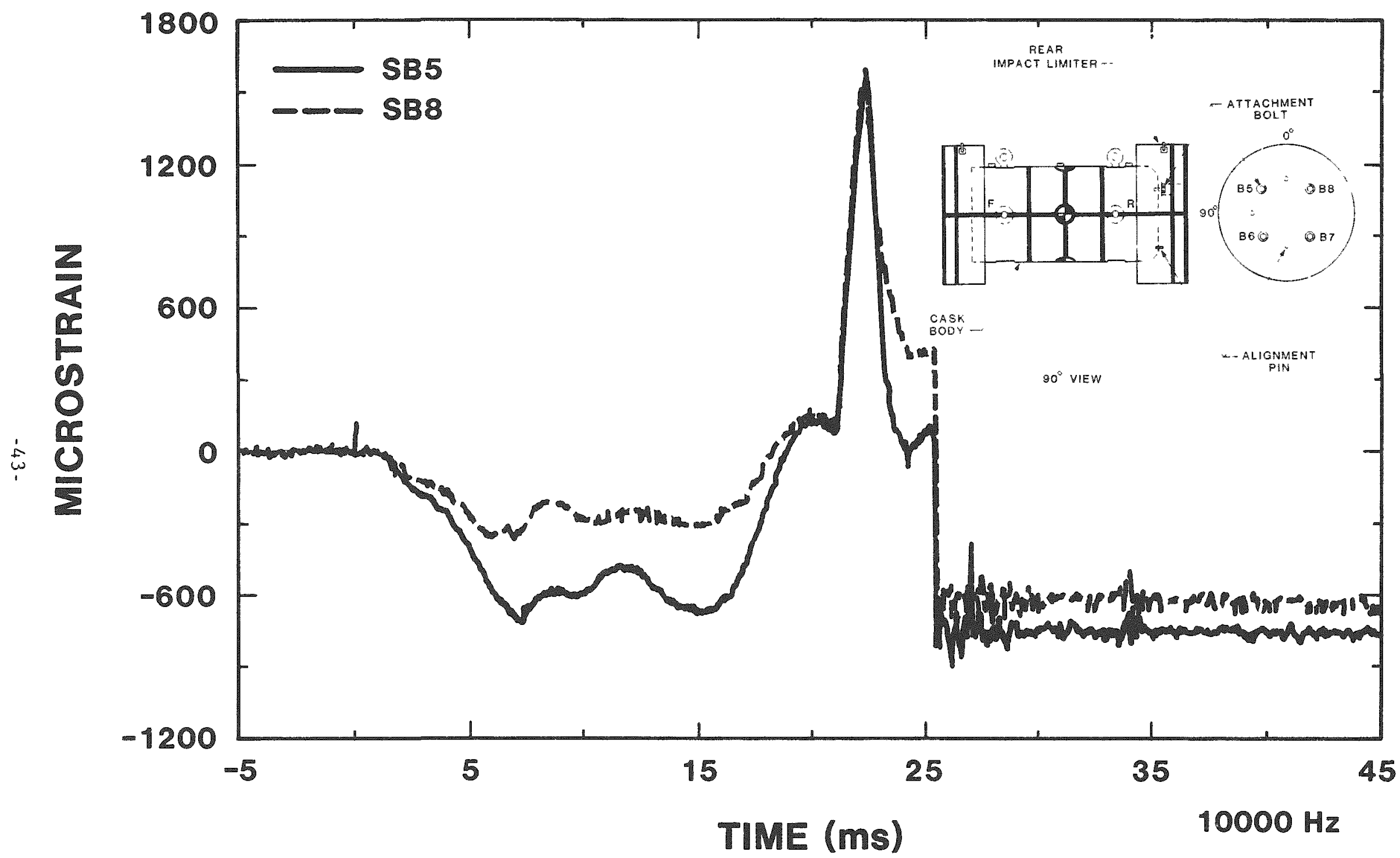

Figure 29. Microstrain Signals From Instrumented Bolts SB5 and SB8 Measured During the Slapdown Drop Test 


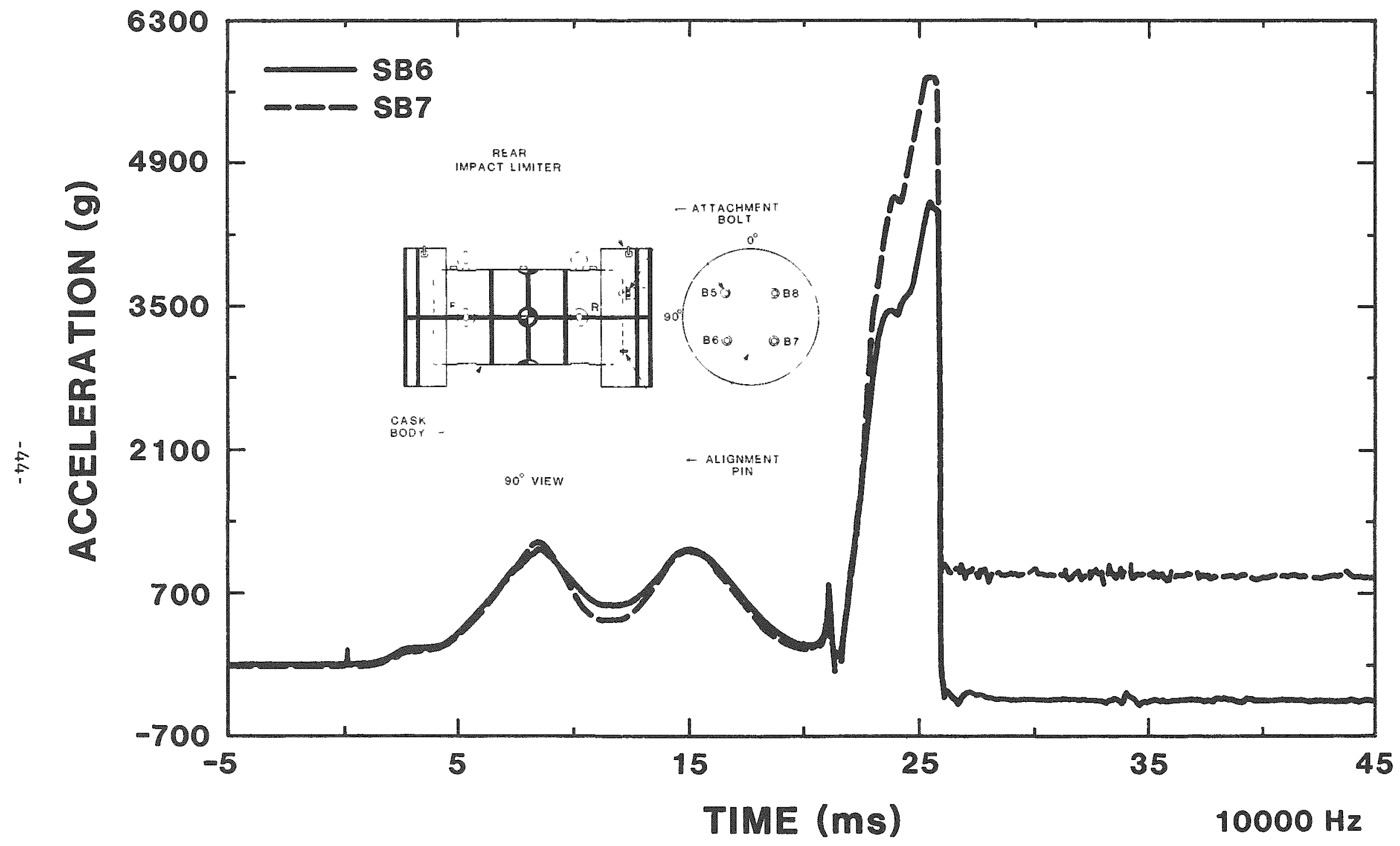

Figure 30. Microstrain Signals From Instrumented Bolts SB6 and SB7 Measured During the Slapdown Drop Test 


\subsection{DISCUSSION OF RESULTS}

The reliability of drop test results depends upon instrumentation accuracy, which, in turn, relies upon the accuracy of the accelerometer and film data. The accuracy of accelerometer results has been reviewed in detail (Madsen et a1., 1987). The review includes a detailed analysis of accelerometer accuracy for the same data acquisition system and data reduction methods applied in this study. Five possible sources of error in the complete process beginning with accelerometer calibration and ending with data reduction were considered. The review concludes that the expected uncertainties are \pm 158 .

For photometric data, the principal error is introduced by reducing poor quality film. If the film is poor, it is difficult to accurately follow the displacement of the structure. Therefore, general judgments regarding the accuracy of film data cannot be made. Based upon a comparison of results from two different cameras, the digitized displacement data are considered reasonably accurate $( \pm 1 / 2$ in.). For impact velocity $(44 \mathrm{ft} / \mathrm{sec})$, results from the streak and the framing cameras agreed within $1 \mathrm{ft} / \mathrm{sec}$.

The impact limiters greatly mitigated the severity of the 30 -ft impact and held cask deceleration levels relatively low. In the end-on drop test, the cask tended to punch through the limiter rather than the 1 imiter crushing at the target interface. Either deformation mode was within the performance envelope. The inner impact limiter structure is not sufficiently rigid to distribute the cask loading, thereby causing crushing along the projected area of the cask body on the limiter.

The force-displacement charactexistic of the impact limiter for the end-on drop condition was calculated using accelerometer data in conjunction with digitized film data. (Calculations are included in Appendix E.) Figure 31 shows the calculated force-displacement curve for the limiter. The curve indicates a peak force of about 1,750.000 Ib. The average stress level in the effective crush area of the impact limiter can be calculated by considering the projected area of the cask 


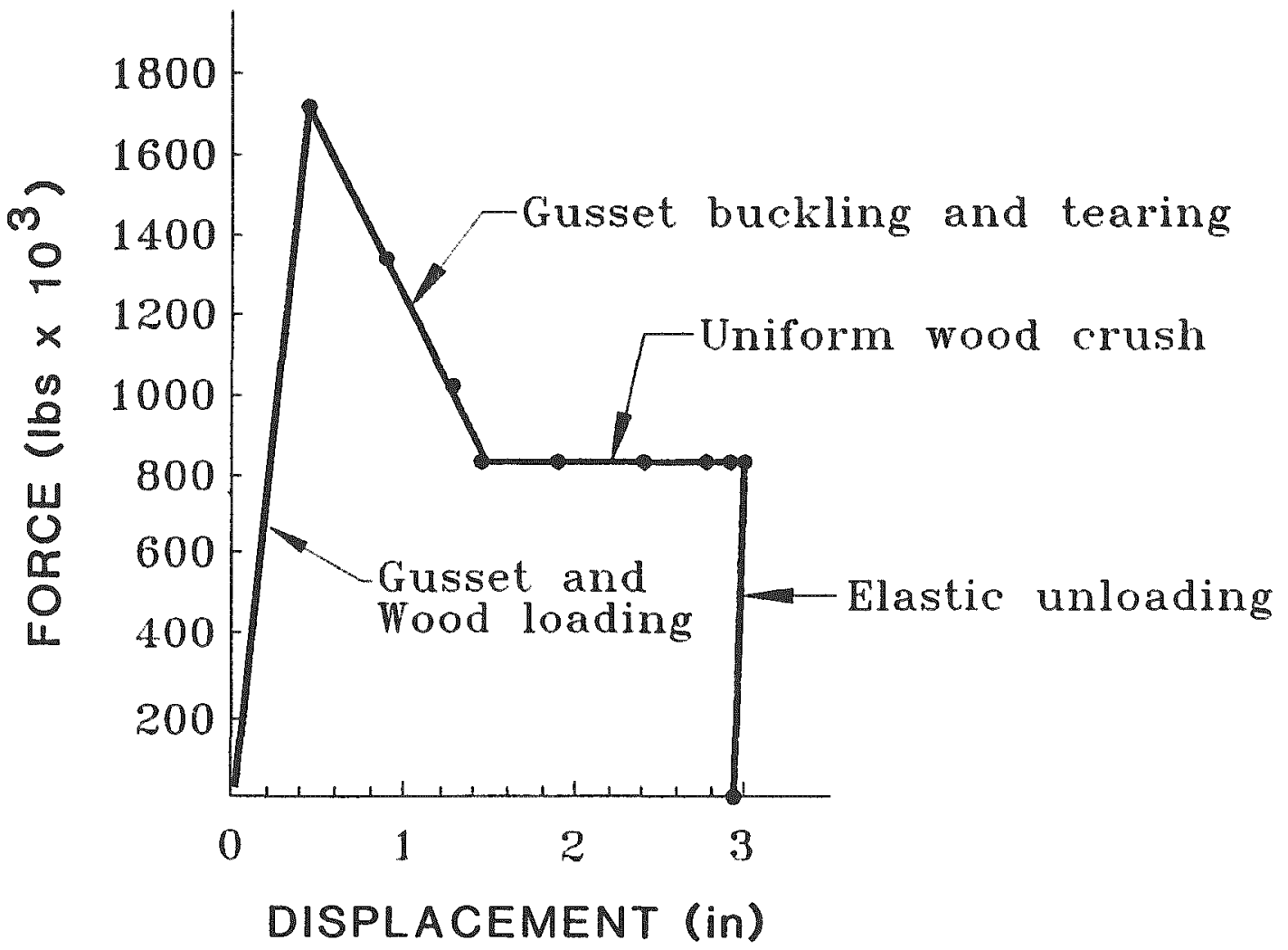

Figure 31. Force vs. Displacement for the Impact Limiter From the End-On Drop Test

(706 in. ${ }^{2}$ ) and the peak crush force $(1,750,000$ 1b). This calculation yields an average stress value of approximately 2500 psi, which is significantly higher than the crush value of balsa. Thus, the embedded metal structure (steel gusset plates) significantly contributes to the peak exhibited by the force-displacement curve (Figure 31).

When buckling begins in the metallic structure, the force level drops significantly and remains at a fairly constant level. The generated force-displacement curve indicates the wood crushed at a force level of about $800,000 \mathrm{lb}$. This value is consistent with the crush strength of balsa. The area under the force-displacement curve, which represents the crush energy, was calculated as a check on the accuracy of the curve. The agreement between the crush energy and the kinetic energy of the system was within 38 . 
The system response to the slapdown drop test was much more complex than for the end-on drop, as expected. Deceleration levels throughout the cask varied significantly. During the primary impact, high deceleration levels on the impact end dropped progressively with distance from the impact point. The secondary impact resulted in decelerations to the bottom end that were higher than those observed on the top end during the primary impact. The peak decelerations recorded on the bottom end were on the order of $140 \mathrm{~g}$, about $40 \%$ higher than what was observed on the top end.

During the secondary impact, combined shear and moment loading tended to dislodge the bottom impact limiter from the cask body. The moment loading generated from the frictional and vertical forces separated the limiter from the cask at the bottom side by pivoting the limiter around the cask; thus the loadings to the upper and lower bolts were different in nature. The upper bolts, which were close to the pivot point, were loaded almost completely in shear. The lower bolts experienced tension and shear. End conditions on the bolts approached fixed: one end was fixed into the cask body and the other end fit snugly into heavy collars welded to the ends of the bolt tubes. These end conditions constrained the bolt ends from rotating, resulting in the creation of large bending stresses in the lower bolts when the impact limiter moved laterally away from the cask body.

As with the end-on test results, filtered accelerometer data along with photometrics data were used to generate force-displacement curves for the impact limiters in the slapdown drop test. A newly developed technique, the sum of weighted accelerations technique (SWAT) (Bateman et al., 1989), was used to reduce the accelerometer data to obtain the force input to the cask. A deconvolution technique was used to check the SWAT calculations. (Details for this process are included in Appendix F.) Figure 32 shows force-displacement results for both the primary and secondary impacts. The secondary impact produced a larger peak force, approximately 500,000 1b; the primary impact peak force was approximately 400,000 1b. Figure 32 shows that the crush energy absorbed during the secondary impact was considerably larger than the energy 


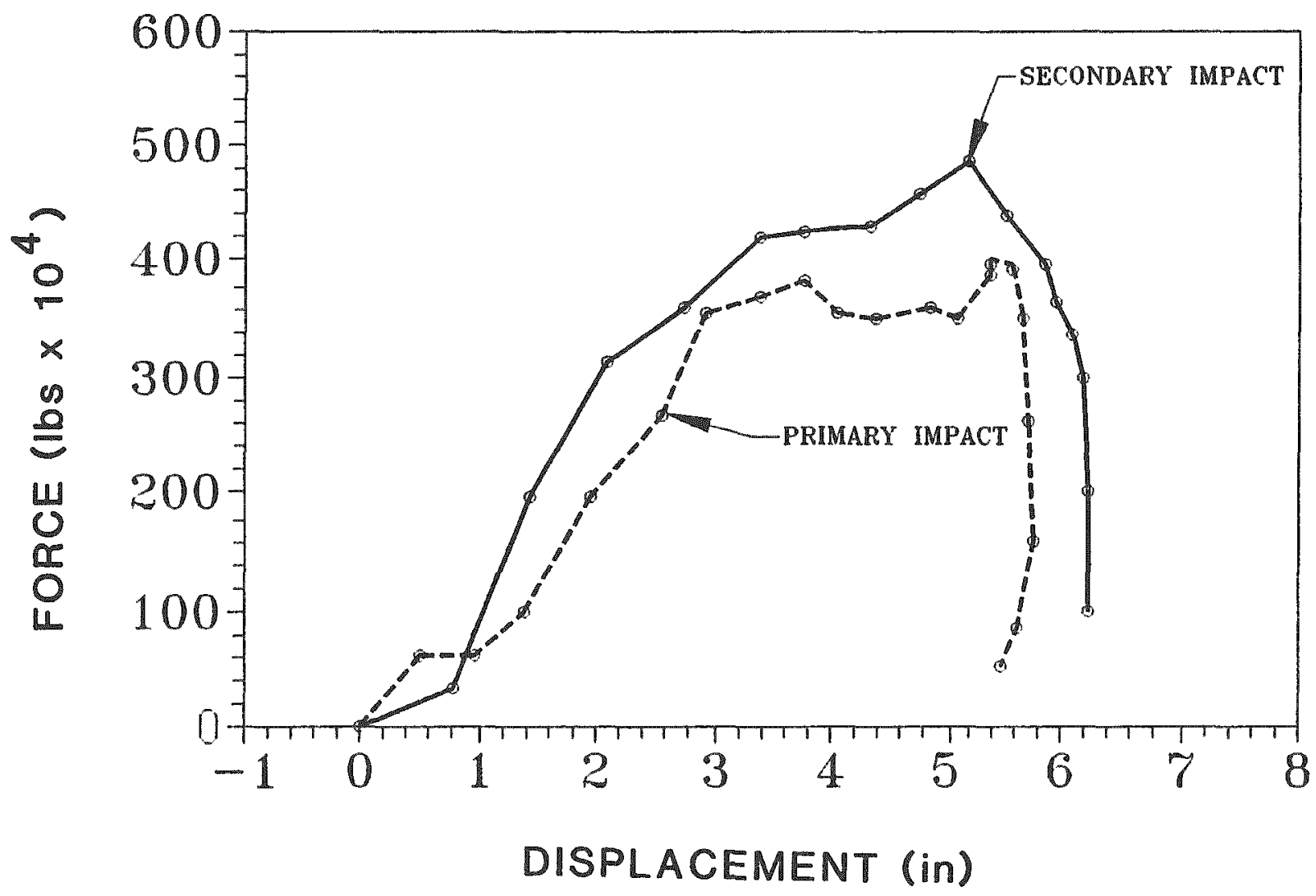

Figure 32. Force vs. Displacement for the Impact Limiter From the Slapdown Drop Test

absorbed in the primary impact. The sum of the crush energy, corresponding to the areas under both curves, agreed within $6 \%$ with the kinetic energy of the system. This good agreement supports the calculated force-displacement curves. 


\subsection{CONCLUSIONS}

The impact limiters are designed to greatly mitigate forces and decelerations to the cask body. In the end-on drop test, decelerations to the cask were limited to about $100 \mathrm{~g}$ and were uniform throughout the cask. The limiter deformation mode involved the cask punching into the limiter rather than the limiter crushing at the target interface.

In the slapdown drop test, decelerations levels varied throughout the cask structure. The primary impact resulted in deceleration values of about $100 \mathrm{~g}$ at the top end (primary impact end) of the cask. The secondary impact was more severe and resulted in deceleration levels of about $140 \mathrm{~g}$ at the bottom end of the cask.

Well-established scaling laws indicate that decelerations in scale model impact tests vary with the full-scale system as the inverse of the scale factor. The scale factor for the model system tested was 3; therefore decelerations in the full-scale system are expected to be one-third of the values observed in the tests.

The secondary impact resulted in extremely severe forces on the bottom impact limiter retention bolts, leading to bolt failure. A strengthened impact 1 imiter retention system should be implemented. 


\section{:NT MPROFILM This Phe}


APPENDIX A

FABRICATION DRAWINGS FOR THE MODEL CASK AND IMPACT LIMITERS

TN-BRP/REG SCALE MODEL, IMPACT LIMITER TESTS, FRONT IMPACT LIMITER TN-BRP/REG PACKAGING, TEST BODY FOR IMPACT LIMITER TESTS

TN-BRP/REG SCALE MODEL, IMPACT LIMITER TESTS, REAR IMPACT LIMITER 


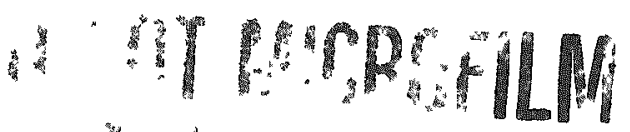

$$
\begin{aligned}
& \text { Ma } 8 a^{2}
\end{aligned}
$$





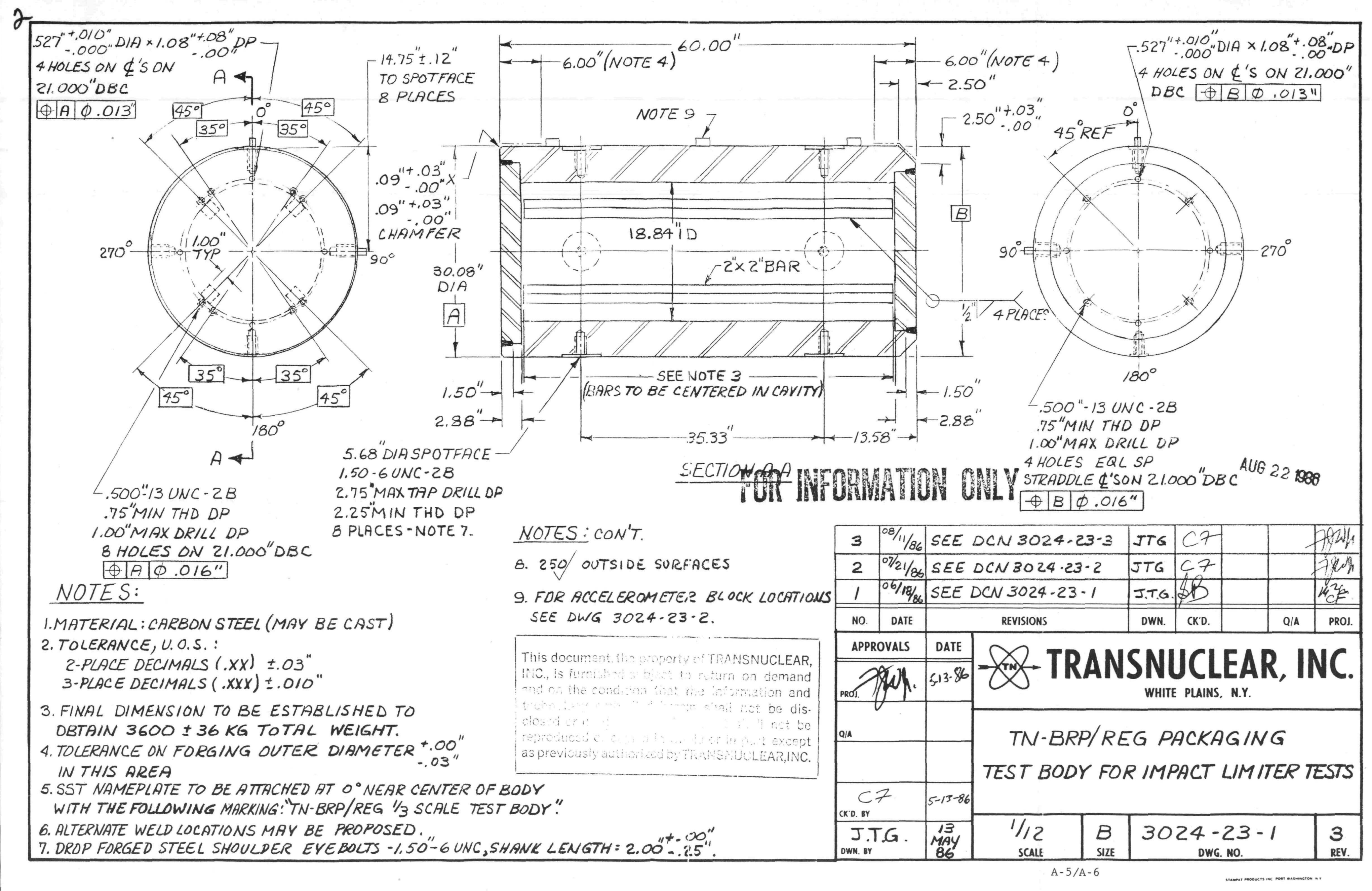




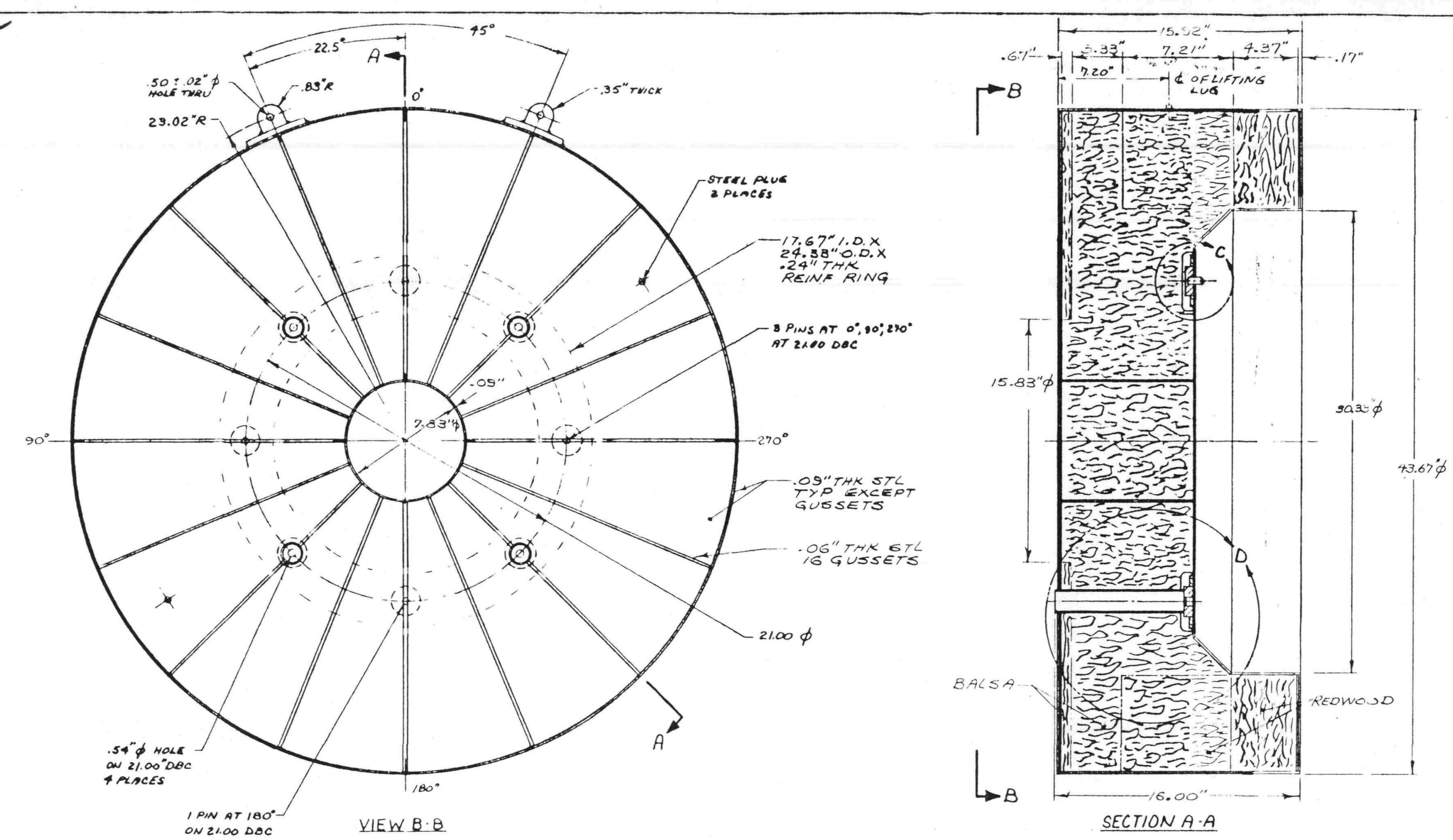

\section{NOTES:}

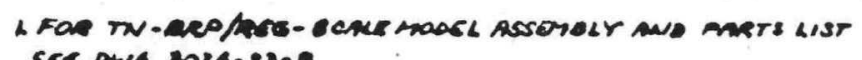

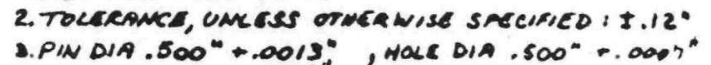

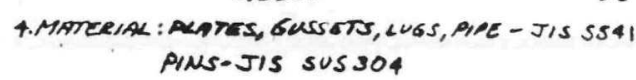

$\operatorname{OCT} 15080$

Wh

This document the property of TRANSNUCLEAR, INC., is fumished stbect to return on demand and on the condition thet fomation and technolog onbodict hact shin not bo disreproduced ot coot in wive or in vart except as previously atthorized by TRANSNUCLEAR,INC.

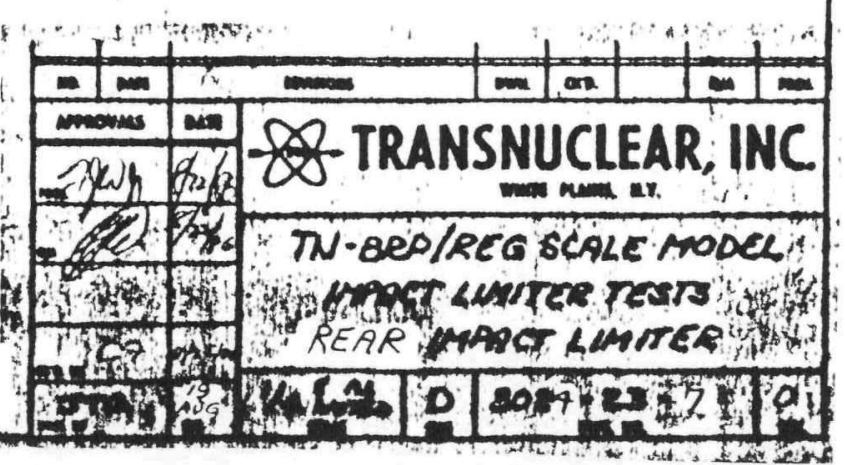


2 
APPENDIX B

INSTRUMENTATION SPECIFICATIONS

B-1 $/ 3-2$ 


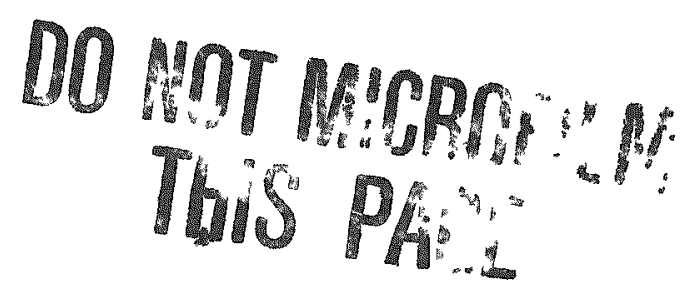

B -2 
This appendix presents information on the test instrumentation used in the drop tests, including manufacturer's specifications and other pertinent information.

Three types of accelerometers were used. These are listed below, along with their $\mathrm{g}$ Iimit and frequency response.

$\begin{array}{lcc}\text { Mode1 } & \text { g Limit } & \text { Frequency Response (kHz) } \\ 2262 & 1000 & 1.5 \\ 2264 \mathrm{~A}-5 \mathrm{~K}-\mathrm{R} & 5000 & 8 \\ 7270 \mathrm{~A} & 2000 & 10\end{array}$

Figures B-1 through B-3 include specifications for these devices. Some of the Mode1 $7270 \mathrm{~A}$ accelerometers were soft-mounted, as indicated in the text. Figure B-4 details how this was accomplished. Special aluminum mounting blocks were fabricated as illustrated. Each mounting block contained two small aluminum plates bonded with a 0.010-in. layer of polysulfide rubber.

All accelerometers were calibrated using a shaker table and centrifuge. Figures B-5 through B-8 include sample calibration results for $7270 \mathrm{~A}$ accelerometers using both hard and soft mountings.

The instrumented bolts used to measure forces tending to dislodge the impact 1imiters were Strainsert SDH-QB-1/2-13NC x $21 / 2 \mathrm{Lg}$. Each bolt was calibrated to $18,200 \mathrm{lb}$. Figure $\mathrm{B}-9$ shows the results of a calibration test conducted at Sandia National Laboratories. Each instrumented bolt was capable of carrying a load of about 27,000 $1 \mathrm{~b}$. 


\title{
ENDEVCO@ MODELS 2262-1000/2262C-1000 PIEZORESISTIVE ACCELEROMETERS
}

\author{
$\pm 1000 \mathrm{~g}$ Damped
}

The Models 2262-1000 and 2262C-1000 are rugged, damped accelerometers that measure static and dynamic acceleration ENDEVCO S PIEZITE Type P-9 prezoresistwe elements are employed in a full bridge circult to obtain a high level low impedance output at $\pm 1000 \mathrm{~g}$ full scale The Model $2262 \mathrm{C}$ is a six-wire device with a pair of fixed precision resistors in half the bridge designed especially for shunt calibration The Model 2262 utilies four-active arms for acceleration measurement

The units will withstand up to 25 times therr rated range without damage or calibration shift The use of subcritcal viscous damping extends their useful frequency range and reduces the effect of spurous, high frequency vibrations

The broad requency response from steady state to $2000 \mathrm{~Hz}$ makes these transducers ideal for measurement of transient type phenomena such as encountered in rocket engine ignitions, package testing. transportation shock and automotive crash studies

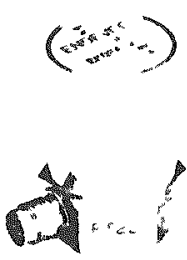

(All values are typical at $-75^{\circ} \mathrm{F}\left[i 24^{\circ} \mathrm{C}\right]$ untess othermse specified)

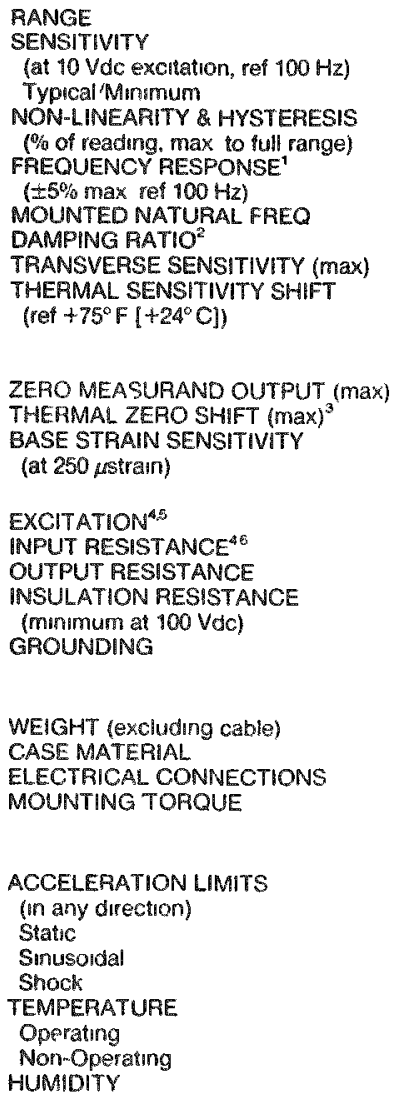

MODEL 2262C-1000

$\pm 1000$

\section{PERFORMANCE}

$9 \$ 1000$

$m V_{7} g \quad 05 / 0375$

0. $\quad+1$

$\mathrm{Hz} \quad 0$ to 1500

$\mathrm{Hz}$ 6000, typical

o 3

$\begin{array}{ll}0 \% & -2 / 0 r-4 \\ \circ & 0+75 /+200\end{array}$

०C $\quad-18+24+93$

$m V=10$

600005

ELCTPICAL

Vde 100

$\Omega \quad 560$

$\Omega \quad 350$

MS 100 leads to case

Cable sheld common to case Cable shield common to case Gase isolated from sensors Case isolated from sensors

PHYSICAL

oz (gm) 1 (28)

Stamless steel, type 416

integral six-pin connector

Hole for 10-32 mounting stu

$1816 \mathrm{i}-\mathrm{Bn}(2 \mathrm{Nm})$

\section{ENYIRONMENTAL}

$$
\begin{aligned}
& \begin{array}{ll}
9 & 1000 \\
g & 1000
\end{array} \\
& 91000 \quad 1000
\end{aligned}
$$$$
92500 \text { half-sme pulse } 2500 \text { half-sme pulse }
$$

$1(28)$

Stanless steel type 416

Integral six-pin connector

$025 / 0187$

11

0 to 4500

6000, typlcal
$07 .+015 / 010$

3

$2 / 0^{t}-4$

$0+75 i+200$
$-18 i+24 i+93$

$\pm 10$

005

100

1000

18 lbf $=$ !n $(2 \mathrm{Nm})$

g stud

0 to $+200(-18$ to 193$)$

20 to $-220(-29$ to -104$)$

ing and glass-to-metal fusion

\footnotetext{
CALIBRATION DATA SUPPLIED

at $75^{\circ} \mathrm{F}\left[24^{\circ} \mathrm{C}\right]$ and 1000 Vde exctatson]

FREQUENCY RESPONSE

SENSITIVITY $\{2 \mathrm{~A} 100 \mathrm{~Hz}\}$

ZERO MEASUAAND OUTPUT

MAXIMUM TMANSVERSE SENSITIVTTY

MOUUTED NATURAL FREOUENCY

DAMPING RATIO

INPUT AND OUTPUT RESISTANCE
}
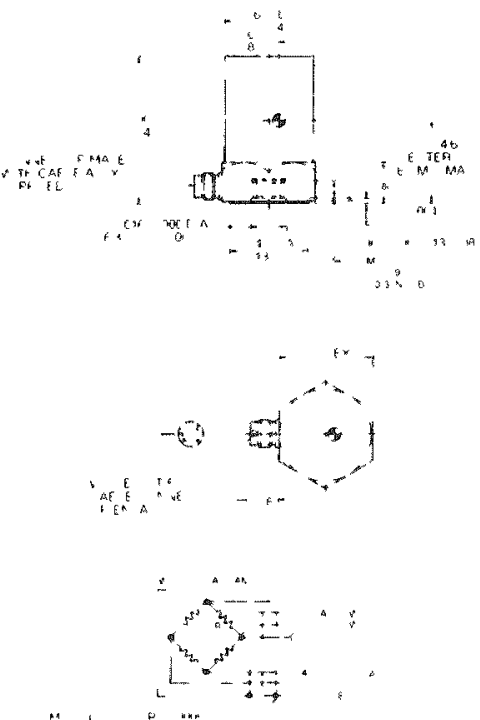

NOTES
"Frequency Response 58 ic makmum 0 to 2000 $\mathrm{Hz}$

Damping ratios 2202 typ cal ato $+200 \mathrm{~F}(18$ +93 C)

Thermal zero Shift milwols specifed are at 0 . $200^{\circ} \mathrm{F}\left(-18 \quad-93 \mathrm{C}\right.$ reference $\left.+75 \mathrm{~F}+24^{\circ} \mathrm{C}\right)$

Afatedexctatron is $100 \mathrm{Vdc}$. The strangage elements have a positive tempe rature cooficien of resictanue of approximately 056 pes of

- Other excitation voltages may besed to 150 Voc but should be specified di tme of order to obtan a more accurdts calibration warmuo ime to mect all spectications is one munute maxmum Endevco Model 4423 Signal Conditioner is iscommended as the excraton source

CMeasured at approximatefy 1 Vde Bndgr resstar ce increases with appled woltag ACCESSORIES INCLUDED

Medel 29813 (1032) or Model 29814 (M5 mette) mountro stud

Model 2262 Model 3022830 Cable Assembly 4 conductor shilded $30 \mathrm{in}(76 \mathrm{~cm})$ long

Model 2262C Model 3023B 30 Cab' Assemb , 6 conductor shelded $30 \mathrm{n}$ in $(76 \mathrm{C} \mathrm{C}$; long

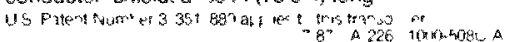

Figure B-1. Data Sheet for an Endevco $2 \angle 6 \angle-10 u U$ piezoresistive

Accelerometer 


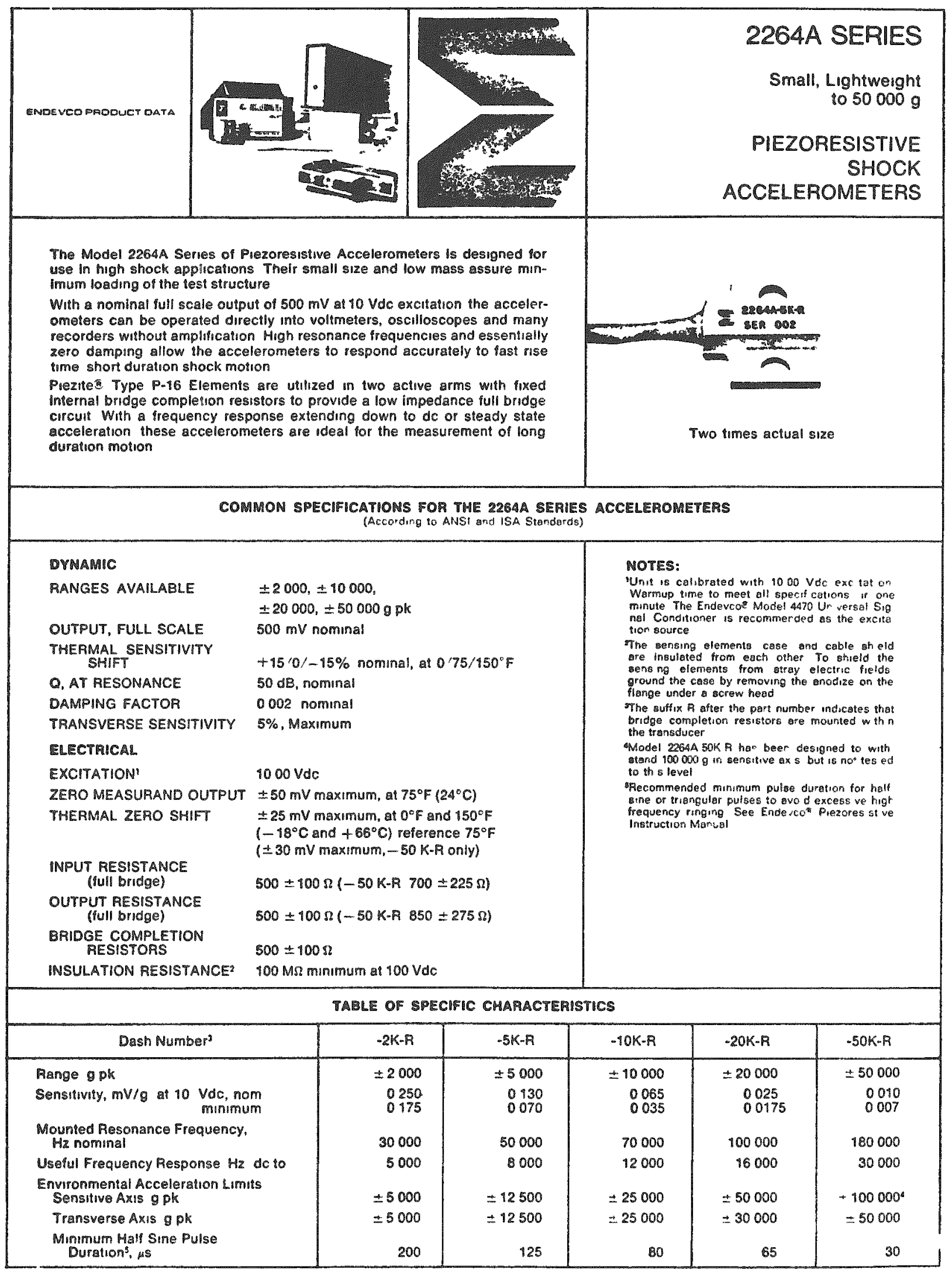

Figure B-2. Data Sheet for an Endevco 2264 Piezoresistive Accelerometer 


\section{ENDEVCO® SERIES 7270A \\ PIEZORESISTIVE ACCELEROMETERS}

High $g$ High Resonant Frequency

The Model 7270A Serles of Plezoresistive Accelerometers are rugged undamped unts designed for shock measurements ENDEVCO chemically sculptures the sensing system of the $7270 \mathrm{~A}$ from a single prece of silicon This etched slicon chip includes the intertial mass and strain gages arranged in an active four-arm Wheatstone bridge circuit complete with a novel on-chip zero balance network The low mass, extremely small size and unique construction of the element blends an exceptionally high resonant frequency with characteristics such as low impedance. high overrange and zero damping for no phase shift The high resonant frequency of these sensors permits their survival in the presence of these high frequency components in a shock pulse that could shatter the seismic system of accelerometers having lower resonance High resonance frequencies and zero damping allow the accelerometers to respond accurately to fast rise twme, short duration shock motion With a frequency response extending down to dc or steady state accelerations these transducers are ideal for measurement of long duratmon transients

(All values are typical at $+75^{\circ} \mathrm{F} 1+24^{\circ} \mathrm{C}$ ) with 10 volts excitation appled untess otherwse spectied)

RANGE

SENSITIVITY

(at 10 Vdc excitation, ref $100 \mathrm{~Hz}$ )

Minimum/Maximum

NON-LINEARITY \& HYSTERESIS

(\% of reading max, to full range)

FAEOUENCY RESPONSE

( $5.5 \%$ max ref $100 \mathrm{~Hz}$ )

MOUNTED RESONANT FREO

TRANSVERSE SENSITIVITY (max)

THERMAL SENSITIVITY SHIET

(ref $475^{\circ} \mathrm{F}\left[+24^{\circ} \mathrm{C}\right.$ )

ZERO MEASURAND OUTPUT (maX)

THERMAL ZERO SHIFT (max)

BASE STRAIN SENSITIVITY

(at 250 ustrain)

OVERRANGE LIMITS

EXCITATION ${ }^{3 *}$

INPUT RESISTANCE"

OUTPUT RESISTANCE

INSULATION RESISTANCE

(minumum at $100 \mathrm{Vdc}$ )

GROUNDNG

WEIGHT (excluding cable)

CASE MATERIAL

ELECTRICAL CONNECTIONS

MOUNTING TOROUE

TEMPERATURE

Operating

Non-Operating

HUMIDITY

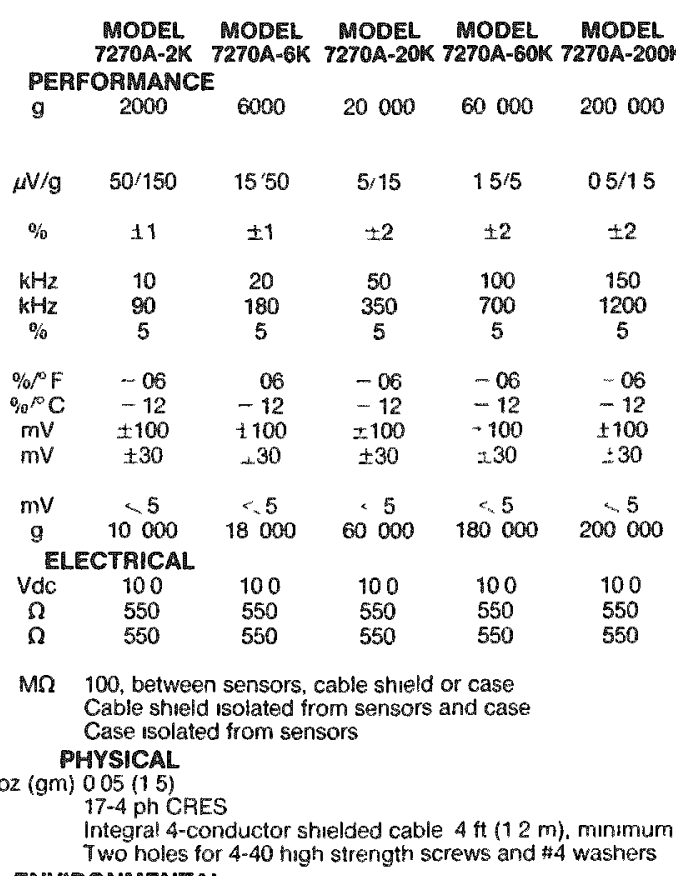

\section{ENVIRONMENTAL}

of $(C \mathrm{C})-30$ to $150(18$ to -66$)$
of $(\mathrm{C})-65$ to $+250(-54$ to +121$)$ Sealed by apoxy

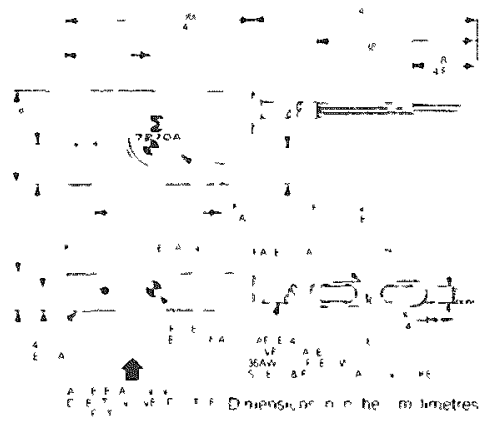

NOTES

Frequency response should devate by less than $\pm 5^{\circ}$ fromdcto indicated frequency Acceleration levels of conventional technous are too low for accurate conventional technoues are too low for accurate andys of the frequency response of the higher
pange models Measurement uncertanties above 10 $k H z$ prevents stating $\pm 5^{\circ} \mathrm{e}$ as a specitication limit to als but the 2000 g range

Thermal zero shift specified is at 0 to $-150 \mathrm{~F}$ ( 18 to $\left.+66^{\circ} \mathrm{C}\right)$ reference $+75^{\circ}=(+24 \mathrm{C})$

${ }^{3}$ Rated exclation is $100 \mathrm{Vdc}$ The stran gage elements have a postive temperature confficient of resistance of asproximate $014^{\circ}$ o per ${ }^{n} \mathrm{~F}$

${ }^{4}$ Other excitation voltages may be used to $120 \mathrm{Vdc}$ but should be spocited at time of order to obtain a more accurate calibration warmup turne to meet al specifcetions is two minutes maxmum

SMeasurand at approximately $1 \mathrm{Vdo}$ Broge resistance increases with applied voltage

Use $8 \pm 2$ b an $(27 \mathrm{Nm}$ ) mounting torque acoustic couplant and high strength steol screws to : 1 insure intmate contact between accels someter and mount ing surace and (2) to prevent yelding of the screw ing surace and (2) to prevent yemer an one screw and loss on force daetoshochs above $100 \mathrm{co0g}$ Los of meani giul data and possut damage to the accelerometer due to rathing on its mounitng surface can result from using ether tou high or too low a value of mounting torque if large transverse shocks are antuppated the use of hqud thread-locking com pounds is recommended to rejuce loss of screw preload

The use of low strength mounting material (such as aluminuml is not recommended However if such is the case epoxy should be used between the trans ducer and mountng surface to supplement the strength of the threads

The cable should be mounted securely with tape or glue leaning a stra? reduef of botween 4 inch and nen at the trans tucer

IMPORTANT Freukney conterl of shits whet exceed the overranges limis of the 7270 a oter contain significant signal ampitudes well above $100 \mathrm{kHz} 5 \mathrm{sig}$ nal condivonng with insufficuent bardweth may atteruate the signal and give sign ficantly lower ind cated peak acceteraions

\section{ACCESSORES INCLUDED}

Two EHi37 4.40 " "socket head can screw two 17147 size 4 specia flat washers 


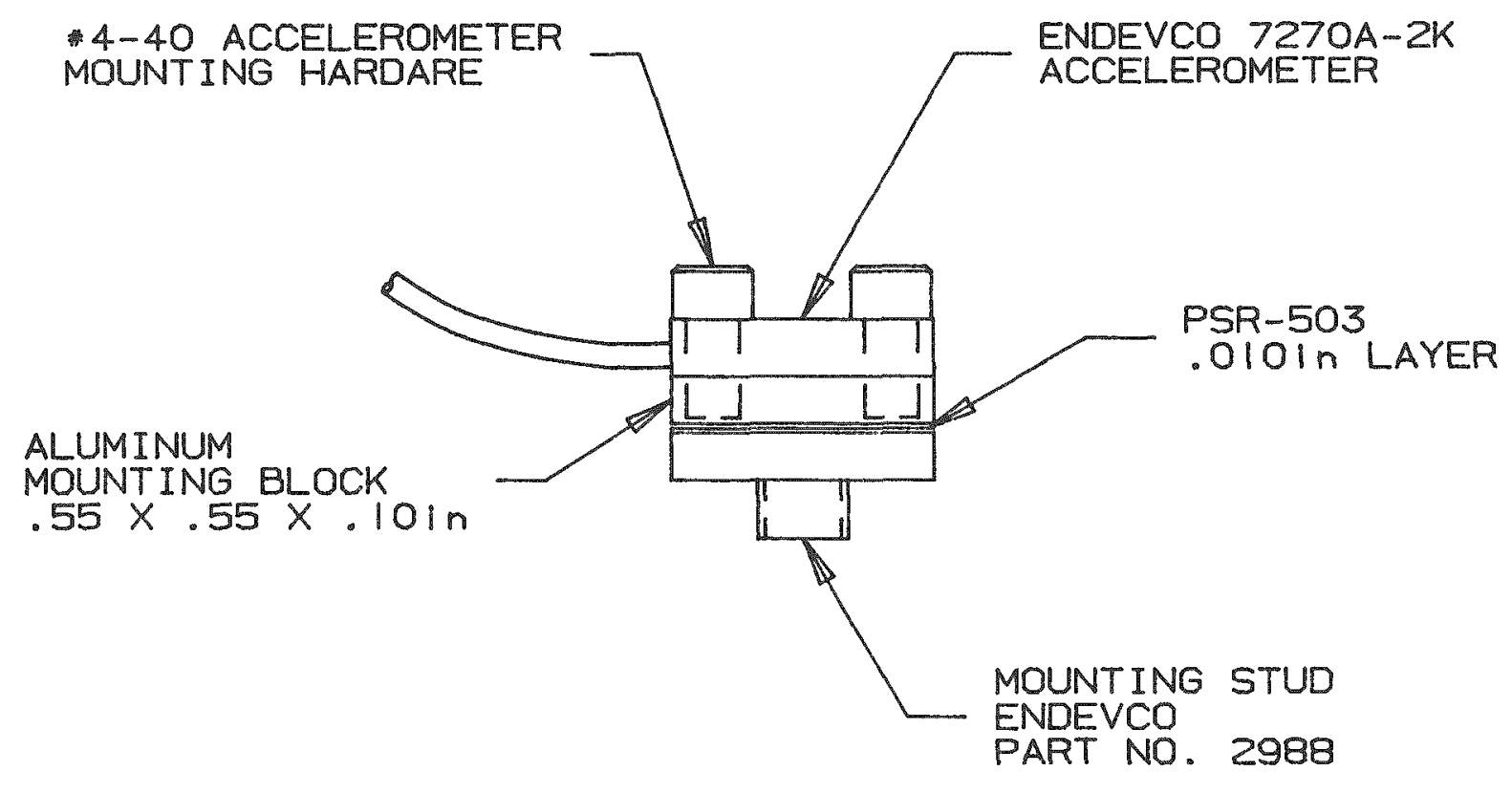

PSR = POLYSULFIDE RUBBER

Distributed by Tracon. Inc.

Figure B-4. Schematic of a Soft-Mounted Endevco 7270A-2K Piezoresistive Accelerometer 
TRANSOUCER CALIERATION REPORT

SANDIA LABS $7241 \quad 10 / 12 / 1988$

\begin{tabular}{|c|c|c|c|c|}
\hline MANUFACTURER & ENDEVCO & & & \\
\hline MODEL & $7270 A-2 k$ & & & \\
\hline SERIAL & $8625 F$ & & DATAF ILE & 楳 \\
\hline TRANEDUCER TYPE & SEMICONDUCTOR & STRAINGAGE & & \\
\hline CERTIFIED BY & $\mathrm{BG}$ & & & \\
\hline EXPIRATION DATE & $5 / 1 / 1989$ & & & \\
\hline TEMPERATURE & AMBIENT & FACILITY USED & SHAKER & \\
\hline REQUESTING ORG. & 6323 & & & \\
\hline COMMENTS: & D. BRONOWSKI & SOFT MOUNTED. & & \\
\hline
\end{tabular}

\begin{tabular}{|c|c|c|c|}
\hline PEFERENCE & FREQUENCY & TRANSDUCEF & PERCENT \\
\hline UNITS & HERTZ & OUTPUT & DEUIATION \\
\hline 6 & & $4 V / U / 6$ & FROM $100 \mathrm{HZ}$ \\
\hline 30.00 & 100.00 & 9.26259 & 0.00 \\
\hline 30.00 & 200.00 & 9.25899 & -.04 \\
\hline 30.00 & 500.00 & 9.27967 & .18 \\
\hline 30.00 & 1000.00 & 9.31743 & .59 \\
\hline 30.00 & 1500.00 & 9.36443 & 1.10 \\
\hline 30.00 & 2000.00 & 9.43334 & 1.84 \\
\hline 30.00 & 2500.00 & 9.53315 & 2.92 \\
\hline 30.00 & 3000.00 & 9.64397 & 4.12 \\
\hline 30.00 & 3500.00 & 9.76785 & 5.45 \\
\hline 30.00 & 4000.00 & 9.91798 & 7.08 \\
\hline 30.00 & 4500.00 & 10.04354 & 8.43 \\
\hline 30.00 & 5000.00 & 10.08580 & 8.89 \\
\hline 30.00 & 5500.00 & 10.36513 & 11.90 \\
\hline 30.00 & 6000.00 & 10.54446 & 13.84 \\
\hline 30.00 & 6500.00 & 10.76269 & 16.20 \\
\hline 30.00 & 7000.00 & 11.11137 & 19.96 \\
\hline 30.00 & 7500.00 & 11.37444 & 22.80 \\
\hline 30.00 & 8000.00 & 11.58926 & 25.11 \\
\hline 30.00 & 8500.00 & 11.90390 & 28.52 \\
\hline 30.00 & 5000.00 & 12.13323 & 30.99 \\
\hline 30.00 & 9500.00 & 12.25934 & 32.35 \\
\hline 30.00 & 10000.00 & 12.41848 & 34.07 \\
\hline \multicolumn{2}{|c|}{ INFUT RESISTANCE } & 476. OHMS & \\
\hline \multicolumn{2}{|c|}{ OUTPUT RESISTANCE } & 471. OHMS & \\
\hline \multicolumn{2}{|c|}{ INSULATION RESISTANCE } & $\because 10 M E G$ & \\
\hline \multicolumn{2}{|c|}{ ZERO OFFSET } & 0.0000 VOLTS & \\
\hline \multicolumn{2}{|c|}{ TEST EXCITATION } & 9.96 VOLTS & \\
\hline
\end{tabular}

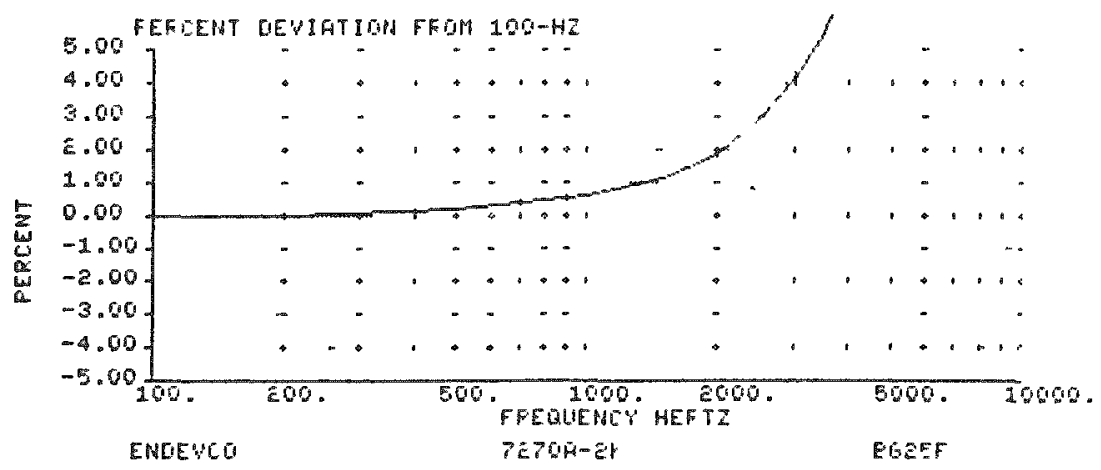

UV V.G O 100HZ: 9.E6E

Figure B-5. Shaker Calibration of a Soft-Mounted Endevco 7270A Accelerometer 
TDANSDUCER CALIBRATICA REPORT

SANDIA LABS $724111 \% 4 / 1988$

$\begin{array}{lll}\text { MANUFACTURER } & \text { ENDEUCO } & \\ \text { MODEL } & 7270 A-2 K & \\ \text { SERIAL } & \text { BG25F } & \\ \text { TRANSDUCER TYFE } & \text { SEMICONDUCTOR STRAINGAGE } & \\ \text { CERTIFIED BY } & \text { FR } & \text { EXFIRATION DATE G: } 1 / 1989 \\ \text { TEMPERATURE } & \text { AMEIENT } & \text { FACILITY USED 5OOD-G CENTRIFUGE }\end{array}$

REQUESTING ORG. 6323

COMMENTS: DAVE BRONOWSKI ... E-4ETE

FOSITIUE DIR. ONLY, SOFT MOUNTED...

\begin{tabular}{|c|c|c|c|c|c|}
\hline REFERENSCE & TOTAL RAW & TRANSDUCER & FERCENT & FEF & RCENT \\
\hline UNITS & OUTFUT & DUTPUT & DEUIATIDN & DEVI & ATION \\
\hline G & $u U$ & UVIVIG & FULLSCALE & BEST FIT & LII \\
\hline 399.0 & 25547.00 & 3.30386 & -.02 & & -.1 \\
\hline 799.5 & 62754.01 & 9.29363 & -.08 & & -.2 \\
\hline 1199.0 & 100129.0 & 9.31708 & -.01 & & -.8 \\
\hline 1601.8 & 137700.0 & 9.31922 & .01 & & .6 \\
\hline 1997.8 & 174650.0 & 9.32136 & .03 & & \\
\hline
\end{tabular}
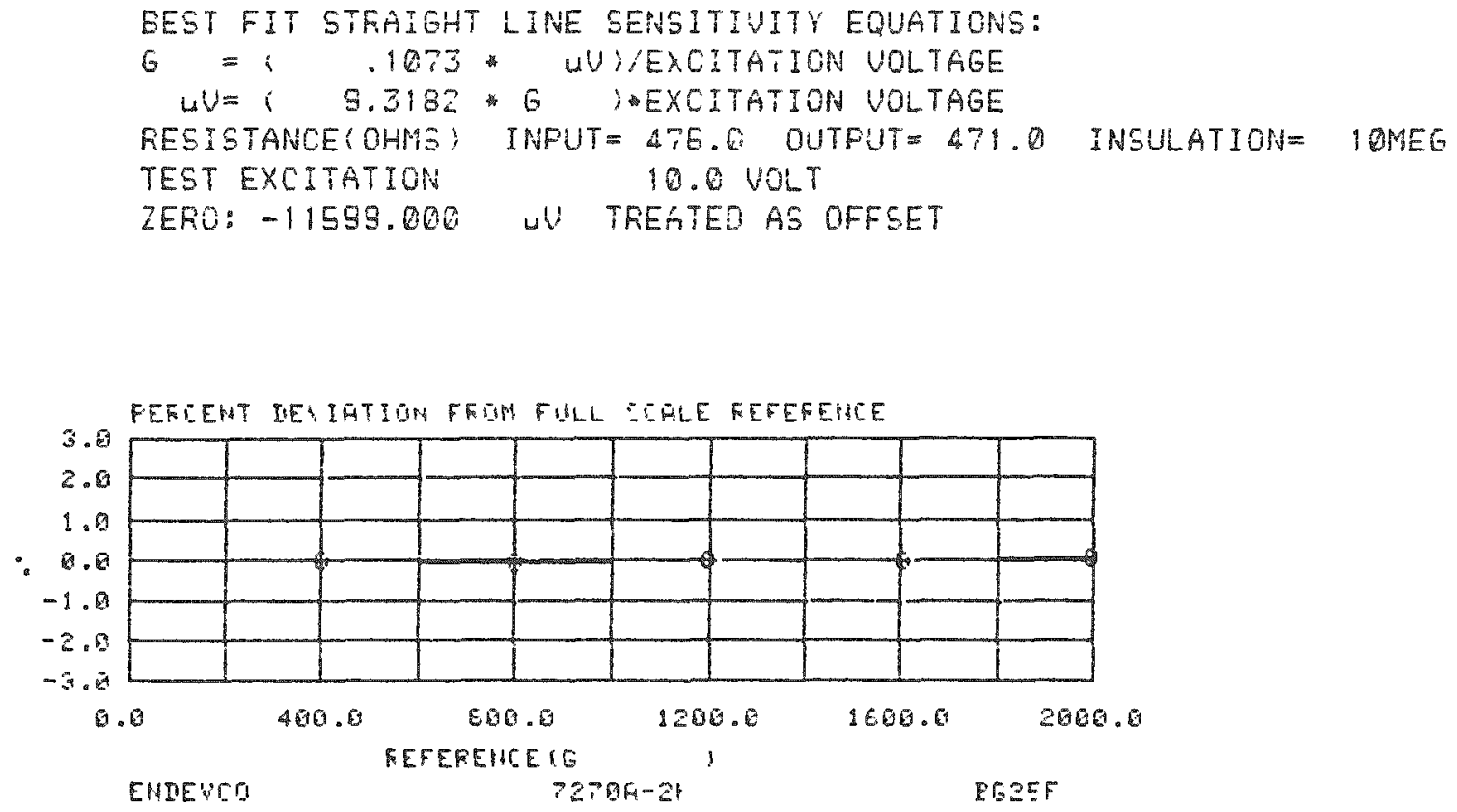

Figure B-6. Centrifuge Calibration of a Soft-Mounted Endevco 7270A Accelerometer 
TRANSDUCER CALIBRATION REPORT

SANDIA LABS $7241 \quad 10 / 12 / 1988$

$\begin{array}{llll}\text { MANUFACTURER } & \text { ENDEUCO } & & \\ \text { MODEL } & 7270 A-2 K & & \\ \text { SERIAL } & \text { CES6F } & & \\ \text { TRANSDUCER TYPE } & 5 E M I C O N D U C T O R & \text { STRAINGAGE } & \\ \text { CERTIFIED BY } & \text { BG } & & \\ \text { EXPIRATION DATE } & 5 / 1 / 1989 & & \\ \text { TEMPERATURE } & \text { AMBIENT } & \text { FACILITY USED } & \text { SHAKER } \\ \text { REQUESTING ORG. } & \text { 6323 } & & \\ \text { COMMENTS: } & \text { D. BRONOWSKI } & & \end{array}$

\begin{tabular}{|c|c|c|c|}
\hline REFERENCE & FFEQUENCY & TRANSDUCER & PERCENT \\
\hline UNITS & MERTZ & OUTPUT & DEVIATION \\
\hline 6 & & $u W / U / 6$ & FROM $100 H Z$ \\
\hline 30.00 & 100.00 & 7.59337 & 0.00 \\
\hline 30.00 & 200.00 & 7.67937 & -.18 \\
\hline 30.00 & 500.00 & 7.68687 & -.08 \\
\hline 30.00 & 1000.00 & 7.65237 & -.01 \\
\hline 30.00 & 1500.00 & 7.69327 & -.00 \\
\hline 30.00 & 2000.00 & 7.69809 & .05 \\
\hline 30.00 & 2500.00 & 7.70354 & .13 \\
\hline 30.00 & 3000.00 & 7.71010 & .22 \\
\hline 30.00 & 3500.00 & 7.71318 & .26 \\
\hline 30.00 & 4000.00 & 7.71816 & .32 \\
\hline 30.00 & 4500.00 & 7.72415 & .40 \\
\hline 30.00 & 5000.00 & 7.73799 & .58 \\
\hline 30.00 & 5500.00 & 7.75179 & .76 \\
\hline 50.00 & 6000.00 & 7.74825 & .71 \\
\hline 30.00 & 6500.00 & 7.75670 & .82 \\
\hline 30.00 & 7000.00 & 7.76092 & .88 \\
\hline 30.00 & 7500.00 & 7.74256 & .64 \\
\hline 30.00 & 8000.00 & 7.77067 & 1.00 \\
\hline 30.00 & 8500.00 & 7.78255 & 1.16 \\
\hline 30.00 & 9000.00 & 7.80625 & 1.47 \\
\hline 30.00 & 9500.00 & 7.78183 & 1.15 \\
\hline 30.00 & 10000.00 & 7.79727 & 1.35 \\
\hline \multicolumn{2}{|c|}{ INPUT RESISTANCE } & 498. OHMS & \\
\hline \multicolumn{2}{|c|}{ OUTPUT RESISTANCE } & 455. OHMS & \\
\hline \multicolumn{2}{|c|}{ INSULATION RESISTANCE } & >IOMEG & \\
\hline \multicolumn{2}{|c|}{ ZEFO OFFSET } & 0.0000 VOLTS & \\
\hline \multicolumn{2}{|c|}{ TEST EXCITATION } & 9.96 VOLTS & \\
\hline
\end{tabular}

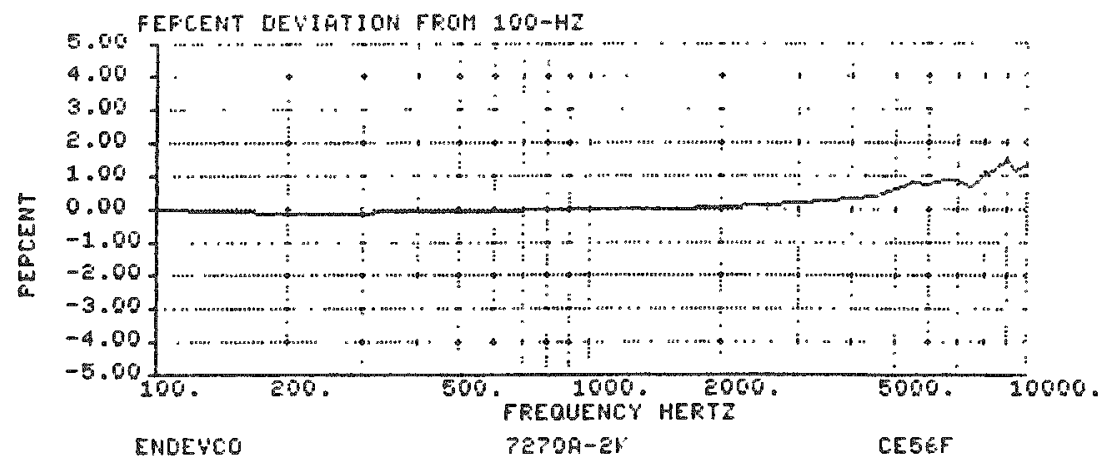

UV.V.G [ 100HZ:7.6934

Figure B-7. Shaker Calibration of an Endevco $7270 \mathrm{~A}$ Accelerometer 
TRANSDUCER CALIBRATION REPORT

SANDIA LABS $7241 \quad 10 / 12 / 1988$

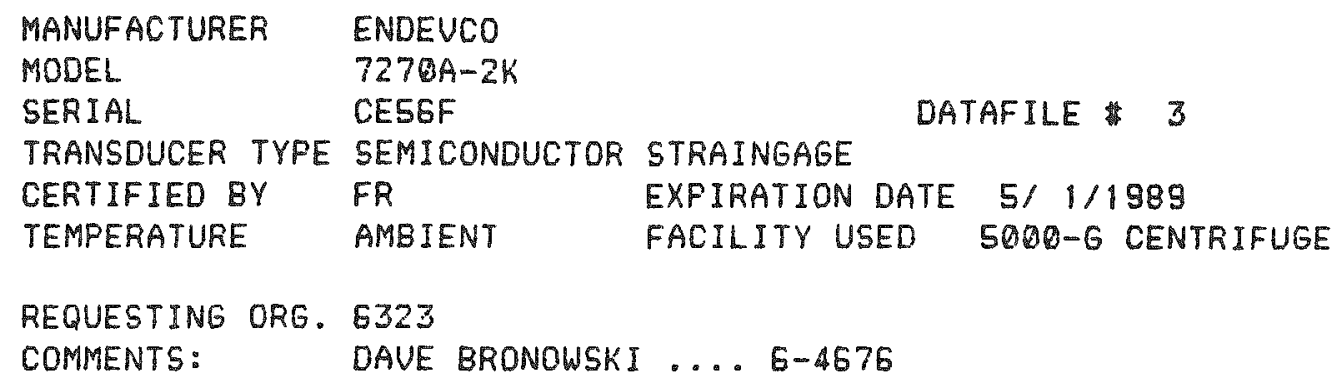

SENSITIUITY $=$

\subsection{WWIV/G \\ 7.8171282 UVIV/G}

BEST FIT STRAIGHT LINE SENSITIUITY EQUATIONS:
$G=(.1279 *$ UV) $/$ EXCITATION VOLTAGE
$U V=(7.8171 * G \quad)$ EXCITATION VOLTAGE

RESISTANCE (OHMS) INPUT $=498.0$ OUTFUT $=495.0$ INSULATION $=310 M E G$ TEST EXCITATION 10.0 VOLT

ZERO: -29358.000 UU TREATED AS OFFSET

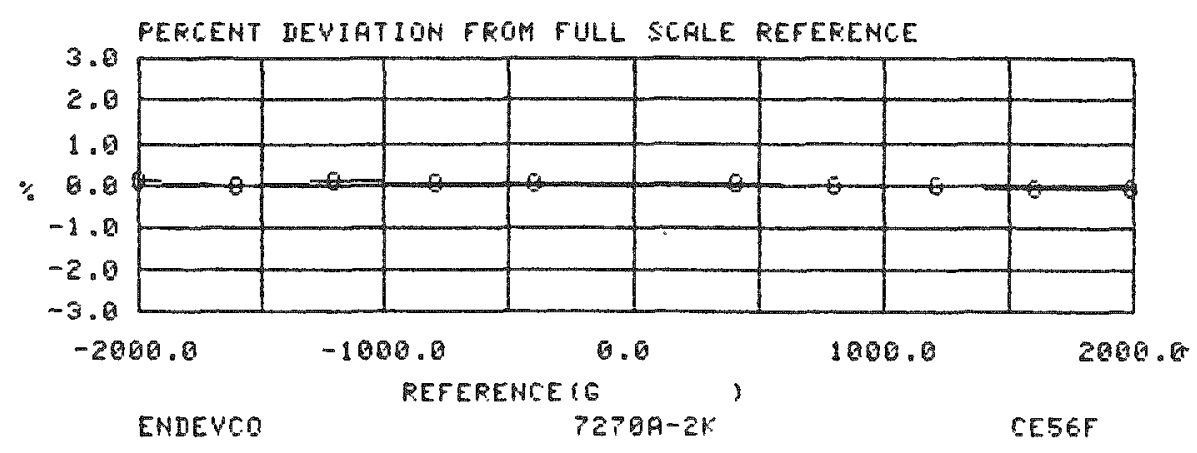

Figure B-8. Centrifuge Calibration of an Endeven $7270 \mathrm{~A}$ Accelerometer 


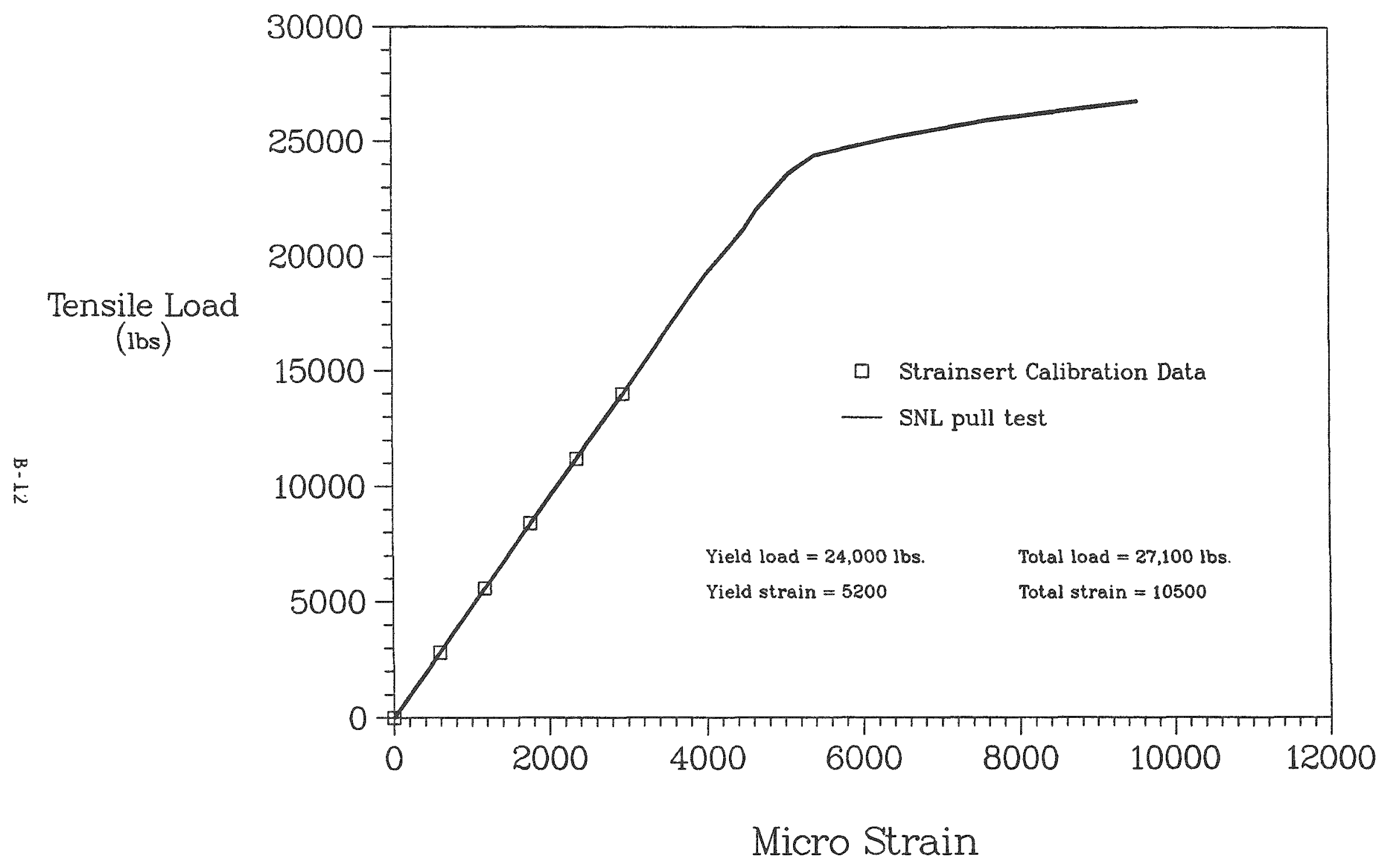

Figure B-9. Force Calibration Test for an SDH-QB-1/2-13NC $\times 21 / 2 \mathrm{Lg}$ Strainsert Bolt 
APPENDIX C

POSTTEST MEASUREMENTS

c. $1 / c-2$ 


\section{- TI HROFILM Hois Phis}


This appendix contains tabulated measurements of dimensional differences observed on the impact limiters after each test. Measurements were made pre- and posttest (Figure $\mathrm{C}-1$ ). The differences observed after the first test, with only one limiter in place, are listed in Table C-1. Differences observed on both limiters after the slapdown drop test are listed in Tables $\mathrm{C}-2$ and $\mathrm{C}-3$. In Table $\mathrm{C}-2$, the impact line of the limiter corresponds to location D1 (zero degrees), and the L1-L3 deformations range from 4.083 to $2.654 \mathrm{in.}$ Because of a change in the test procedure, necessitated by the inability to remove the top impact limiter, the bottom limiter was rotated 180 degrees and the impact line for this limiter was at location D9 (180 degrees). Table C-3 shows the L1-L3 deformations, which ranged from 3.41 to $3.288 \mathrm{in}$.

As described in the text, the cask "punched" into the impact limiter about 3 in. This is reflected in the $B 1$ and $B 2$ as well as the F1 and F2 readings of Table $\mathrm{C}-1$.

In the slapdown drop test, damage to the limiters occurred where the sides of the limiters contacted the target. The resulting deformations are reflected in differences in dimensions L1, L2, and L3. Figure C-2 illustrates the magnitude of the deformations sustained by the limiters at a section through the contact area. 

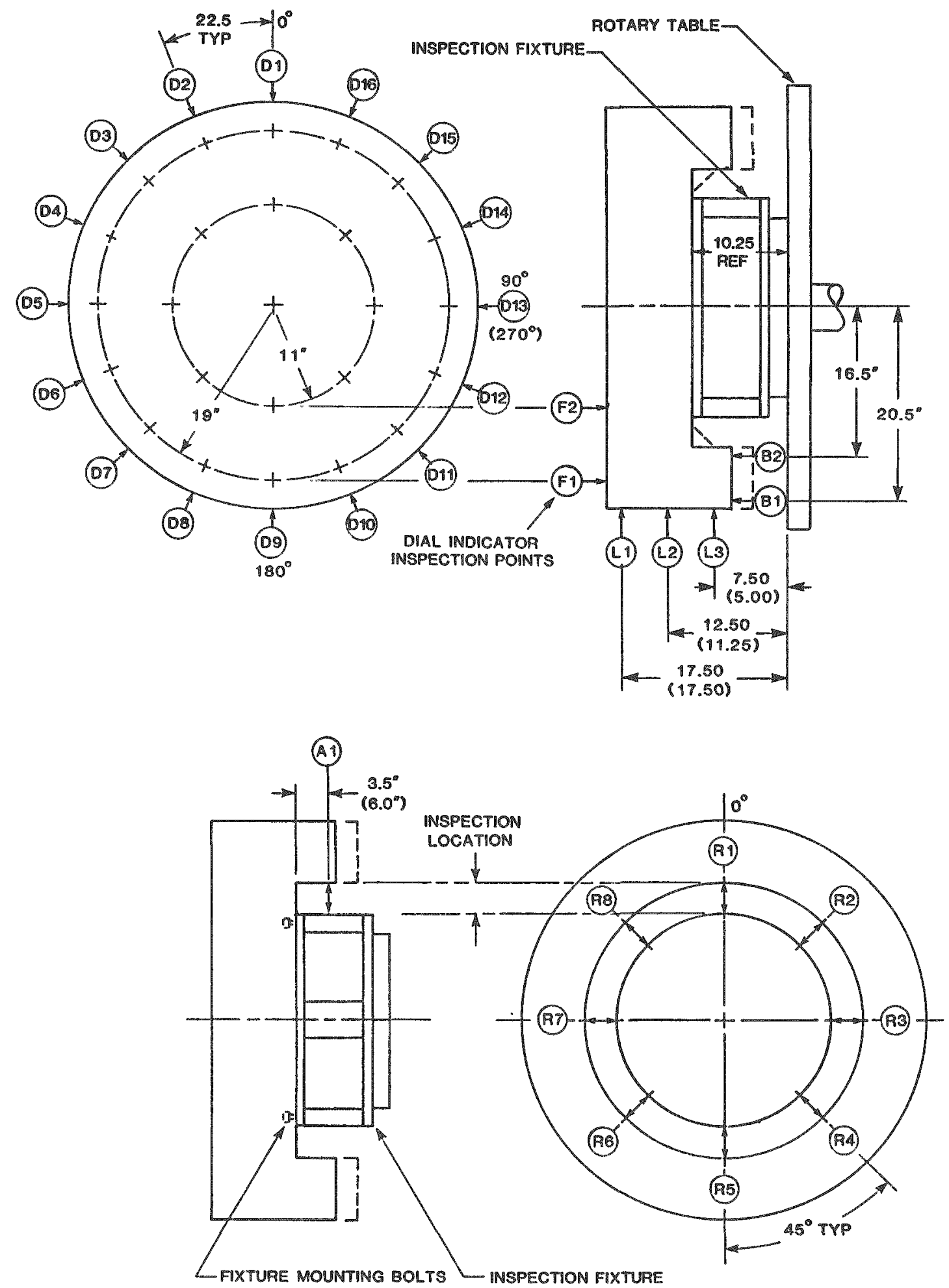

Figure C-1. Schematic of Measurements From the Impact Limiter 
TABLE $C-1$

DIMENSIONAL DIFFERENCES FOR THE TOP END IMPACT LIMITER AFTER THE END-ON DROP TEST

\section{Differences Impact Limiter Inspection Data}

Limiter Designation: Fl Drop Test No.: NFS-1 Accuracy: \pm .030

Internal Cavity Measurements

\begin{tabular}{lllllllll} 
Long. & \multicolumn{9}{c}{ Radial Location } \\
Loc. & R1 & R2 & R3 & R4 & R5 & R6 & R7 & R8 \\
\hline A1 & not applicable & & & & &
\end{tabular}

Exterior Surface Measurements

\begin{tabular}{|c|c|c|c|c|c|c|c|}
\hline \multirow{2}{*}{$\begin{array}{l}\text { Tan. } \\
\text { Loc. }\end{array}$} & \multicolumn{7}{|c|}{ Longitudinal Location } \\
\hline & B1 & B2 & L1 & $\mathrm{L} 2$ & L3 & F1 & $\mathrm{F} 2$ \\
\hline D1 & +3.137 & $\%$ & +0.024 & -0.008 & -0.070 & -3.199 & -3.109 \\
\hline D2 & +3.152 & +2.708 & -0.003 & lug & -0.100 & -3.186 & \\
\hline D3 & +3.153 & +2.785 & -0.033 & -0.076 & -0.151 & -3.221 & -3.133 \\
\hline$D 4$ & +3.153 & +2.748 & -0.066 & -0.091 & -0.135 & -3.153 & $\ldots$ \\
\hline D5 & +3.045 & $x$ & -0.083 & -0.084 & -0.125 & -3.117 & -3.137 \\
\hline $\mathrm{D6}$ & +2.980 & +2.677 & $=0.080$ & -0.076 & -0.106 & -3.027 & $\ldots$ \\
\hline D7 & +2.878 & +2.496 & -0.049 & -0.069 & -0.102 & -2.952 & -3.002 \\
\hline D8 & +2.783 & +2.484 & -0.067 & -0.062 & -0.109 & -2.828 & \\
\hline D9 & +2.629 & $\ldots$ & -0.028 & +0.034 & -0.019 & -2.785 & -2.962 \\
\hline D10 & +2.683 & +2.295 & -0.017 & 0.000 & -0.041 & -2.754 & $\ldots$ \\
\hline D11 & +2.763 & +2.361 & +0.008 & +0.038 & -0.033 & -2.825 & -2.930 \\
\hline D12 & +2.867 & +2.424 & +0.016 & -0.002 & -0.044 & -2.883 & $\ldots$ \\
\hline D13 & +2.946 & $x$ & +0.028 & +0.025 & -0.037 & -2.987 & -3.016 \\
\hline D14. & +3.001 & +2.685 & +0.050 & +0.023 & -0.042 & -3.024 & $\ldots$ \\
\hline D15 & +3.063 & +2.720 & +0.069 & +0.034 & -0.013 & -3.073 & -3.065 \\
\hline D16 & +3.101 & +2.720 & +0.058 & lug & -0.023 & -3.130 & $\ldots$ \\
\hline
\end{tabular}

Measured by: D. R. Bronowski.

*Unable to measure: Accelerometer, Blocks. 
TABLE C-2

DIMENSIONAL DIFFERENCES FOR THE TOP IMPACT LIMITER AFTER THE SLAPDOWN DROP TEST

\section{Differences Impact Limiter Inspection Data}

Limiter Designation: F1 Drop Test No.: NFS-2 Accuracy: .030

Internal Cavity Measurements

Long.

Radial Location

$\begin{array}{llllll}\text { Loc. } & \mathrm{R} 1 & \mathrm{R} 2 & \mathrm{R} 3 & \mathrm{R} 4 & \mathrm{R} 5\end{array}$

A1 limiter on body/unable to measure

R6

R7 R8

Exterior Surface Measurements

\begin{tabular}{|c|c|c|c|c|c|c|c|}
\hline Tan. & & & ongitudi & al Loca & & & \\
\hline Loc. & B1 & B2 & L1 & $\mathrm{L} 2$ & L3 & F1 & F2 \\
\hline D1 & +1.054 & $*$ & -4.083 & -3.333 & -2.654 & -3.96 & +0.023 \\
\hline $\mathrm{D} 2$ & +1.161 & +0.759 & -2.440 & $*$ & -1.077 & -0.803 & $\ldots$ \\
\hline D3 & +0.547 & +0.499 & +0.015 & -0.014 & -0.050 & -0.521 & -0.055 \\
\hline D4 & +0.130 & +0.175 & +0.045 & +0.074 & +0.134 & -0.131 & $\cdots$ \\
\hline D5 & -0.273 & $*$ & -0.020 & +0.119 & +0.241 & +0.254 & +0.179 \\
\hline D6 & -0.614 & -0.487 & +0.005 & +0.157 & +0.311 & +0.569 & \\
\hline D7 & -0.846 & -0.703 & -0.072 & +0.137 & +0.317 & +0.787 & +0.499 \\
\hline D8 & -0.965 & -0.855 & -0.060 & +0.132 & +0.298 & +0.902 & $\ldots$ \\
\hline D9 & -0.999 & $*$ & -0.079 & +0.097 & +0.243 & +0.923 & +0.587 \\
\hline D10 & -0.953 & -0.825 & -0.087 & +0.116 & -0.298 & +0.869 & $\ldots$ \\
\hline D11 & -0.840 & -0.675 & -0.357 & +0.124 & +0.311 & +0.717 & +0.504 \\
\hline $\mathrm{D} 12$ & -0.616 & -0.451 & +0.010 & +0.173 & +0.357 & +0.525 & $\ldots$ \\
\hline 013 & -0.288 & $*$ & +0.0 & +0.159 & +0.317 & +0.272 & +0.175 \\
\hline 014 & +0.104 & +0.182 & +0.0 & +0.084 & +0.144 & -0.095 & $\ldots$ \\
\hline 015 & +0.521 & +0.492 & +0.021 & -0.069 & -0.144 & -0.507 & -0.084 \\
\hline 016 & +1.018 & +0.934 & -2.158 & $*$ & -.0708 & -0.806 & \\
\hline
\end{tabular}

Measured by: D. R. Bronowski.

Wuable to measure: Accelerometer, Blocks. 
TABLE $C-3$

DIMENSIONAL DIFFERENCES FOR THE BOTTOM IMPACT LIMITER AFTER THE SLAPDOWN DROP TEST

\section{Differences Impact Limiter Inspection Data}

Limiter Designation: R2 Drop Test No.: NFS-2 Accuracy: +.030

Internal Cavity Measurements

\begin{tabular}{lccccccccr} 
Long. & \multicolumn{7}{c}{ Radial Location } \\
Loc. & R1 & R2 & \multicolumn{1}{c}{ R3 } & R4 & R5 & R6 & R7 & R8 \\
\hline A1 & -0.019 & +0.009 & +0.138 & +0.461 & +0.405 & +0.127 & +0.035 & +0.008 \\
\hline
\end{tabular}

Exterior Surface Measurements

\begin{tabular}{lcccccccc} 
Tan. & \multicolumn{7}{c}{ Longitudina1 Location } \\
Loc. & B1 & B2 & L1 & L2 & L3 & F1 & F2 \\
\hline$D 1$ & +0.151 & +0.080 & +0.052 & +0.023 & +0.012 & -0.097 & -0.035 \\
\hline$D 2$ & +0.115 & +0.079 & +0.052 & Iug & +0.017 & -0.082 & $\cdots$ \\
\hline$D 3$ & +0.043 & +0.040 & +0.042 & +0.021 & +0.010 & -0.056 & -0.043 \\
\hline$D 4$ & +0.004 & +0.010 & +0.020 & +0.015 & +0.029 & -0.004 & $-\cdots$ \\
\hline$D 5$ & -0.042 & -0.024 & -0.005 & +0.021 & +0.039 & +0.027 & +0.014 \\
\hline$D 6$ & -0.019 & +0.018 & -0.013 & +0.044 & +0.111 & +0.039 & $-\cdots$ \\
\hline$D 7$ & +0.133 & +0.279 & -0.038 & -0.001 & +0.157 & -0.010 & -0.011 \\
\hline$D 8$ & +1.180 & +1.054 & -1.411 & -1.577 & -1.668 & -0.584 & -- \\
\hline$D 9$ & +0.504 & +1.181 & -3.241 & -3.115 & -3.288 & -0.656 & +0.086 \\
\hline$D 10$ & +0.149 & +0.252 & -1.002 & -1.131 & -1.230 & -0.419 & $-\cdots$ \\
\hline$D 11$ & -0.026 & +0.028 & -0.047 & -0.183 & -0.094 & +0.053 & +0.027 \\
\hline$D 12$ & -0.061 & -0.039 & -0.019 & +0.030 & +0.082 & +0.072 & $-\cdots$ \\
\hline$D 13$ & -0.019 & -0.014 & -0.005 & +0.026 & +0.047 & +0.046 & +0.034 \\
\hline$D 14$ & +0.037 & +0.021 & +0.013 & +0.018 & +0.067 & +0.018 & --- \\
\hline$D 15$ & +0.089 & +0.057 & +0.029 & +0.022 & +0.038 & -0.016 & -0.006 \\
\hline$D 16$ & +0.116 & +0.088 & +0.048 & 149 & +0.025 & -0.084 & $-\cdots$ \\
\hline 7
\end{tabular}

Measured by: D. R. Bronowski. 


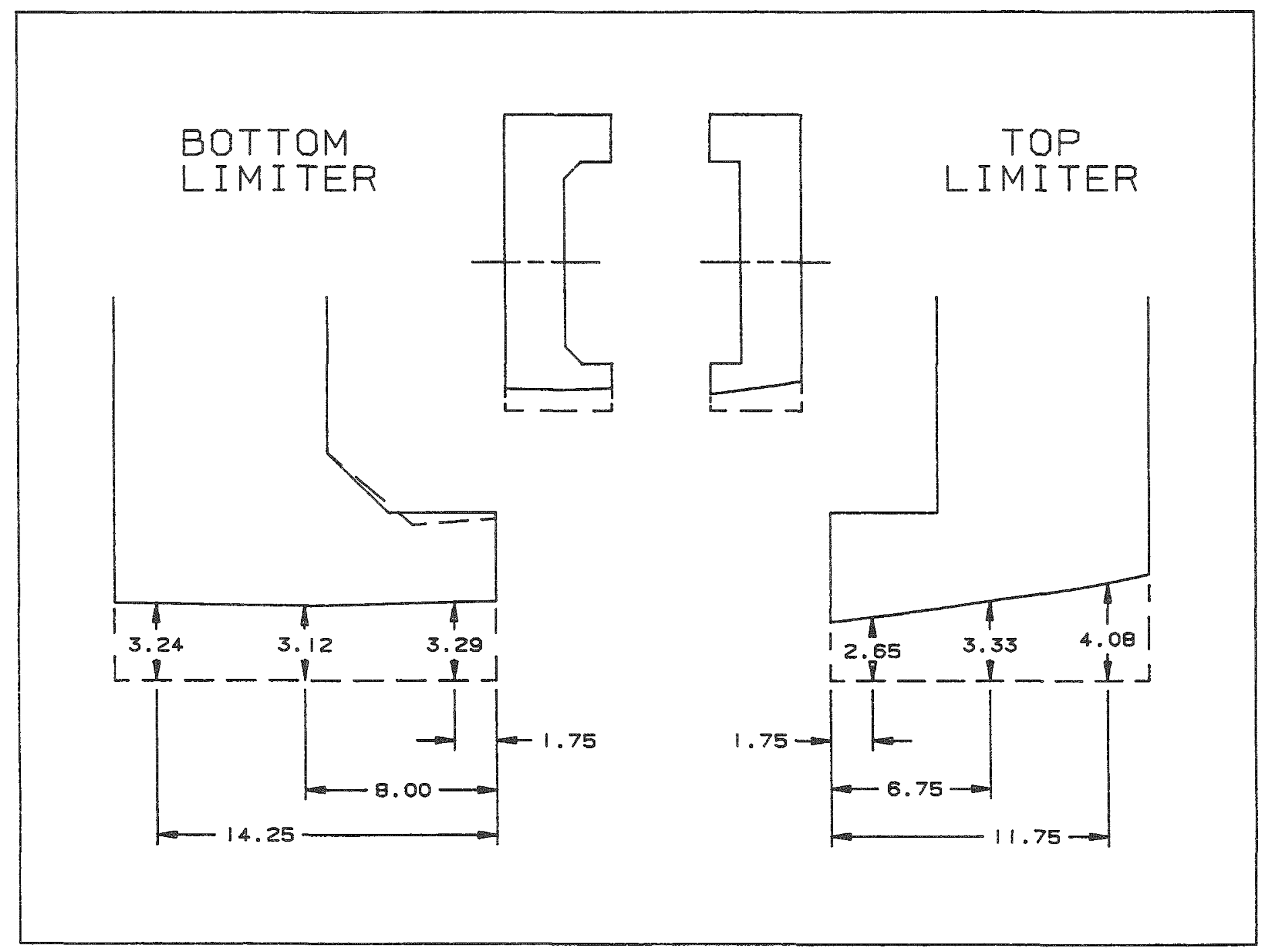

Figure C-2. Lateral Deformations Sustained by Impact Limiters 
APPENDIX D

MICROGRAPHS OF BOLT FAILURE SURFACES

AND A DISCUSSION OF BOLT FAILURE MECHANISM

$$
\text { D-1 - }
$$


DO WOT Micpr.iLM

D- 2 
The fracture surfaces of the failed instrumented bolts were analyzed in detail by visual inspection and by micrographs obtained with a scanning electron microscope. Figures D-1 and D-2 illustrate micrographs of the upper and lower bolts, respectively. The upper bolts exhibit flat, smeared surfaces perpendicular to the bolt axis. These surface conditions indicate that the upper bolts failed in shear. The failure surfaces on the lower bolts exhibit ductile fracture dimples. There is no evidence of flaws that could have initiated the fractures. The lower bolts appear to have failed as a result of both axial tension and bending.

The mechanism by which the bolts failed can be deduced from the bolt strain data and the observed motion of the cask during the impact based on the photometric data. The microstrain traces from the two upper bolts indicate relatively low peak strain levels (about 1700) which were well below the yield point of the bolt material. Therefore these bolts were not highly stressed in tension. The peak strain levels for the lower bolts were quite high (about 6000), indicating that these bolts failed in a combination of tension and bending.

To determine cause of failure for the bolts, the nature of the forces acting on the impact limiter at the time of bolt failure must be determined. Two principal forces acted on the impact limiter to produce tension in the lower bolts during the secondary impact: the force generated by the tendency of the tapered end of the cask to push the limiter away as the cask is forced against the limiter and a frictional force at the target/limiter interface. The direction and magnitude of the frictional force can easily be estimated by examining the kinematics of the cask during the secondary impact and the magnitude of the normal impact force acting on the limiter at the time of bolt failure. The magnitude of the vertical velocity (lateral velocity was negligible) and rotation of the center of gravity of the cask at the time of bolt failure are indicated in Figure D-3. The normal force acting on the impact limiter at this time was about $450,000 \mathrm{lb}$, as indicated by the SWAT data (Appendix F, Figure F-9). The direction and magnitude of the velocity of 


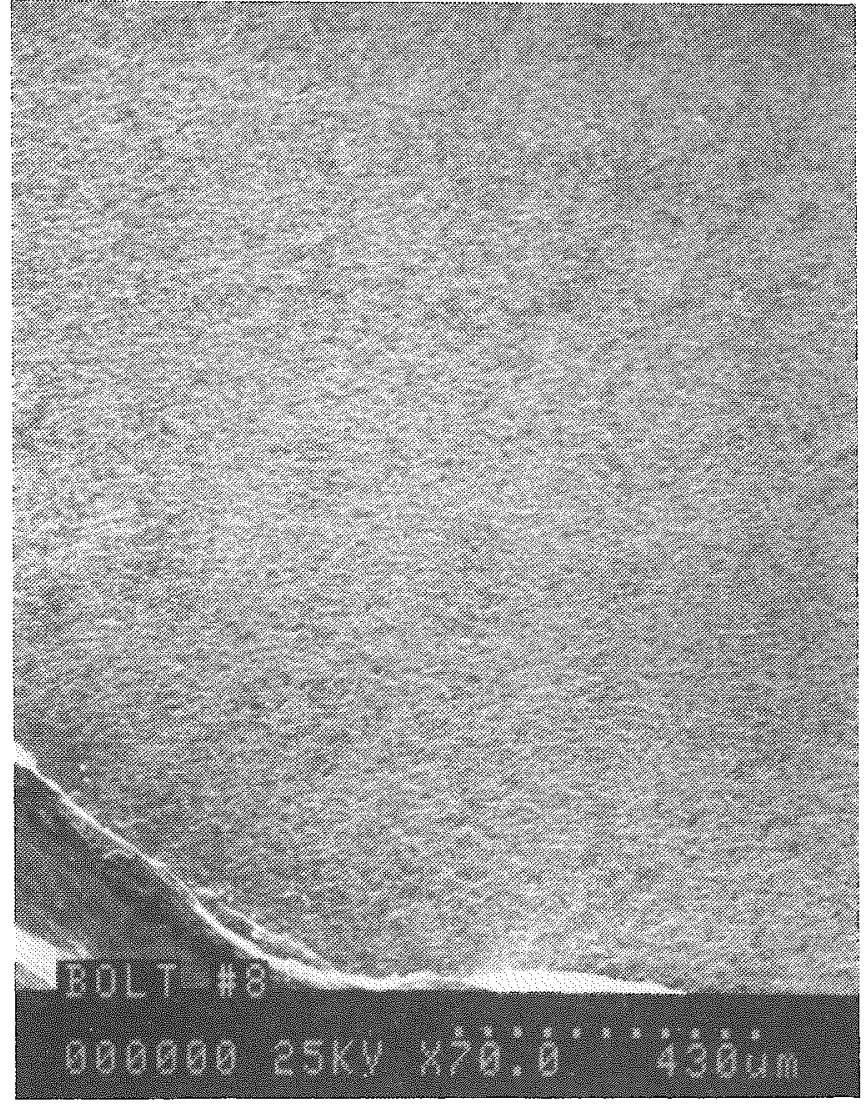

Flat sheared surface, low mag.

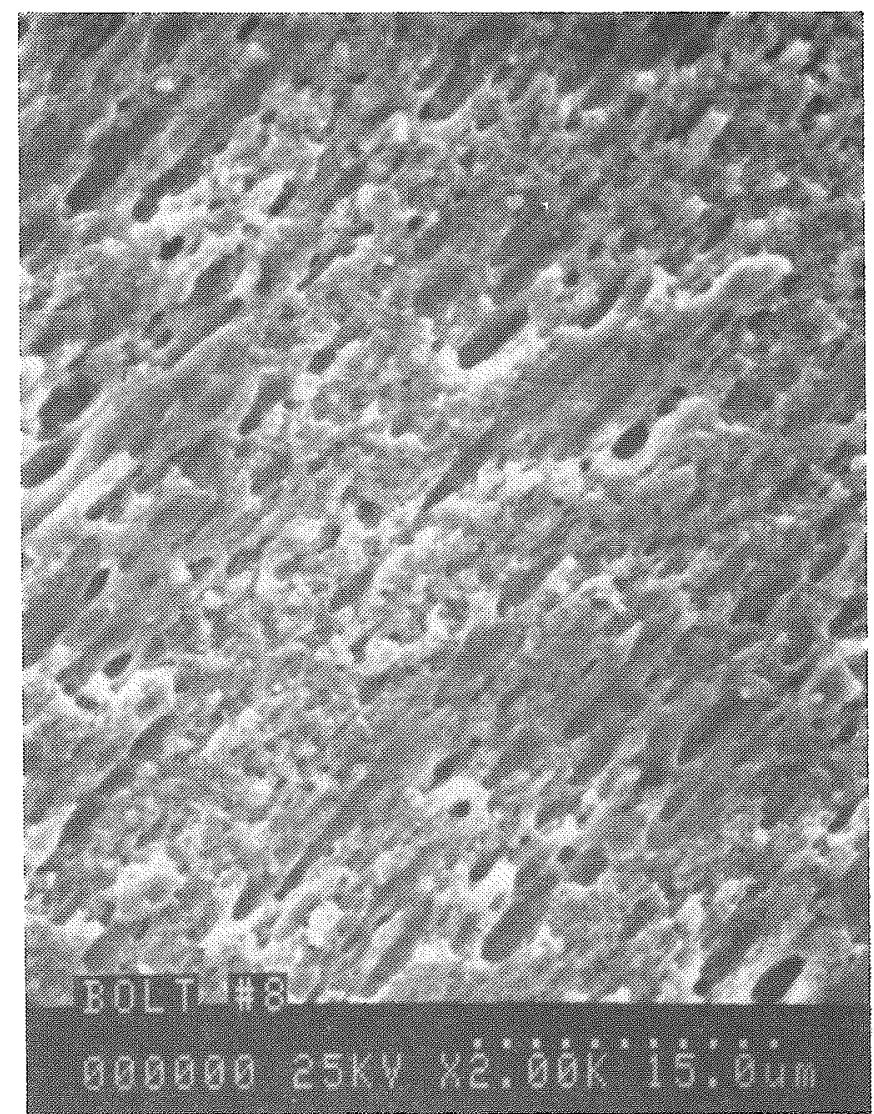

Shear ductile fracture dimples 


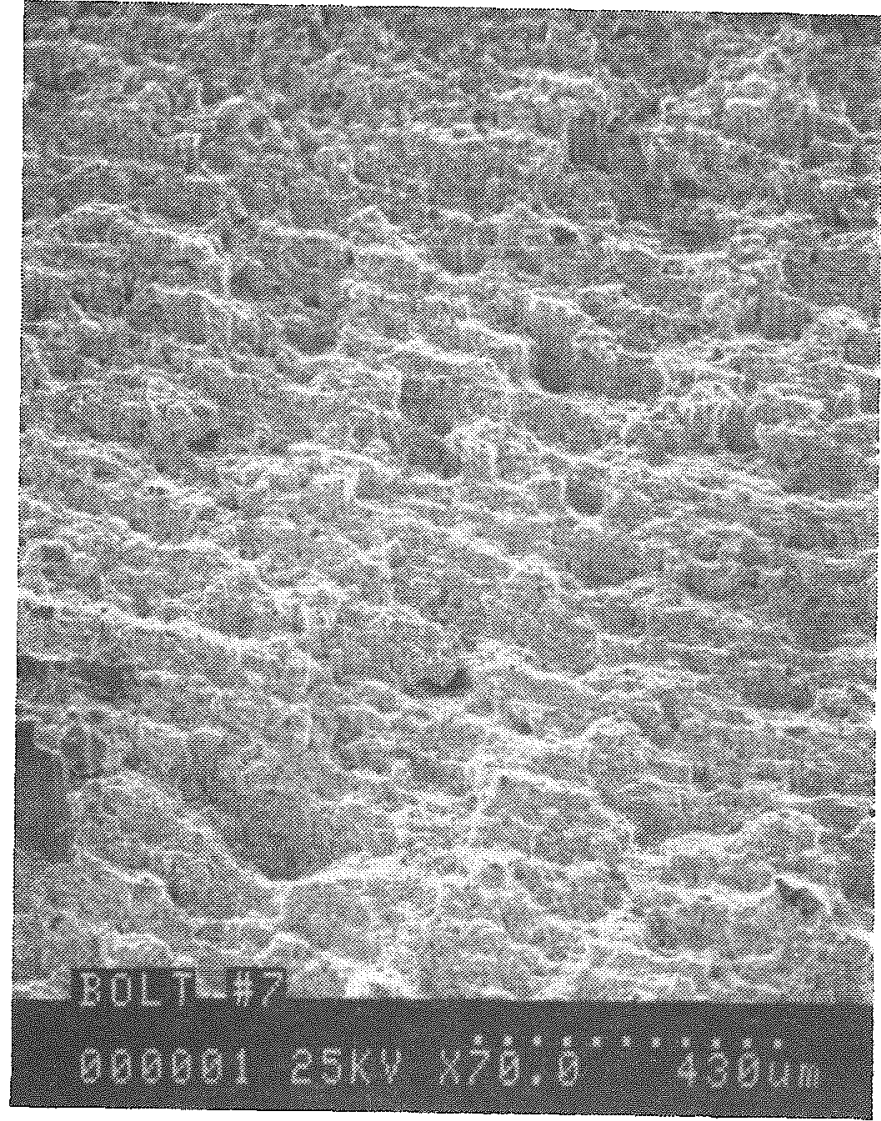

Ductile fracture ridges, low mag.

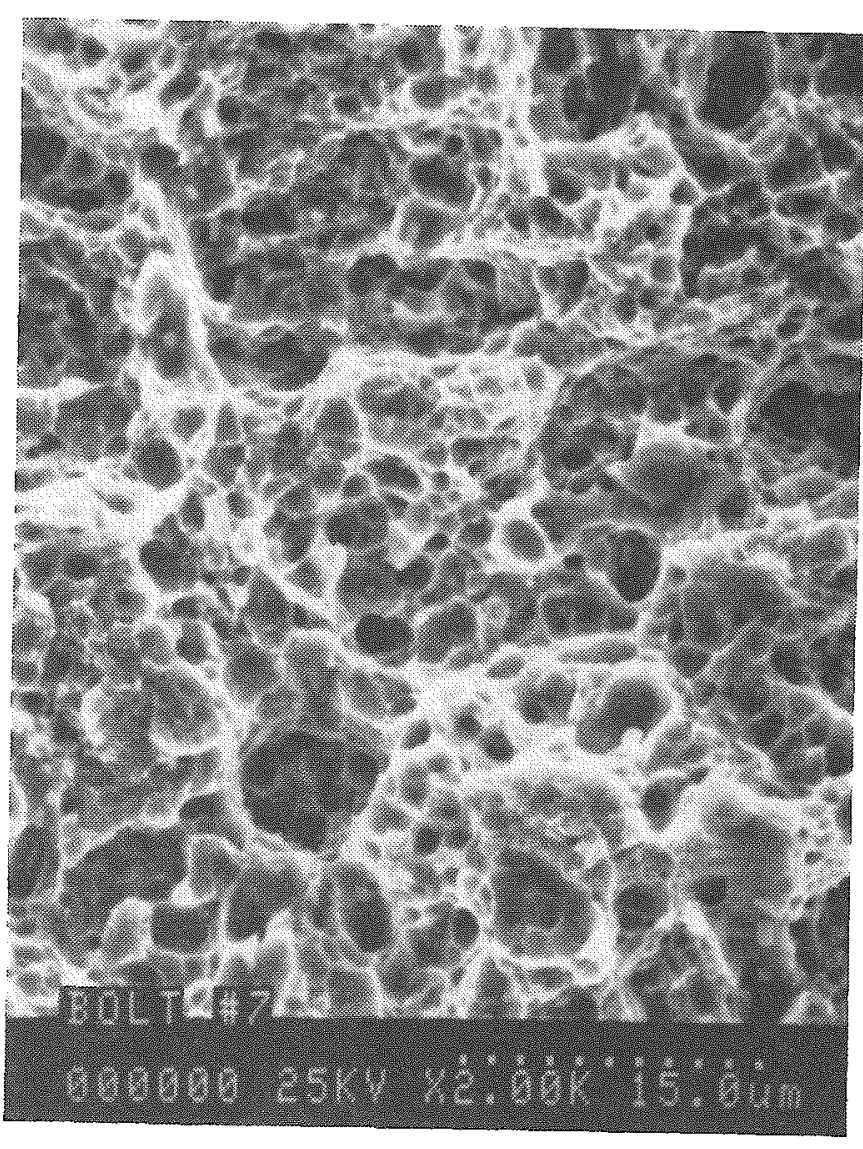

Tensile ductile fracture dimples

Figure D-2. Micrographs of Fracture Surface of Lower Bolt 


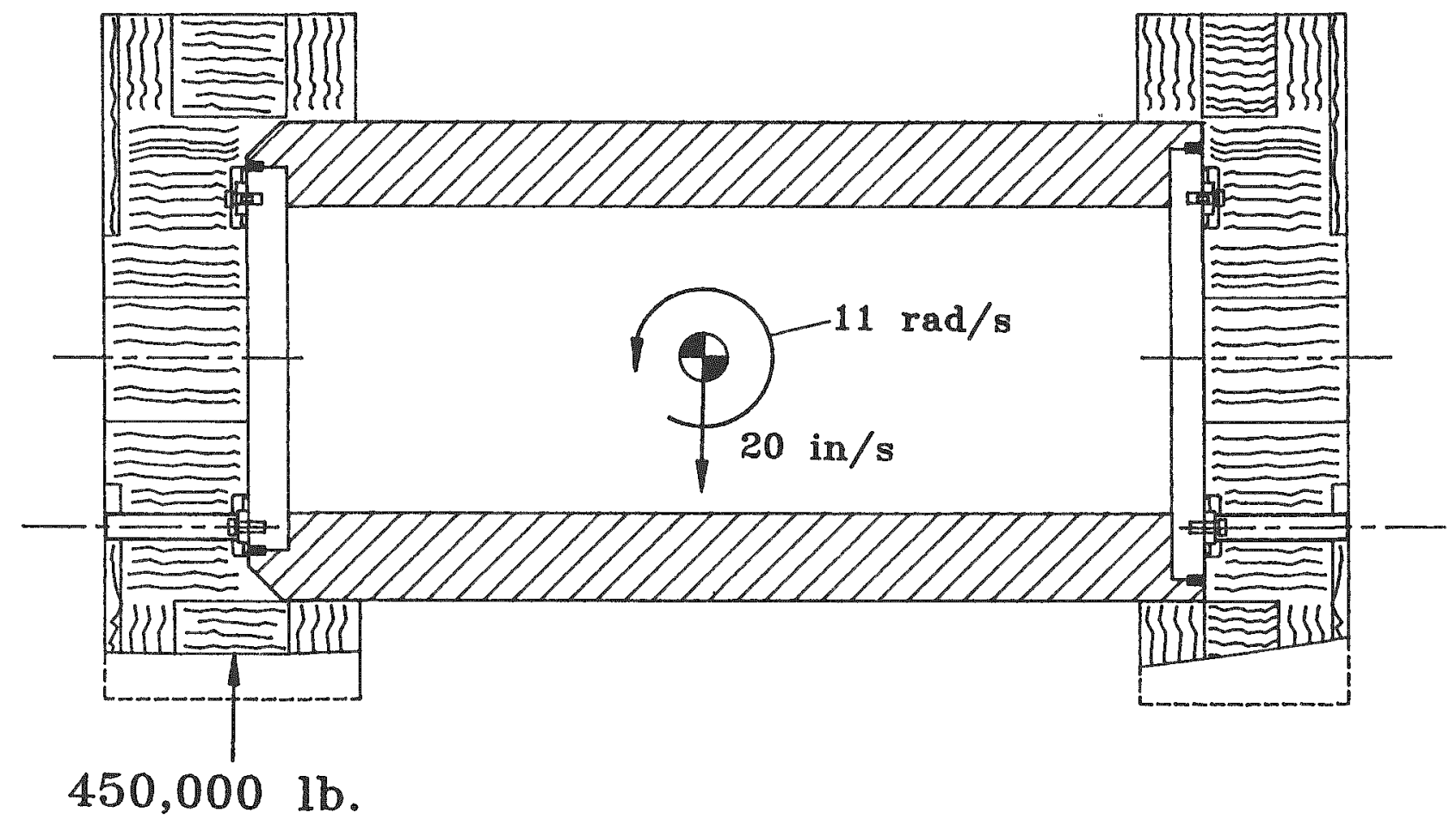

Figure D-3. Velocity Conditions of the Cask at Time of Bolt Failure

points on the impact limiter adjacent to the target can easily be calculated using a basic kinematic equation for plane motion:

$$
\mathrm{V}=\mathrm{V}_{\mathrm{CG}}+\omega \times \mathrm{r}
$$

The horizontal component will come from the rotational term. The position vector from the center of gravity to the limiter/target interface is approximately $3 \mathrm{ft}$. Considering the rotational velocity of $11 \mathrm{rad} / \mathrm{sec}$, the rotational term will be about $33 \mathrm{ft} / \mathrm{sec}$. This velocity component will be down and to the right making an angle of approximately 30 degrees with the vertical. The horizontal component will then be to the right with a magnitude of approximately $15 \mathrm{ft} / \mathrm{sec}$ and the frictional force on the limiter will be to the left.

The forces acting on the impact limiter are illustrated in Figure D-4. As the cask moves downward it presses on the inside surface of the impact limiter. Because of the tapered edge there is a component that would tend to load the bolt in tension. There are also frictional 


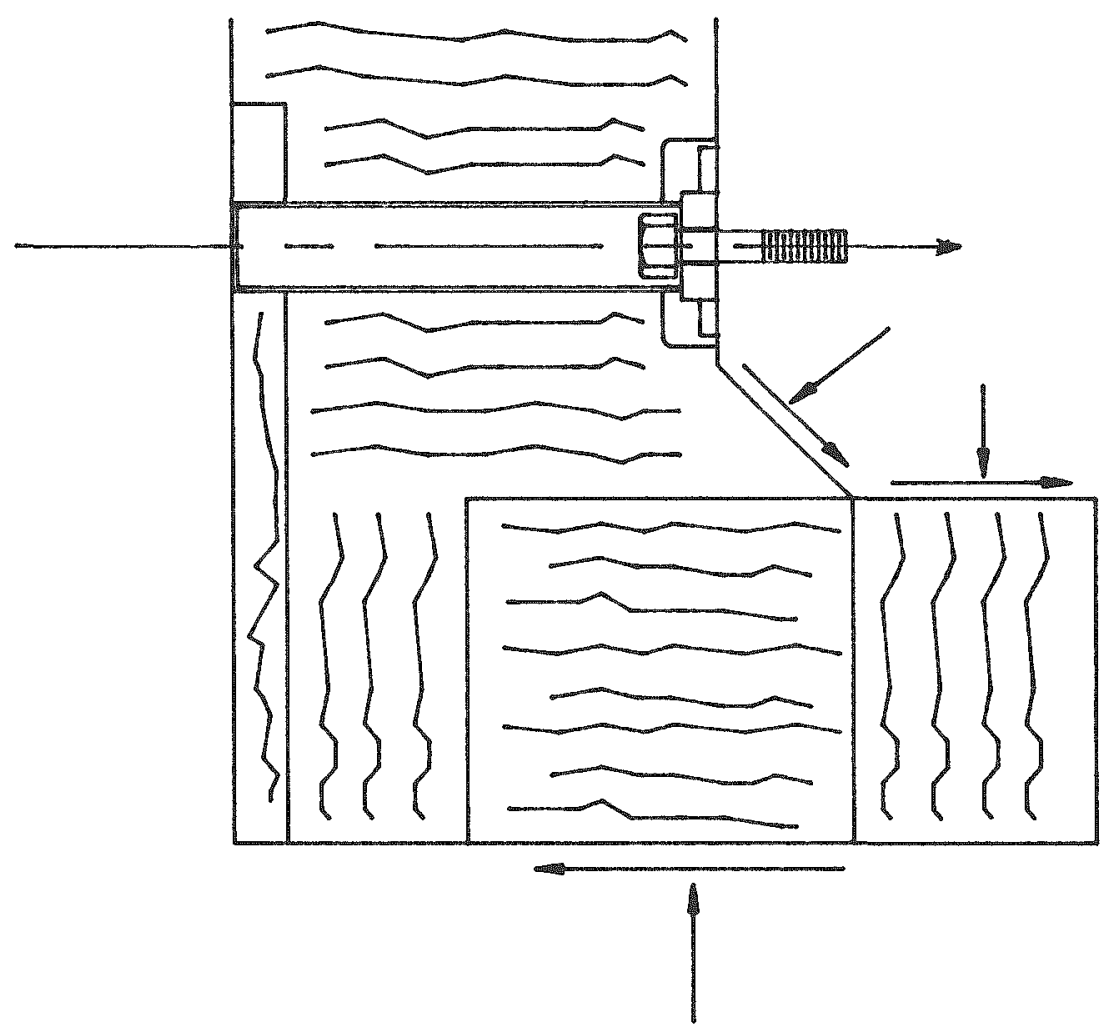

Figure D-4. Forces Acting on Limiter at Time of Bolt Failure

forces at the cask/1imiter interface, however, and these tend to negate the outward force on the tapered surface. Estimating the magnitude of these would be very difficult and would require a known force distribution on the inner surface of the limiter and a value for the coefficient of friction. The frictional force at the limiter/target interface tends to load the bolt in tension. The magnitude of this force can be easily calculated using the value of the coefficient of friction for steel on cast iron (0.2). Based on this, the frictional force would have a value of $90,000 \mathrm{lb}$. The load at the bolt would be somewhat amplified since the limiter is trying to pivot about a point near the upper bolt. The frictional force then has a larger moment arm than the bolt force. However, even neglecting the moment arm effect, the 90,000-1b frictional force is larger than the ultimate strength of the bolts. The ultimate bolt force is estimated to be about 27,000 1b per bolt for a total of $54,000 \mathrm{lb}$. It is believed that the forces at the cask/limiter interface generated by the tapered end of the cask are much less significant and did not greatly contribute to the bolt failure. 
The shearing action that resulted from the secondary impact was more severe at the upper bolt location. This is probably because the impact limiter moved outward slightly at the bottom bolts, whereas it was forced against the cask at the upper bolt location. This allowed some amount of elongation and bending of the lower bolts resulting in a different failure mode. The upper bolts were not loaded in tension because the impact limiter was forced up and against the cask causing a concentrated shearing action. The required shearing force per bolt is estimated to be about one-half of the tension force needed for failure (about 13,500 1b). While much of the lateral force was absorbed by crushing of the limiter, a sufficient amount was transmitted through the limiter body to shear the upper bolts.

The original bolts were undersized and were not able to handle the forces generated by the secondary impact. It is believed that this situation can be corrected by simply increasing the bolt diameter. 
APPENDIX E

DERIVATION OF FORCE-DISPLACEMENT CURVES FOR

IMPACT LIMITERS FROM ACCELEROMETER AND FILM DATA 


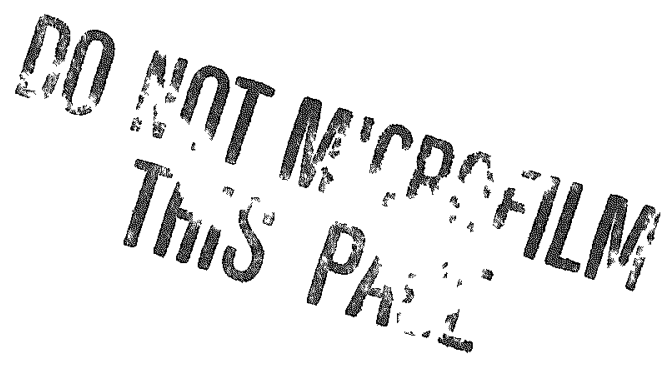

$E-2$ 
After the first test, the force-displacement characteristics for the impact limiter in an end drop situation were estimated by fitting an idealized pulse to accelerometer data filtered to $2000 \mathrm{~Hz}$. This frequency rate was selected to capture the rise time of the deceleration pulse to the greatest extent possible. Figure E-1 illustrates the raw data and the idealized curve fitted to it. The force on the impact limiter was calculated by multiplying the deceleration value by the weight of the system ( $8210 \mathrm{lb}$ including the weight of the cask body and one impact limiter). These data were used in conjunction with film data which provided vertical displacement as a function of time. Results are presented in Table $\mathrm{E}-1$.

\section{TABLE E-1}

FORCE-DISPLACEMENT RESULTS FOR THE END-ON DROP TEST

\section{Time (s) Deceleration (g) Force (Ib) Displacement (ft)}

$\begin{array}{llcc}0.0 & 0 & 0 & 0 \\ 0.00085 & 210 & 1,724,100 & 0.038 \\ 0.00200 & 162 & 1,330,020 & 0.075 \\ 0.00300 & 122 & 1,001,620 & 0.110 \\ 0.00350 & 100 & 821,000 & 0.120 \\ 0.00500 & 100 & 821,000 & 0.160 \\ 0.00700 & 100 & 821,000 & 0.200 \\ 0.00900 & 100 & 821,000 & 0.230 \\ 0.01100 & 100 & 821,000 & 0.243 \\ 0.01280 & 100 & 821,000 & 0.250 \\ 0.01580 & 0 & 0 & 0.245\end{array}$




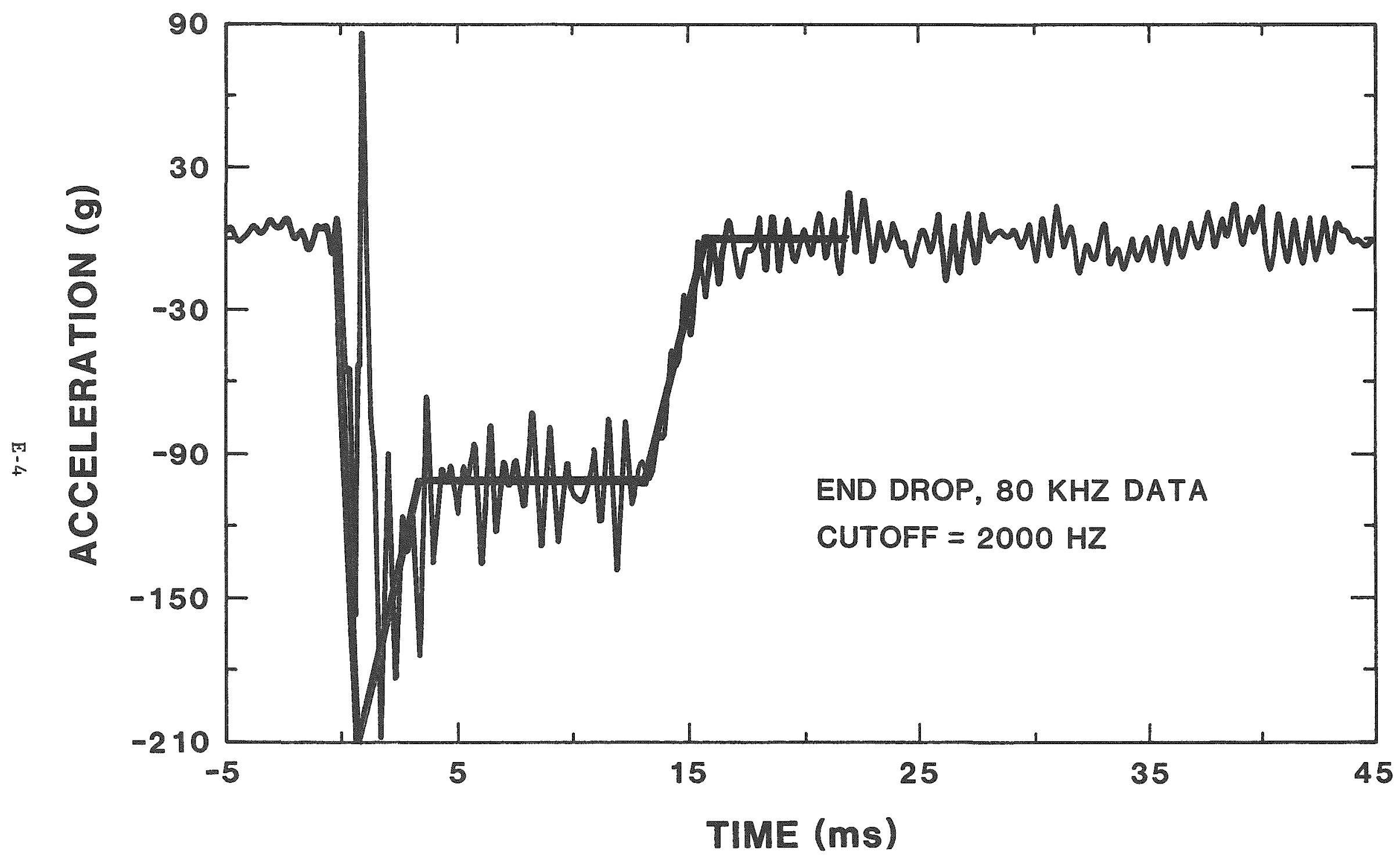

Figure E-1. Accelerometer Trace Used to Estimate Force for End-On Drop Test 
After the second test, sum of weighted accelerations technique (SWAT) data from the accelerometers became available to generate the force-displacement curves for the impact limiters in the slapdown configuration. Figure E-2 illustrates the SWAT results for the forces acting on the cask. Displacement data were again obtained from highspeed film data. Displacement data with the time-varying cask attitude were used to calculate crush distance (including crush at the inside and outside surfaces of the limiter). Kinematic relationships were used to calculate the motion of a point adjacent to the crush area in terms of the displacement and rotation of the center of gravity (CG) of the cask.

The calculation method will be reviewed by referring to Figure E-3, which illustrates the geometry of the cask in the primary and secondary impacts. For the primary impact, Point $\mathbb{A}$ was assumed to be at the centroid of the crush area of the impact limiter. At the time of contact, the impact angle was equal to 12.4 degrees, and Point $A$ was $1.747 \mathrm{ft}$ below the $\mathrm{CG}$ of the cask. The relationship (Figure E-3(a)) of the motion of Point $A$, in feet, relative to the displacement of the $C G$ and the angular position of the cask can be shown to be

$$
\Delta \mathrm{Y}_{\mathrm{A}}=-\Delta \mathrm{Y}_{\mathrm{CG}}-\mathrm{r} \sin (26.75+\beta)+1.747 .
$$

This equation utilizes absolute values, from Table $\mathrm{E}-2$, for the displacement of the $C G$ and cask rotation, $\beta$. Table E-2 presents the displacement data, for the $C G$, used in the analysis. Figure $E-3(b)$ illustrates the geometry for the secondary impact. The vertical displacement of Point $B$ can be calculated as the vertical displacement of the CG plus the displacement relative to the $C G$ as follows:

$$
\Delta \mathrm{Y}_{\mathrm{B}}=\Delta \mathrm{Y}_{\mathrm{CG}}+\mathrm{r} \sin \Delta \beta \cos \Delta \beta
$$

The data listed in Table $E-2$, with the SWAT force-time data included in Figure E-2, were used to generate impact limiter force-displacement curves. Table E-3 lists the force-displacement result for the primary and secondary impacts. 


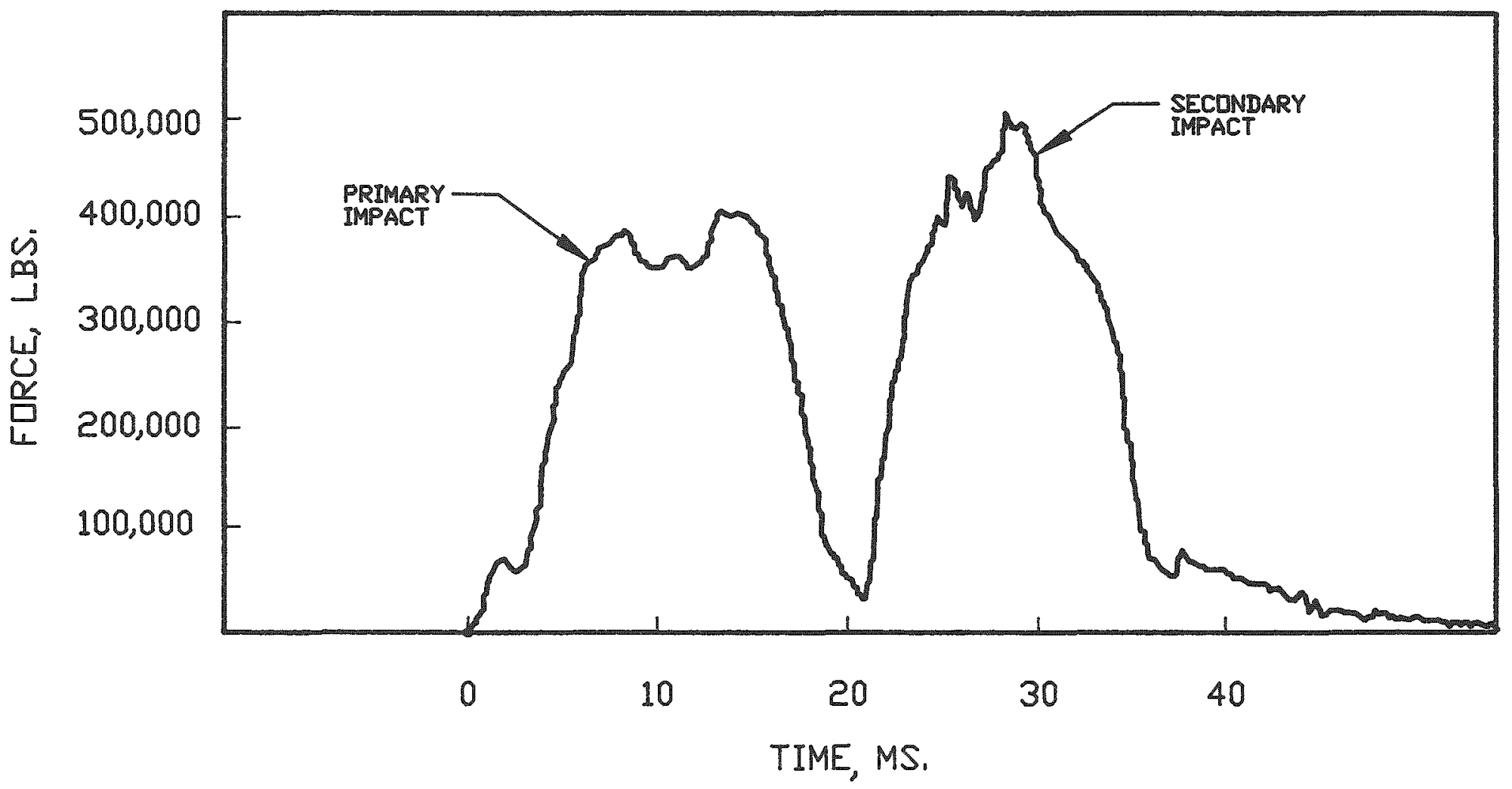

Figure E-2. SWAT Data Used to Estimate Forces on the Cask During Slapdown Drop Test 

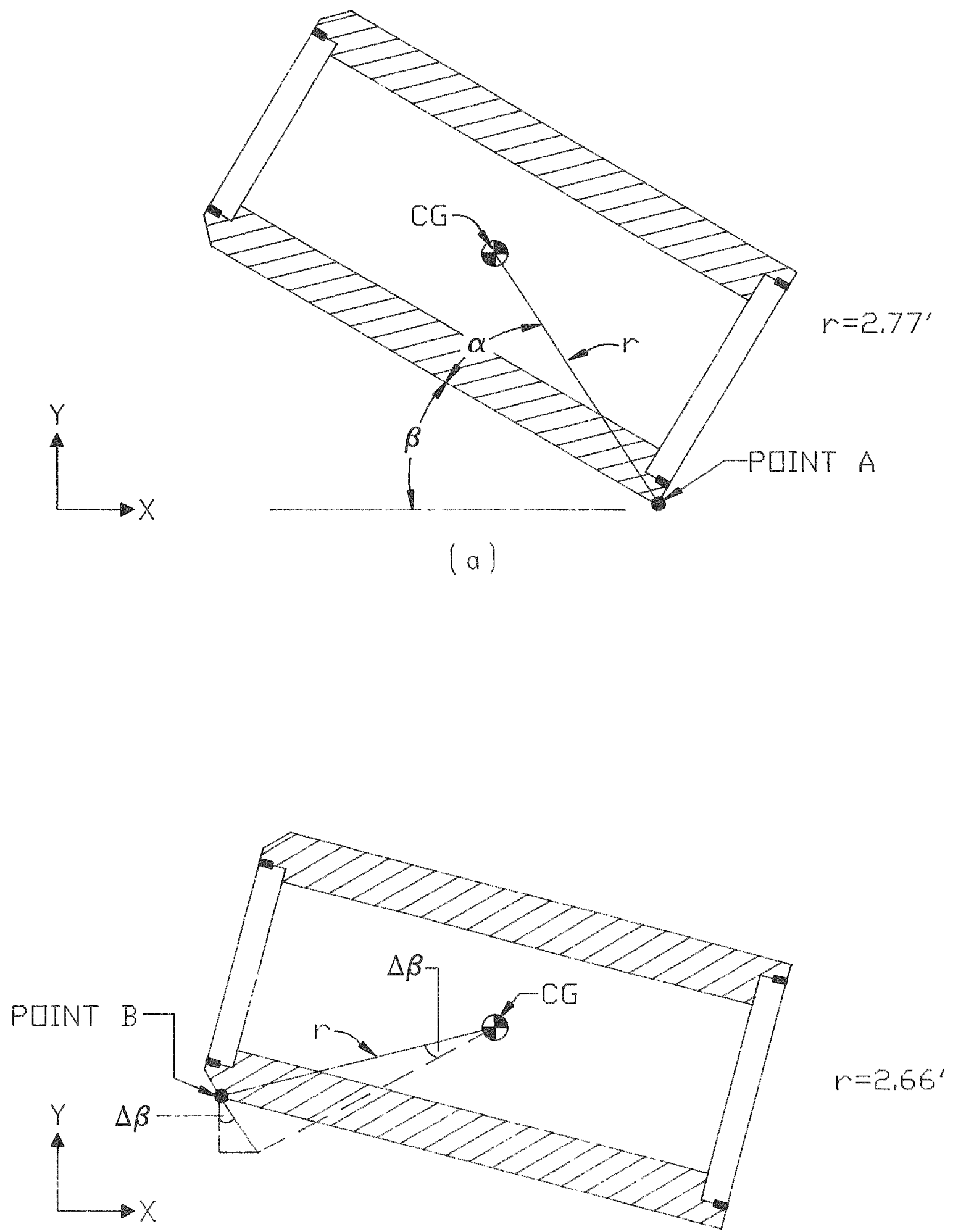

(b)

Figure E-3. Geometric Relationships Used to Calculate Displacement at End of Cask Relative to the Center of Gravity 
DISPLACEMENT AND ROTATION OF THE CENTER OF GRAVITY OF THE CASK DURING THE SLAPDOWN DROP TEST

\begin{tabular}{|c|c|c|}
\hline Time (ms) & $\begin{array}{l}\text { Displacement of } \\
\text { Center of Gravity (in.) }\end{array}$ & $\begin{array}{c}\text { Cask Rotation, } \\
\text { (degrees) }\end{array}$ \\
\hline 0 & 0.0 & -12.40 \\
\hline 1 & -0.50 & -12.40 \\
\hline 2 & -0.95 & -12.40 \\
\hline 3 & -1.40 & -12.40 \\
\hline 4 & -2.00 & -12.40 \\
\hline 5 & -2.58 & -12.40 \\
\hline 6 & -3.00 & -12.25 \\
\hline 7 & -3.58 & -12.05 \\
\hline 8 & -4.00 & -11.90 \\
\hline 9 & -4.38 & -11.70 \\
\hline 10 & -4.77 & -11.50 \\
\hline 11 & -5.25 & -11.25 \\
\hline 12 & -5.78 & -10.90 \\
\hline 13 & -6.25 & -10.40 \\
\hline 14 & -6.55 & -9.90 \\
\hline 15 & -6.95 & -9.40 \\
\hline 16 & -7.30 & -8.80 \\
\hline 17 & -7.65 & -8.20 \\
\hline 18 & -8.00 & -7.50 \\
\hline 19 & -8.25 & -6.70 \\
\hline 20 & -8.50 & -5.90 \\
\hline 21 & -8.78 & -5.00 \\
\hline 22 & -9.07 & -4.40 \\
\hline 23 & -9.32 & -3.60 \\
\hline 24 & -9.56 & -2.90 \\
\hline 25 & -9.79 & -2.10 \\
\hline 26 & -10.00 & -1.50 \\
\hline 27 & -10.20 & -1.10 \\
\hline 28 & -10.36 & -0.70 \\
\hline 29 & -10.50 & -0.20 \\
\hline 30 & -10.65 & 0.20 \\
\hline 31 & -10.75 & 0.60 \\
\hline 32 & -10.82 & 0.70 \\
\hline 33 & -10.90 & 0.80 \\
\hline 34 & -10.95 & 0.80 \\
\hline 35 & -11.00 & 0.90 \\
\hline 36 & -11.02 & 0.80 \\
\hline 37 & -11.02 & 0.80 \\
\hline
\end{tabular}


$\underline{\text { TABLE } \mathrm{E}-3}$

CALCULATED IMPACT LIMITER FORCES AND DISPLACEMENTS FOR THE SLAPDOWN DROP TEST

\begin{tabular}{|c|c|c|c|c|c|}
\hline \multicolumn{3}{|c|}{ Primary Impact } & \multicolumn{3}{|c|}{ Secondary Impact } \\
\hline $\begin{array}{l}\text { Time } \\
\text { (ms) }\end{array}$ & $\begin{array}{l}\text { Force } \\
(1 \mathrm{~b}) \\
\end{array}$ & $\begin{array}{c}\text { Displacement } \\
\text { (ft) }\end{array}$ & $\begin{array}{l}\text { Time } \\
\text { (ms) } \\
\end{array}$ & $\begin{array}{l}\text { Force } \\
\text { (1b) }\end{array}$ & $\begin{array}{c}\text { Displacement } \\
\text { (ft) }\end{array}$ \\
\hline 0 & 0 & 0.0 & 20 & 0 & 0.0 \\
\hline 1 & 60,000 & 0.041 & 21 & 35,000 & 0.065 \\
\hline 2 & 60,000 & 0.079 & 22 & 195,000 & 0.117 \\
\hline 3 & 100,000 & 0.116 & 23 & 315,000 & 0.175 \\
\hline 4 & 195,000 & 0.161 & 24 & 360,000 & 0.227 \\
\hline 5 & 265,000 & 0.215 & 25 & 395,000 & 0.283 \\
\hline 6 & 355,000 & 0.245 & 26 & 420,000 & 0.315 \\
\hline 7 & 370,000 & 0.285 & 27 & 425,000 & 0.363 \\
\hline 8 & 385,000 & 0.314 & 28 & 460,000 & 0.395 \\
\hline 9 & 355,000 & 0.338 & 29 & 490,000 & 0.430 \\
\hline 10 & 350,000 & 0.364 & 30 & 440,000 & 0.460 \\
\hline 11 & 360,000 & 0.404 & 31 & 400,000 & 0.487 \\
\hline 12 & 350,000 & 0.423 & 32 & 365,000 & 0.497 \\
\hline 13 & 390,000 & 0.446 & 33 & 340,000 & 0.508 \\
\hline 14 & 400,000 & 0.448 & 34 & 300,000 & 0.512 \\
\hline 15 & 395,000 & 0.463 & 35 & 200,000 & 0.520 \\
\hline 16 & 350,000 & 0.470 & 36 & 100,000 & 0.518 \\
\hline 17 & 265,000 & 0.474 & & & \\
\hline 18 & 160,000 & 0.478 & & & \\
\hline 19 & 85,000 & 0.466 & & & \\
\hline 20 & 50,000 & 0.454 & & & \\
\hline
\end{tabular}




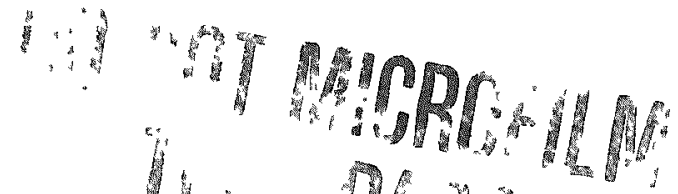

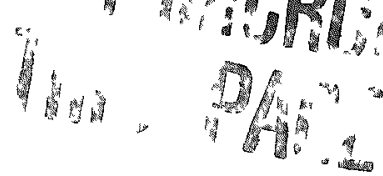$$
\text { E-10 }
$$ 


\section{APPENDIX F}

DETAILS OF THE SUM OF WEIGHTED ACCELERATIONS

AND DECONVOLUTION TECHNIQUES

$$
{ }^{P-1} / F \cdot 2
$$


DO MOT MHEP
This PHE

F-2 
This appendix includes detailed descriptions and results of two techniques used to reduce the accelerometer data and analyze the results of the slapdown test in terms of forces and the moment input to the cask. The techniques include the sum of weighted accelerations technique (SWAT) and the deconvolution technique (DECON). The information presented in this appendix has been extracted from Bateman et al. (1989). In addition to the information presented here, Bateman et al. include a detailed structural characterization of the cask in terms of its vibrational characteristics and a description of laboratory calibration tests.

SWAT determines the external force and moment applied to a structure with free boundary conditions from a sum of weighted acceleration measurements (Gregory et a1., 1986; Priddy et a1., 1988; Priddy et a1., 1989). Two sets of weighting factors are determined from modal analysis results: one set of weighting factors, $W_{i}$, having the units of mass, is used in the SWAT reconstruction of the resultant force vector; and the second set of weighting factors, $G_{i}$, having units of first-moment-ofmass, is used to reconstruct the resultant moment vector. These factors, when used in SWAT, eliminate the elastic response of the cask so that one sum of accelerations yields the rigid body translational acceleration (acceleration of the center of mass) from which the resultant applied force may be determined, and the other sum yields the rotational acceleration from which the resultant applied moment may be determined. The number of accelerometers, $N$, required for force reconstruction in a particular frequency bandwidth is determined by the number of elastic and rigid body modes of the structure in that bandwidth.

The weighting factors for a set of accelerometer measurements can be determined using the mode shape coefficients from a free-body modal analysis. The theoretical development and method for determining the weighting factors are discussed in detail elsewhere (Gregory et al., 1986; Priddy et al., 1988; Priddy et a1., 1989). Briefly, the mode shape coefficients are used in a set of $N$ simultaneous algebraic equations to solve for the $\mathrm{N}$ unknown weighting factors for each component of the force and moment vectors. The equations used to calculate the weights for a force vector particular component are equivalent to a statement of 
orthogonality between the rigid body translational modes and each of the elastic and rigid body modes. Similarly, the weight equations for a moment vector component are equivalent to a statement of orthogonality between the rigid body rotational modes and each of the elastic and rigid body modes.

The weighting factors are used directly with the measured acceleration signals, $a_{i}$, to reconstruct the applied force, $F$, and moment, $T$, with the scalar equations for the one dimensional case:

$$
F=\sum_{i=1}^{N} W_{i} \cdot a_{i}
$$

and

$$
T=\sum_{i=1}^{N} G_{i} \cdot a_{i}
$$

A set of weights can be calculated for each vector component of the force and moment. The acceleration measurements (or the weighted sum) must be low pass filtered consistent with the bandwidth (number of modes) for which the problem was formulated.

The strategic placement of accelerometers can also allow additional modes to be cancelled to extend the usable bandwidth of the force and moment measurements for a given number of accelerometers. One strategy places the accelerometers on the nodal lines for a particular mode (Priddy et al., 1988). A second strategy, used here, allows the elimination of several modes for axisymmetric structures. Rings of symmetrically located accelerometers, where the weights are of equal magnitude, can be used to eliminate certain circumferential harmonic modes.

To measure the axial force component, rings of four accelerometers, equally spaced around the circumference with the sensitive axis of the accelerometers oriented in the axial direction, can be used. This 
accelerometer arrangement is illustrated in Figure F-1. The axial components of the first (bending, $n=1$ ) and second (ovaling, $n=2$ ) harmonic mode shapes at these locations will sum to zero for each ring. This can be shown if the axial acceleration component of the nth harmonic mode shape in cylindrical coordinates is expressed as

$$
a_{n}(x, \theta, t)=A_{n}(x, t) \cdot \sin (n \theta+\phi) .
$$

The acceleration at the ith accelerometer of a ring can then be written as

$$
\begin{gathered}
a_{n 1}(x, t)=a_{n}\left(x, \theta_{1}, t\right)=A_{n}(x, t) \cdot \sin \left(n \theta_{1}+\phi\right) \\
\text { for } i=1,2,3,4
\end{gathered}
$$

where $\mathrm{x}$ is the axial coordinate of the ring, $\theta_{1}$ is the angular coordinate of the ith accelerometer, and $\phi$ is a mode shape position angle. It can be shown that the sum of the axial accelerations at the four accelerometer locations will be zero for all $n$ not divisible by four $(n=1,2,3,5$, $6,7 \ldots)$. To illustrate this concept, an example is shown for $n=1$, in which the angular locations of the four accelerometer are

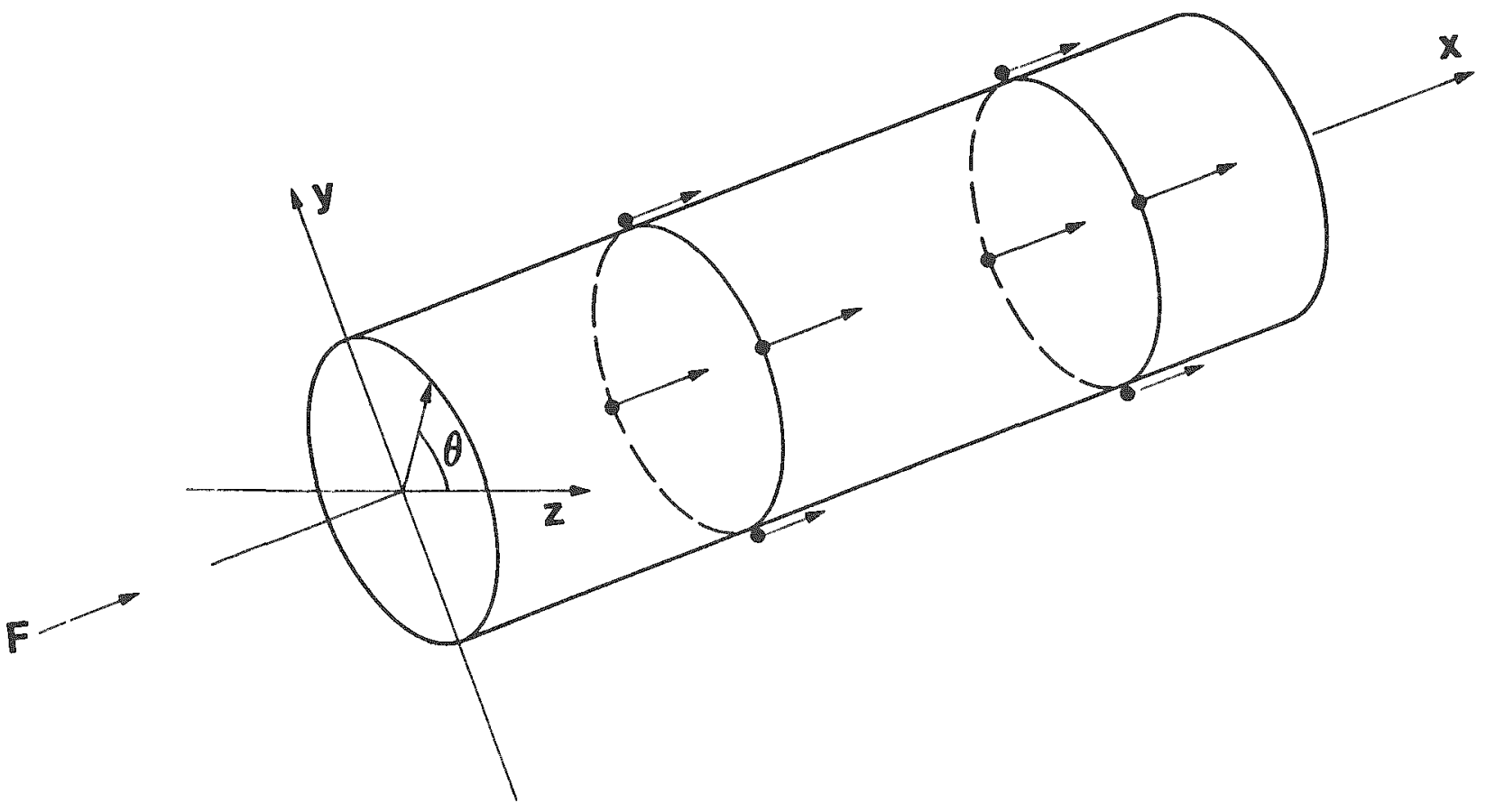

Figure F-1. Accelerometer Placement to Measure Axial Force Component 


$$
\begin{aligned}
& \theta_{1}=\theta \text { (Arbitrary), } \\
& \theta_{2}=\theta+\pi / 2, \\
& \theta_{3}=\theta+\pi, \text { and } \\
& \theta_{4}=\theta+3 \pi / 2 .
\end{aligned}
$$

These four locations are substituted into Equation 4, and a summation of the four acceleration is

$$
\begin{aligned}
\sum_{i=1}^{4} a_{1 i}(x, t)= & A_{1}(x, t) \cdot\left[\sin \left(\theta_{1}+\phi\right)+\sin \left(\theta_{2}+\phi\right)+\sin \left(\theta_{3}+\phi\right)\right. \\
& \left.+\sin \left(\theta_{4}+\phi\right)\right] .
\end{aligned}
$$

This expression may be simplifed with the trigonometric identities,

$$
\begin{aligned}
\sin (\alpha+\pi / 2) & =\operatorname{Cos} \alpha, \\
\sin (\alpha+\pi) & =-\operatorname{Sin} \alpha, \text { and } \\
\sin (\alpha+3 \pi / 2) & =-\operatorname{Cos} \alpha .
\end{aligned}
$$

The relations in Equation 7 are substituted into Equation 6 as

$$
\begin{aligned}
\sum_{i=1}^{4} a_{1 i}(x, t) & =A_{1}(x, t) \cdot[\sin (\theta+\phi)+\cos (\theta+\phi)-\sin (\theta+\phi)-\cos (\theta+\phi)] \\
& =0
\end{aligned}
$$

In the same manner, the sum of the axial accelerations for the other harmonic modes can also be shown to be zero.

The axial components of the zero harmonic $(n=0)$ modes will be equal for each ring. As a result, each ring of accelerometers can be treated as a single measurement point in the calculation of the weighting factors, and the calculated weight is equally divided among the four accelerometers. The required number of rings of accelerometers is then equal to the number of nontorsional, zero harmonic modes, including the axial rigid body translational mode, within the desired frequency bandwidth. 
For lateral force component measurement, accelerometer pairs located 180 degrees apart at different axial stations can be used. The sensitive axis of the accelerometers is oriented in the lateral direction, tangent to the axisymmetric structure, as shown in Figure $F-2$. The tangential components of even harmonic $(n=0,2 \ldots)$ mode shapes will sum to zero for each pair of gages. This can be shown in a manner similar to that for the previous example for the axial component. The tangential components of the first harmonic $(n=1)$ modes will be the same for each accelerometer pair. The pairs can be treated as a single measurement point in the calculation of the weights, and the calculated weight for each axial station is divided equally between the two accelerometers. The required number of accelerometer pairs is equal to the number of first harmonic modes, including the rigid body translational and rotational modes, within the desired frequency bandwidth.

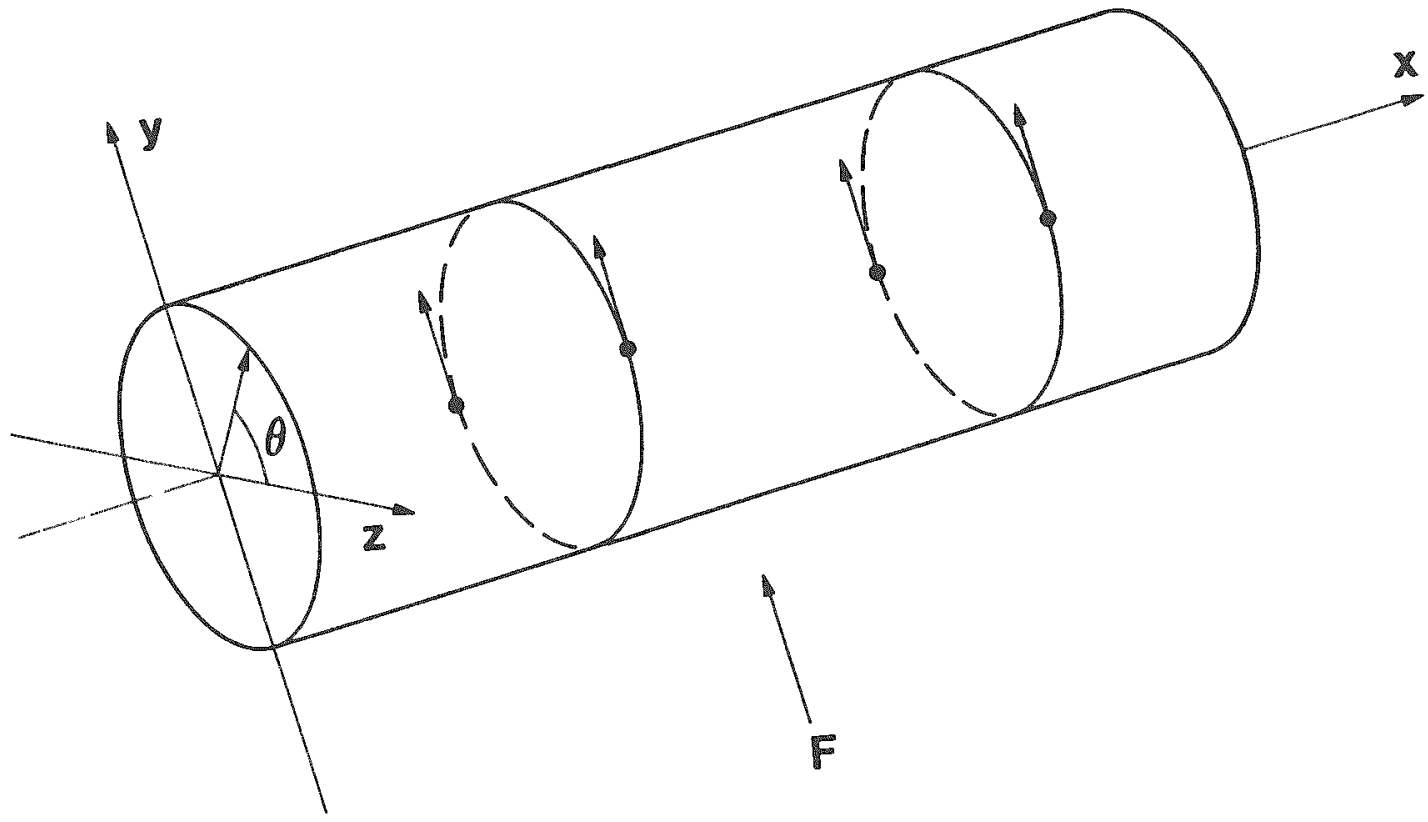

Figure F-2. Accelerometer Placement to Measure Lateral Force Component 
By eliminating certain circumferential harmonic modes, the gage placement strategy described above effectively decreases the modes in a particular bandwidth and increases the number of modes that can be cancelled by the SWAT. As a consequence, the problem formulation for an axisymmetric structure such as the cask is simplified to that which is required for a rod or a beam.

The DECON technique infers the applied force by combining the measured acceleration with impulse response functions. Deconvolution requires that the point of application of the forces on the structure be known. Forces applied at other points contaminate the deconvolution force reconstruction and cannot be separated from the desired forces without reformulation of the problem. Theoretically, the number of accelerometers required is equal to the number of forces to be reconstructed; but the technique is more successful if there are more accelerometers than forces (Hillary and Ewins, 1984). Also, the technique can be implemented with either accelerometers or strain gages and can be used in situations where the number of instrumentation channels is limited (Bateman, 1989).

The deconvolution technique is a solution to the general measurement convolution integral,

$$
\underline{a}(x, t)=\int_{0}^{t} \int_{0}^{L} \underline{h}(x, \xi ; \tau) \underline{f}(\xi, t-\tau) d \xi d \tau,
$$

where $\underline{a}$ is a vector of the accelerometer measurements, $\underline{h}$ is a matrix of characterizations for the cask in the form of impulse response functions for the locations $x$, and $\underline{f}$ is the vector of forces applied at the $\xi$ locations which excite the accelerometer response. The formula in Equation 9 takes into account the spatial distribution of lateral forces which are applied at either end of the cask as shown in Figure F-3. The $\underline{h}(\mathrm{x}, \xi ; \tau)$ functions were measured from forces applied to the two ends of the cask by an instrumented hammer which is typically used for modal analysis. The responses, a, were measured at four locations as shown in Figure F-3, but it was found that by averaging the responses at the same axial location, but 180 degrees apart along the circumference, the effect 


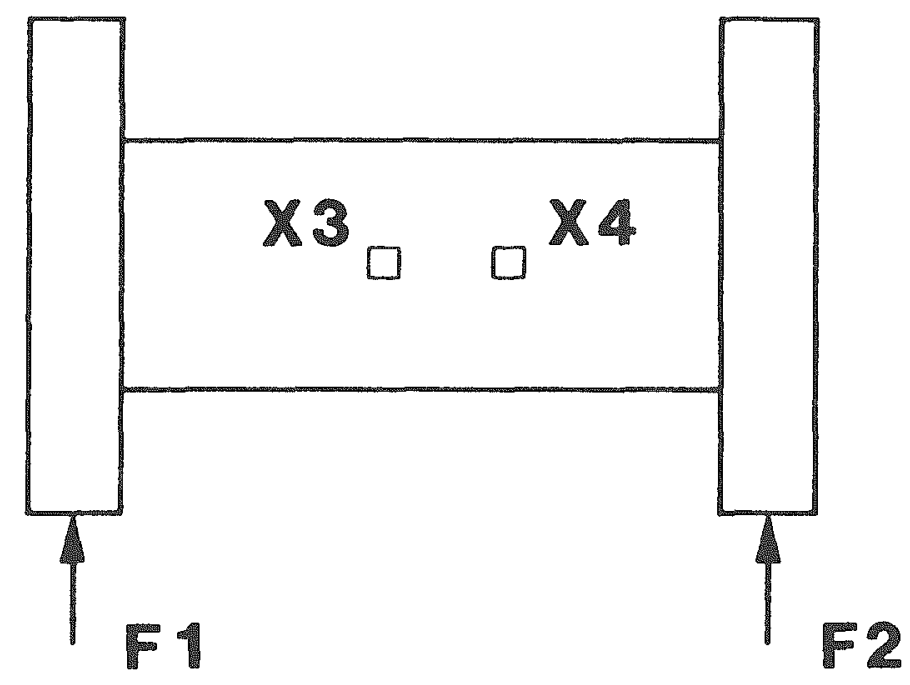

Figure F-3. Accelerometer Locations and Assumed Input Force Points for DECON

of the circumferential harmonic modes was eliminated as explained previously for the SWAT technique. Consequently, both a and $\underline{h}$ were calculated from averaged responses, which reduced the dimension of the vectors and matrices and gave simpler, smoother functions in the frequency domain. The force is calculated from a discrete form of Equation 9 transformed into the frequency domain as

$$
\underline{A}(j \omega)=\underline{H}(j \omega) \mathbb{E}(j \omega),
$$

where $A(j \omega)$ is a $2 \times 1$ vector of the Fourier transforms of the measured responses, $\underline{H}(j \omega)$ is a $2 \times 2$ matrix of frequency response functions (FRF) which are Fourier transforms of the elements in the impulse response function matrix, and $F(J \omega)$ is a $2 \times 1$ vector of the Fourier transforms of the forces applied to the cask. Equation 10 may be solved for the force vector of the two lateral forces applied on either cask end; the Fourier transform of the force vector is 


$$
\underline{F}(j \omega)=\underline{H}^{-1}(j \omega) \mathbb{A}(j \omega) .
$$

The solution of Equation 11 implicitly assumes that the forces applied in the lateral direction are applied at the two cask ends, which are the same locations the cask was excited for the measurement of $\underline{H}$. Additionally, the force vector, $\underline{F}$, represents two separate forces that must be added to determine the resultant force applied to the cask.

To measure the axial force component, one axial force is assumed, as shown in Figure F-1. A ring of four accelerometers is used to eliminate the circumferentially harmonic modes and to simplify the frequency response functions. Because there are four response measurements and one force, the inverse of the frequency response function matrix, $\underline{H}^{-1}$, is formed from

$$
\underline{H}^{-1}=\left[[\underline{H} *]^{T} \cdot \underline{H}\right]^{-1} \cdot[\underline{H} *]^{T}
$$

where $\left[\underline{H}^{*}\right]^{T}$ is the conjugate transpose of $\underline{H}$. In this formulation, $\underline{H}^{-1}$ is the pseudo-inverse and represents an equivalent 1east-squares solution to the force in Equation 11 (Stevens, 1987). The accelerometer ring furthest from the force input is chosen for the deconvolution because the anti-resonances in the FRFs are less severe in magnitude, so there is less noise in the force reconstruction.

As mentioned above, Bateman et al. (1989) also include a description of laboratory calibration tests performed to validate these techniques before implementing them in the drop test. For the SWAT, eight accelerometer responses are each multiplied by the appropriate weight for the force or moment; a summation of weighted accelerations is formed for the force and for the moment. For the DECON technique, a matrix of FRFs from all the force input points to the measured accelerometers is required. There are two force input points assumed and two accelerometer responses; each response was the average of two accelerometer signals. Both techniques were implemented in algorithms on the interactive GENRAD 2515 data acquisition and computer system so that the reconstructed forces could be computed and displayed momentarily after the 
accelerometer responses were acquired both in the laboratory and at the slapdown site.

With the two force reconstruction algorithms implemented for the cask, the cask becomes a force transducer which will measure the externally applied force. The theory discussed previously describes the relationship between the accelerometer responses and the applied force; however, as with any force transducer, the cask must be calibrated to verify the assumed relationships. For the calibration test, the cask was suspended on elastic straps. Instrumented impact hammers were calibrated and used to apply one or more forces, and the accelerometer responses on the cask were measured simultaneously and input to the algorithms. The input forces were measured and stored so that the measured forces could be directly compared with the reconstructed forces. A similar series of calibration tests was performed to validate the DECON algorithm. Because DECON assumes separate input forces at either cask end, two separate force-time histories are computed in contrast to the composite force computed with the SWAT algorithm. Both for the SWAT and the DECON technique, the calibration experiments showed that the algorithms produced accurate applied force reconstructions during the force pulse.

For the slapdown test, the cask was instrumented with numerous cransducers, but only eight accelerometers were used for the force reconstruction. Two accelerometers at each of four axial locations were mounted 180 degrees apart and aligned circumferentially with the cask so that they pointed in the vertical direction. All eight acceleration responses were used for the SWAT algorithm, but only four were used in the DECON algorithm. In both cases, the two acceleration responses at an axial location were first added in the time domain to eliminate some of the circumferentially harmonic modes. Since the cask was dropped with a ten-degree inclination to the horizontal, an impact first on one end and then an impact on the other end was expected to produce two separate impact forces. It was uncertain to what extent the forces would overlap in time. The DECON algorithm computes both of these impact forces as separate functions. In contrast, the SWAT algorithm computes the sum of 
the external force as a single function and the moment about the centerof-mass. The calculated forces and moments are those applied to the cask body by the impact limiters and are not the total force applied to the entire system including the limiters. The results of the slapdown test using these two algorithms are discussed below.

Displayed in Figure $F-4$ is the force time-history computed for the slapdown using the SWAT algorithm. One can see that the impact force lasted approximately thirty-five milliseconds with a peak value of about 500,000 pounds. Also, the two separate force pulses that result from the slapdown impact are clearly visible; the second pulse has a slightly higher peak value as expected for the slap-down (Sjaardema and Wellman, 1988). As a check on the validity of the reconstruction, the force in Figure F-4 was integrated to calculate the impulse, which is equal to the momentum at impact. The calculated impact momentum was within one percent of the theoretical free-fall momentum.

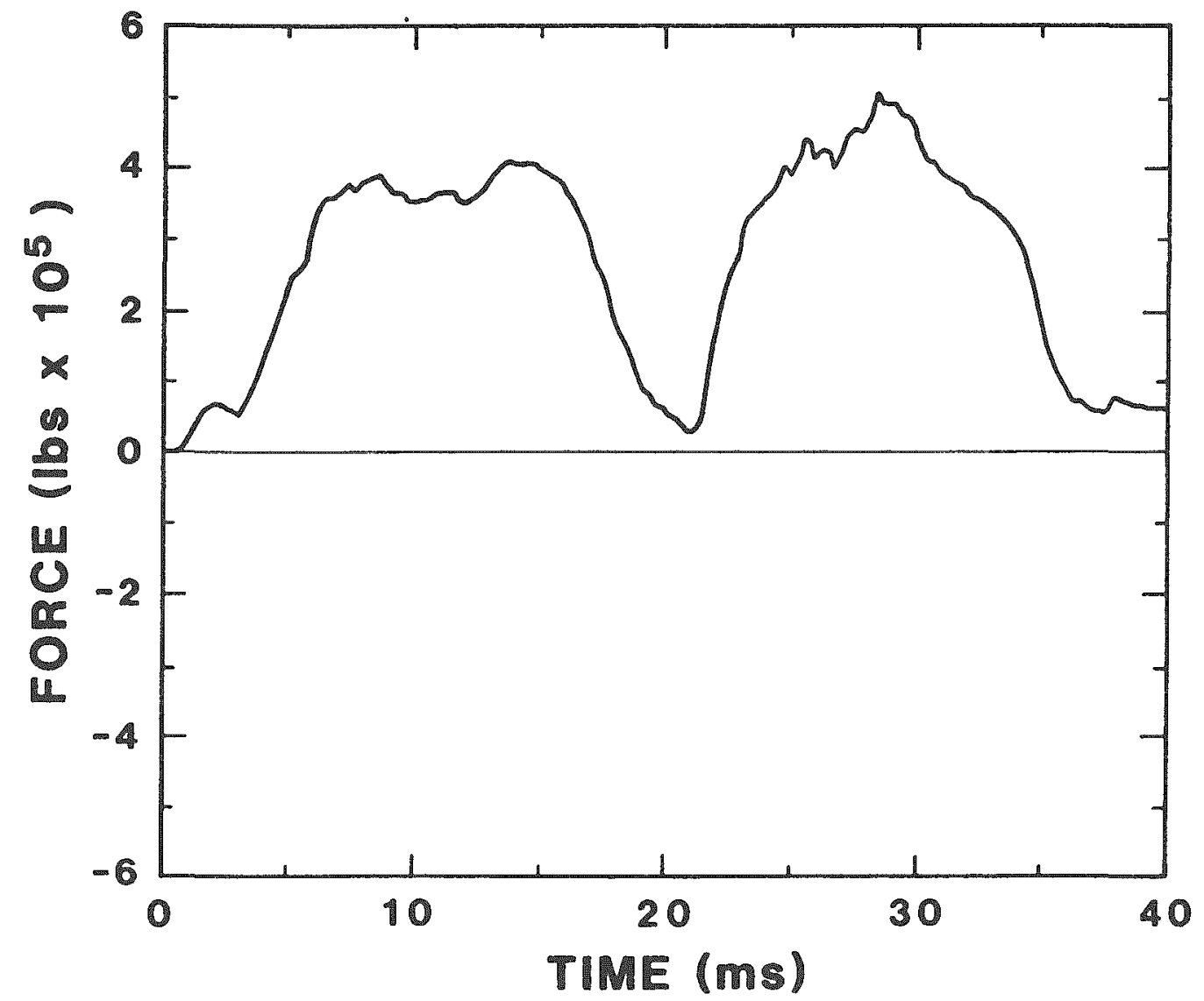

Figure F-4. Reconstructed Lateral Force for Slapdown Test Using SWAT 
Figure F-5 shows the corresponding moment about the center-of-mass, calculated using SWAT, and reflects the two-lobed character of the applied force. The moment is at first positive and then changes sign as the cask slaps down. The second part of the moment is more severe than the first because it has a higher peak magnitude, a faster rise-time, and more sharp peaks. This moment is the total moment resulting from all external loads on the cask and includes moments from forces perpendicular and parallel to the cask axis and moments applied by the impact limiters.

The applied moment is integrated and divided by the cask moment of inertia to calculate the angular velocity during the impact; the angular velocity is shown in Figure F-6. This calculation serves as another check on the reconstruction because the angular velocity was zero at the beginning and the end of the event. The angular velocity shows only a very slight deviation from zero at the end of the record. These data were also compared to angular velocity measurements from high-speed photography; the two results were virtually identical. Angular position was measured from a 400-frame/sec camera and differentiated once to obtain the angular velocity.

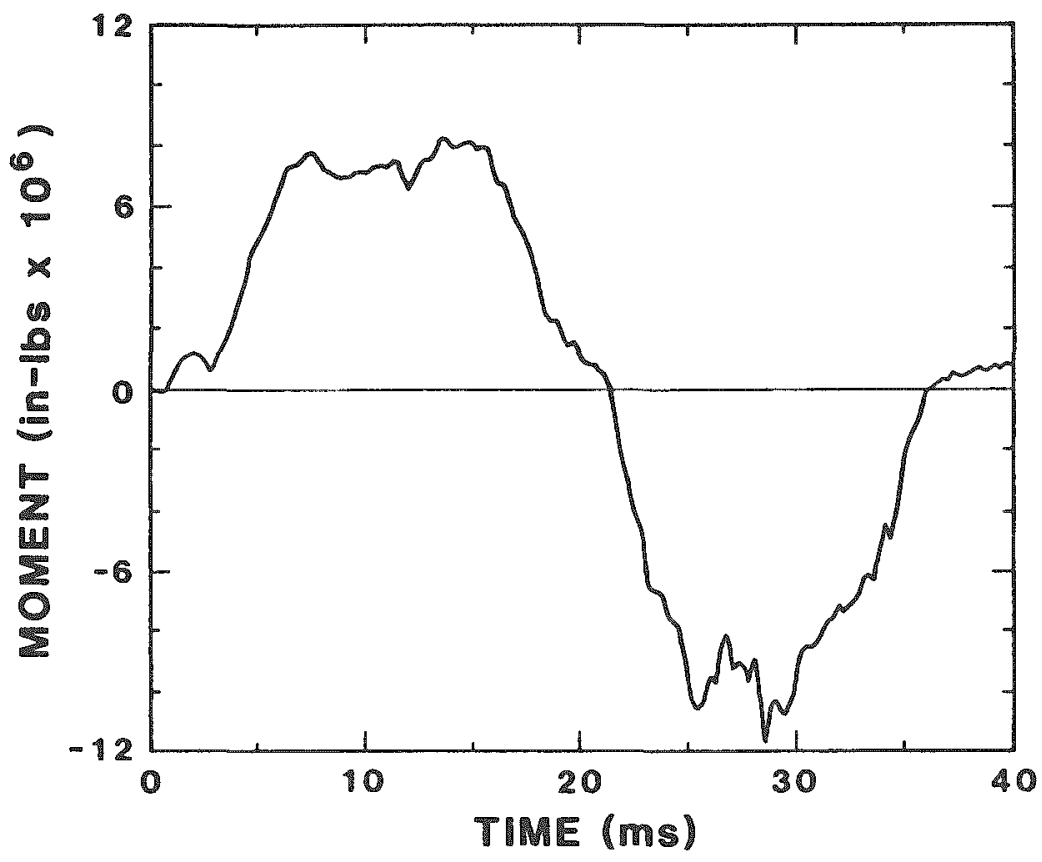

Figure F-5. Reconstructed Moment for Slapdown Test Using SWAT 


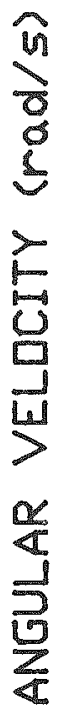

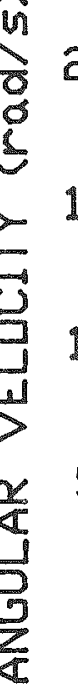
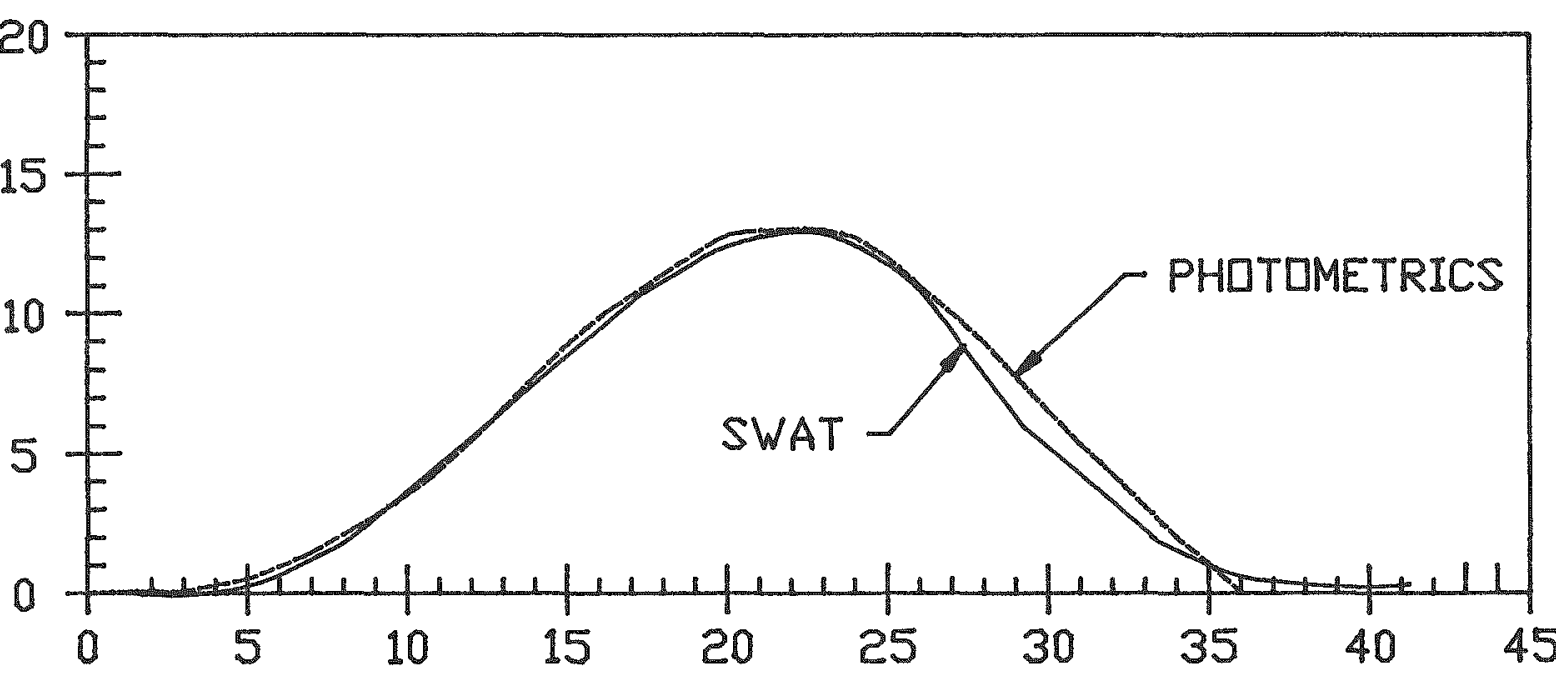

TIME (MS)

Figure F-6. Reconstructed Angular Velocity for Slapdown Test

Using DECON, the external forces were also reconstructed, assuming two impact forces perpendicular to the cask axis applied at either cask end. The two reconstructed forces are shown in Figure $F-7$ and F-8. The same character is evident in these forces as those reconstructed using SWAT: a large positive force initially at the primary impact followed by another large force at the second impact end. The two reconstructions also show interactions between the cask and the limiters outside the respective impact durations.

A comparison of the force reconstruction from SWAT to that from DECON is made by adding the two forces from DECON to obtain the total external force. This comparison is in Figure F-9; the results are remarkably similar. The primary impact shows extremely close agreement between the two reconstructions. For the second impact, DECON produces slightly larger values, but the shape of the force is quite similar including all the high-frequency spikes. 


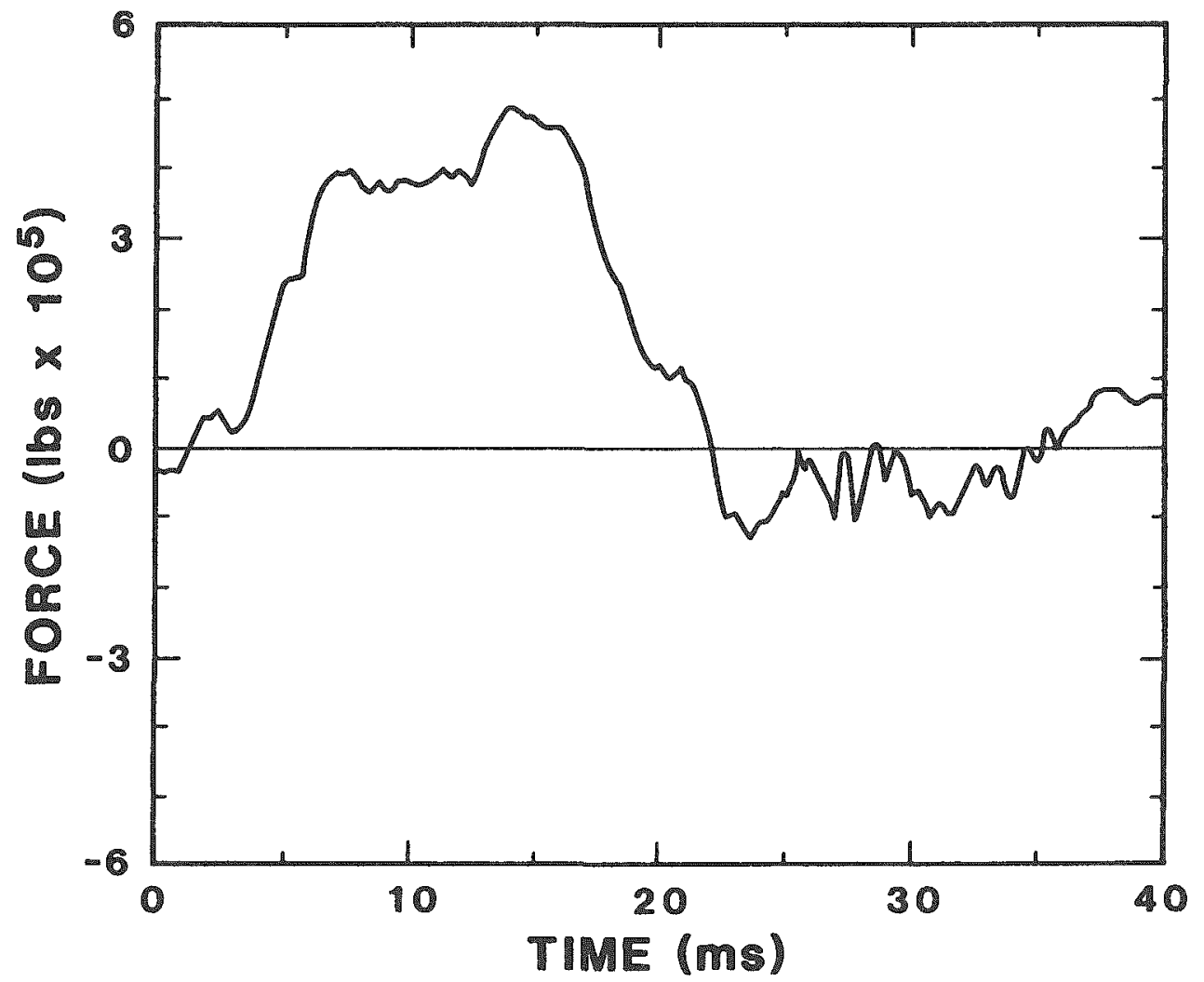

Figure F-7. Force Reconstruction for Primary End Using DECON

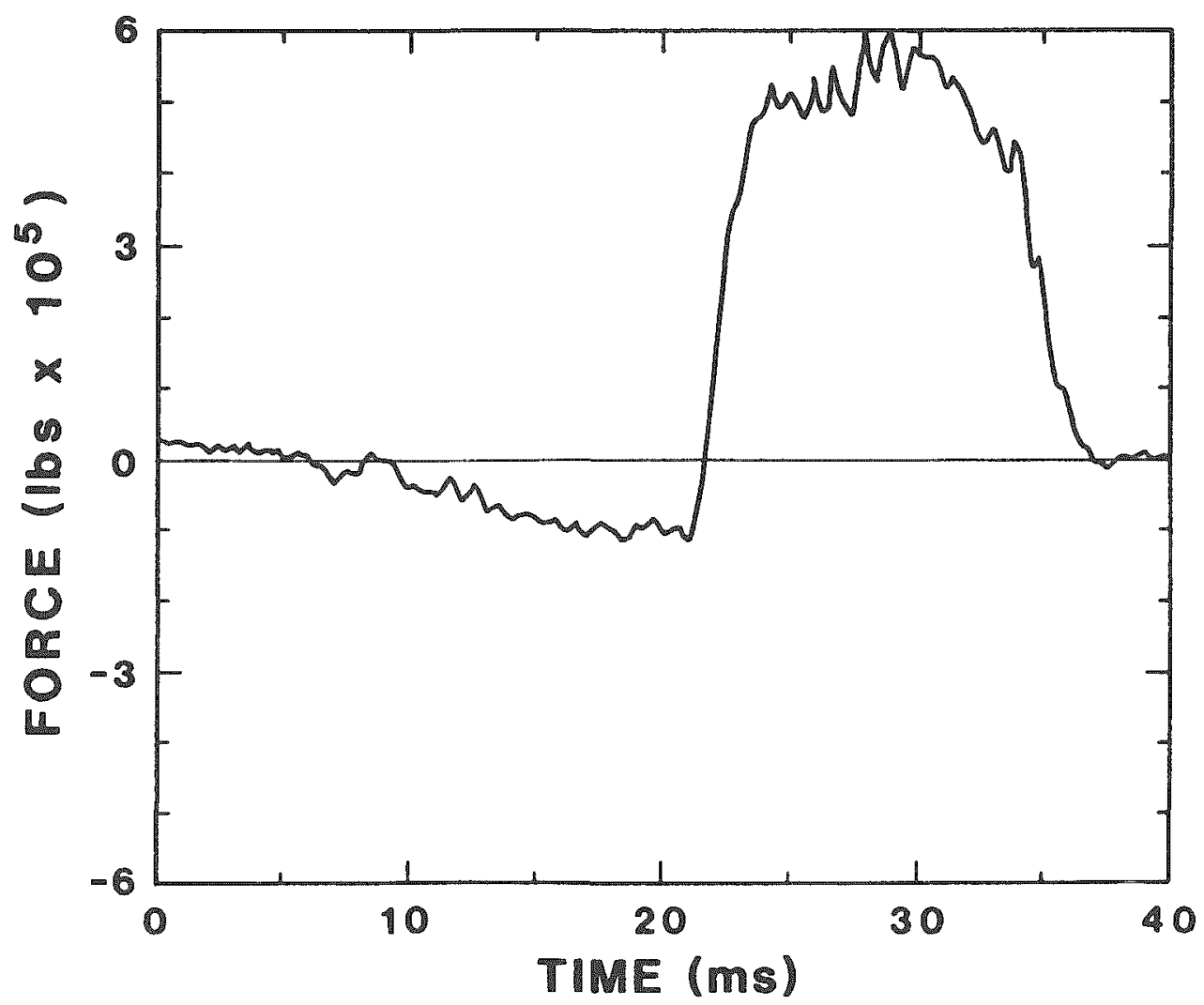

Figure F-8. Force Reconstruction for Secondary End Using DELON 


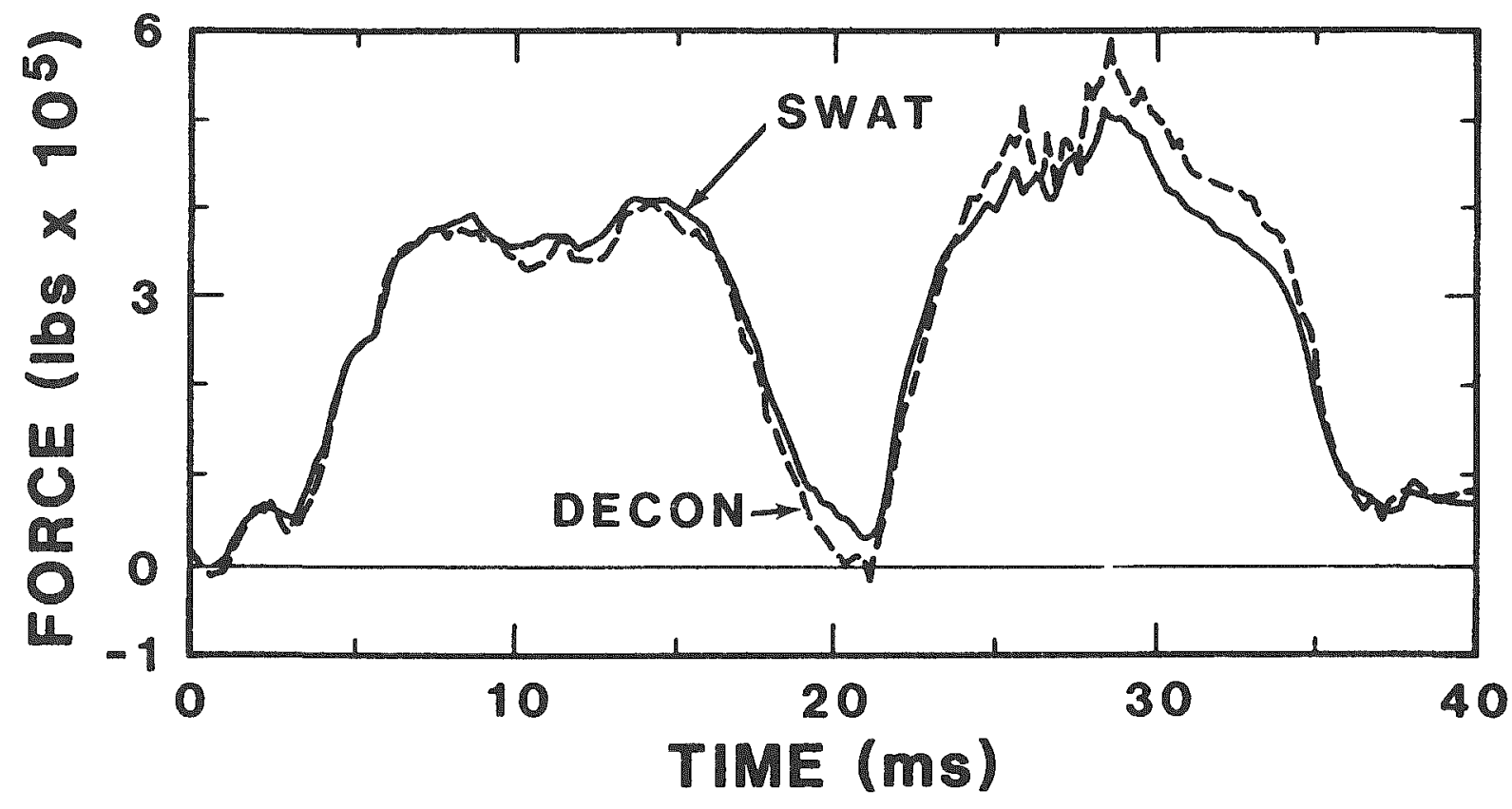

Figure F-9. Comparison of Reconstructed Forces from SWAT and DECON

Figure F-10 compares the SWAT results to results obtained from a single accelerometer with the data filtered to $1500 \mathrm{~Hz}$. As can be seen, there is good agreement. However the accelerometer trace contains a considerable amount of high-frequency response which is not representative of the cask body as a whole. That is, it does not represent the rigid body motion of the cask. Filtering accelerometer data to a frequency below the fundamental frequency of the cask body greatly smooths the data but also affects the rise time and peaks. Figure F-11 is a plot of force versus time for the cask from the slapdown test with data from the two techniques superimposed. The filtered accelerometer data is from an accelerometer trace filtered to $500 \mathrm{~Hz}$. As can be seen there is good general agreement; however, the filtered data fails to accurately capture the rise time of the pulse and, in the secondary impact, underestimates the peak value by about 20 z 


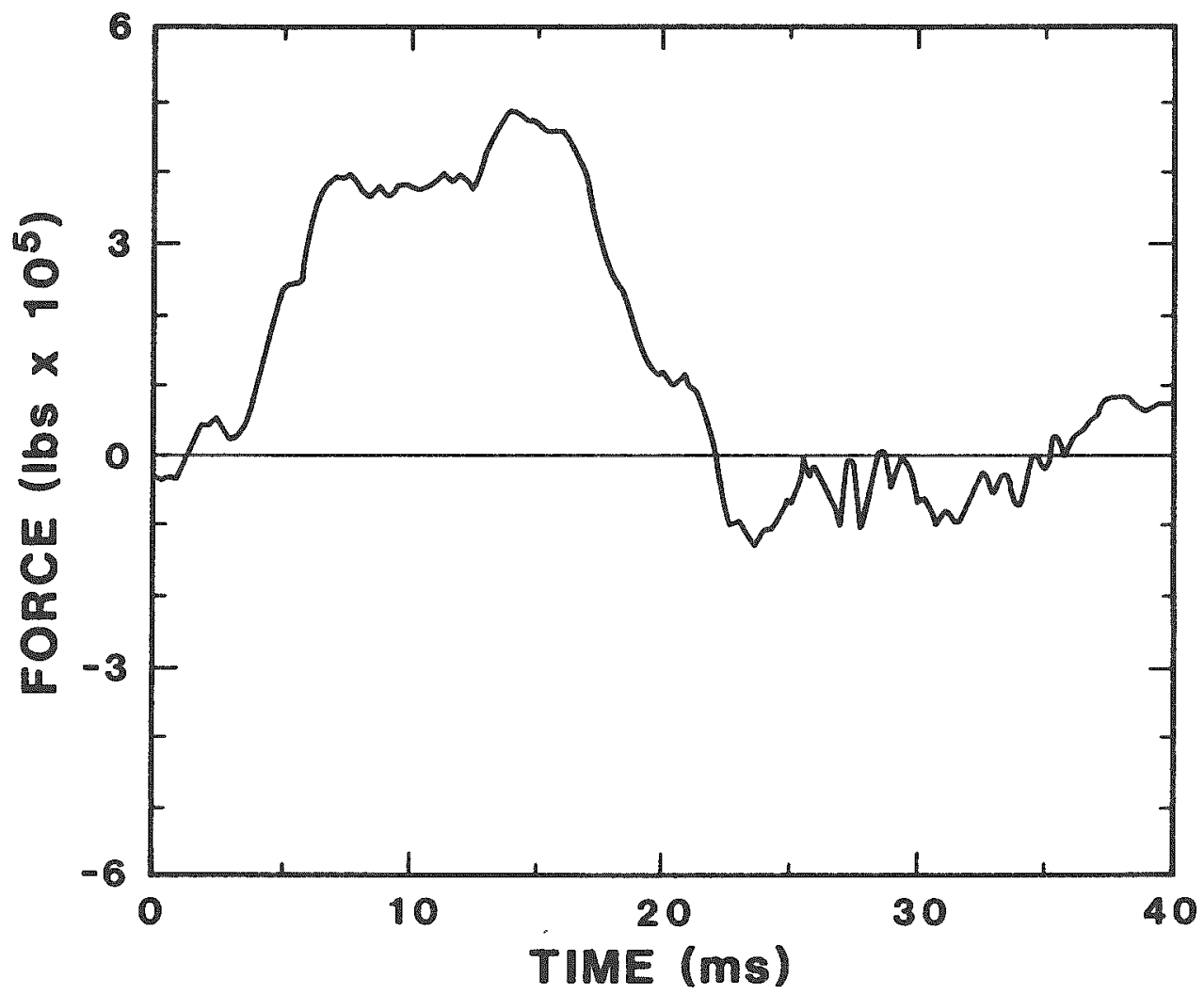

Figure F-7. Force Reconstruction for Primary End Using DECON

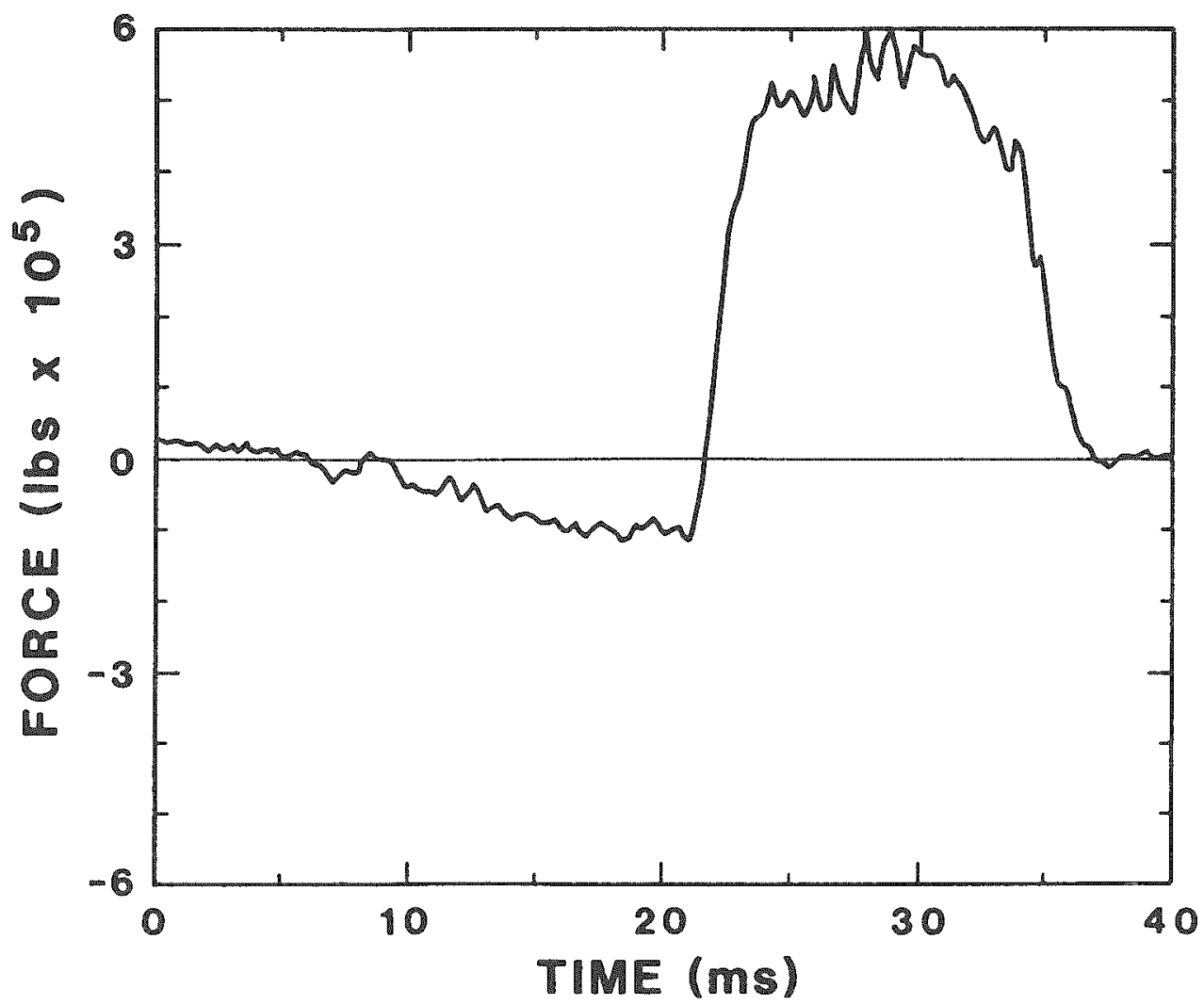

Figure F-8. Force Reconstruction for Secondary End Using DECON 


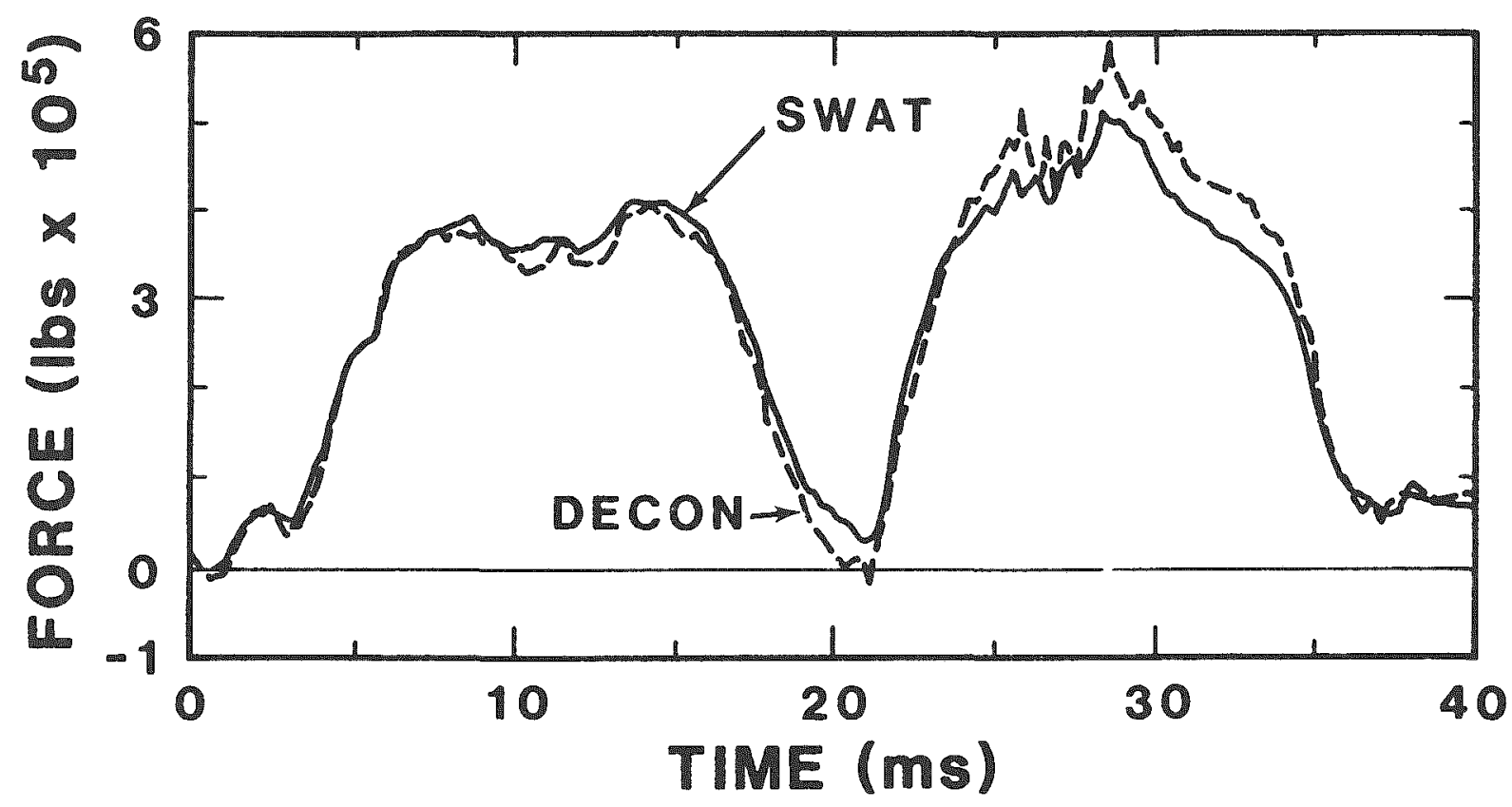

Figure F-9. Comparison of Reconstructed Forces from SWAT and DECON

Figure F-10 compares the SWAT results to results obtained from a single accelerometer with the data filtered to $1500 \mathrm{~Hz}$. As can be seen, there is good agreement. However the accelerometer trace contains a considerable amount of high-frequency response which is not representative of the cask body as a whole. That is, it does not represent the rigid body motion of the cask. Filtering accelerometer data to a frequency below the fundamental frequency of the cask body greatly smooths the data but also affects the rise time and peaks. Figure F-11 is a plot of force versus time for the cask from the slapdown test with data from the two techniques superimposed. The filtered accelerometer data is from an accelerometer trace filtered to $500 \mathrm{~Hz}$. As can be seen there is good general agreement; however, the filtered data fails to accurately capture the rise time of the pulse and, in the secondary impact, underestimates the peak value by about $20 \%$. 


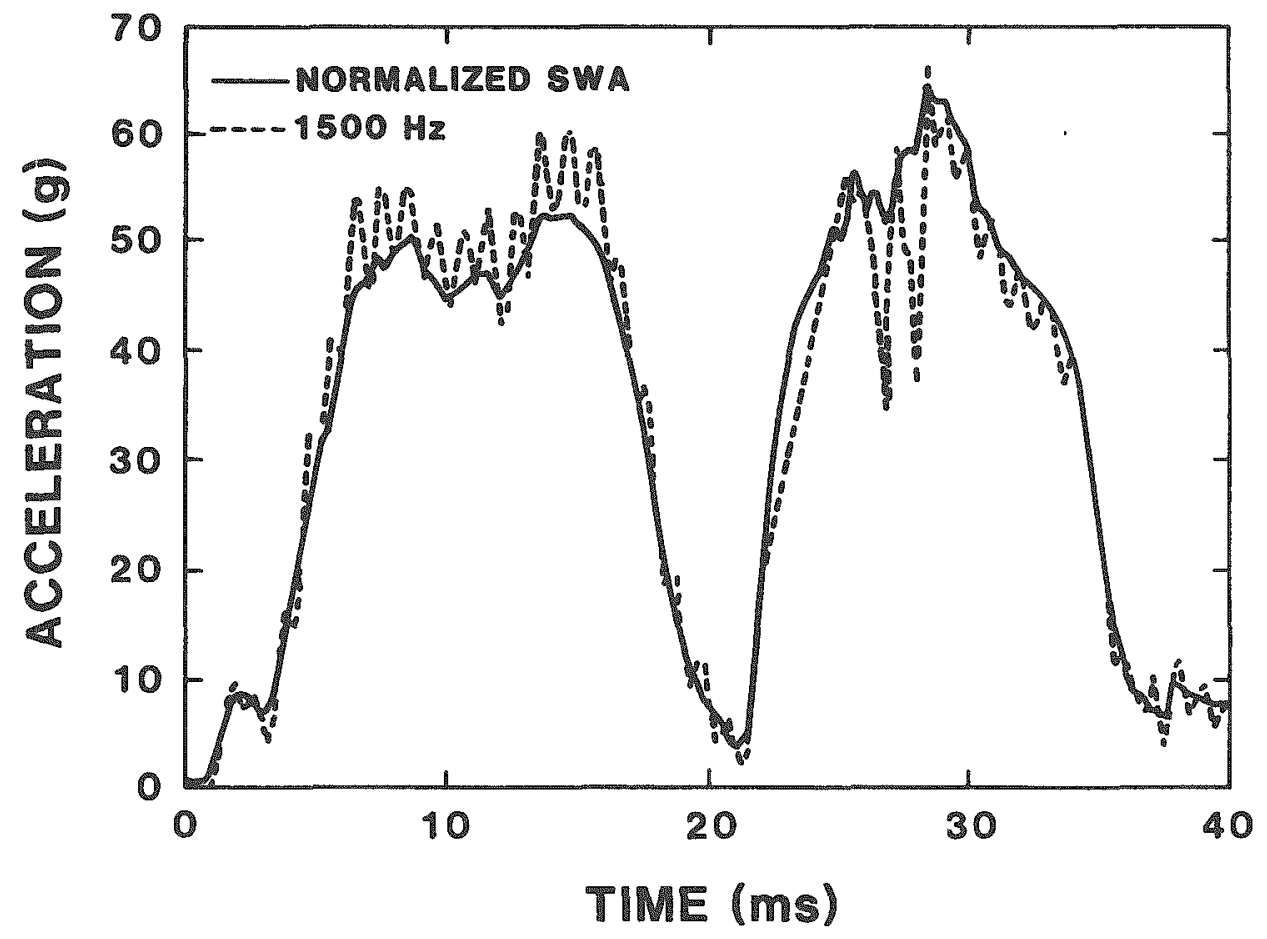

Figure F-10. Comparison of Normalized SWAT and 1500-Hz Filtered Accelerometer Data

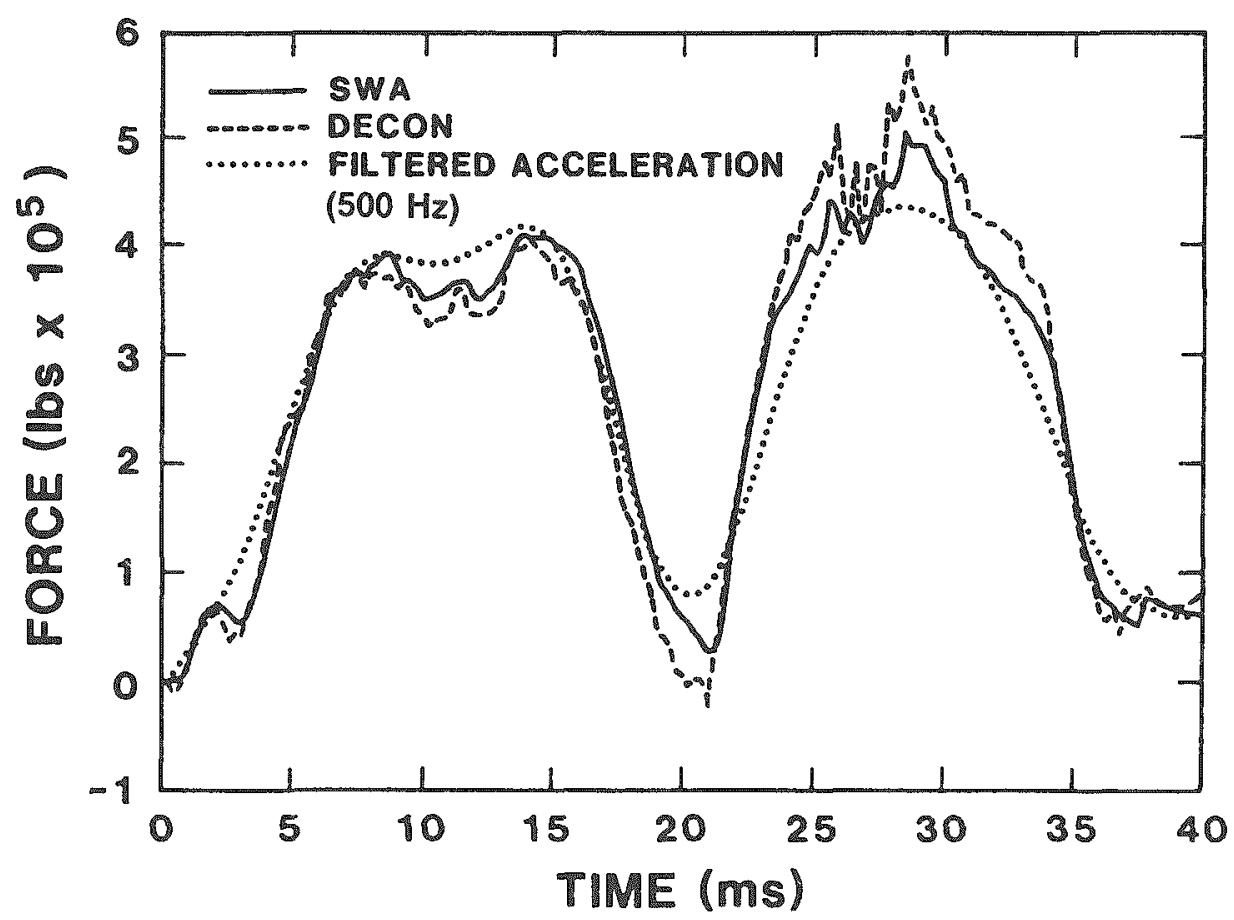

Figure -11 . Comparison of Reconstructed Forces From SWAT and DECON with Force Estimated by Conventional Filter Technique 
Bateman, V. I., 1989. "Force Reconstruction for the G-M118 Field Test of the Strategic Earth Penetrator Weapon," SAND88-3046/UC-32, National Technical Information Service, Springfield, VA.

Bateman, V. I., T. G. Carne, D. L. Gregory, S. W. Attaway, and H. R. Yoshimura, 1989. "Force Reconstruction for the Slapdown Test of a Nuclear Transportation Cask," SAND88-3045, Sandia National Laboratories, Albuquerque, NM.

Gregory, D. L., T. G. Priddy, and D. O. Smallwood, 1986. "Experimental Determination of the Dynamic Forces Acting on Non-Rigid Bodies," SAE Technical Paper Series, Paper No. 861791, Aerospace Technology Conference and Exposition, Long Beach, CA.

Hillary, B., and D. J. Ewins, 1984. "The Use of Strain Gages in Force Determination and Frequency Response Function Measurements," Proceedings of the 1984 Internal Modal Analysis Conference, Orlando, FL, February 69. pp. 627-634.

Priddy, T. G., D. L. Gregory, and R. G. Coleman, 1988. "Strategic Placement of Accelerometers to Measure Forces by the Sum of Weighted Accelerations," SAND87-2567/UC-38, National Technical Information Service, springfield, VA.

Priddy, T. G., D. L. Gregory, and R. G. Coleman, 1989. "Measurement of Time-Dependent External Moments by the Sum of Weighted Accelerations," SAND88-3081/UC-38, National Technical Information Service, Springfield, VA.

Sjaardema, G. D., and G. W. Wellman, 1988. "Numerical and Analytical Methods for Approximating the Eccentric Impact Response (Slapdown) of Deformable Bodies," SAND88-0616/UC-71, National Technical Information Service, Springfield, VA.

Stevens, K. K., 1987. "Force Identification Problems - An Overview," Proceedings of the 1987 SEM Spring Conference on Experimental Mechanics, Houston, TX, June 14-19, pp. 838-844. 
U.S. Department of Energy

office of Scientific \& Technical Information (175)

Oak Ridge, TN 37830

Attn: DOE/OSTI-4500-R74 UC-820

U.S. Department of Energy (2)

1000 Independence SW

Washington, DC 20585

Attn: W. Lake, $\mathbb{R W}-323$

C. Kouts, RW-323

U.S. Department of Energy (6)

Washington, DC 20545

Attn: S. Denny, EM-51

L. Harmon, EM-53

F. Falci, EM-51

H. R. Yoshimura, EM-51

U. S. Department of Energy

Office of Security Regulations

Washington, DC 20545

Attn: J. Leonard, EH-321

U. S. Department of Energy (2)

Albuquerque Operations office

Albuquerque Headquarters

P.O. Bos 5400

Albuquerque, NM 87115

Attn: P. Saxman

K. Golliher

U. S. Department of Energy

Chicago Operations office

9800 S. Cass Avenue, B1dg. 350

Argonne, IL 60439

Attn: R. Rothman

Transnuclear, Inc.

Two Skyline Drive

Hawthorne, NY 10532-2120

Attn: F. J. Williams
U. S. Department of Energy (2)

Idaho Operations Office

550 Second Street

Idaho Fal1s, ID 83401

Attn: M. Fisher

K. Svinicki

EG\&G Idaho, Inc. (3)

1580 Sawtelle Street

Idaho Falls, ID 83415

Attn: D. Abbott

W. Mings

Southwest Engineering Associates 3616 Derick

E1 Paso, TX 79925

Attn: M. Huerta

$\begin{array}{ll}1521 & \text { S. W. Attaway } \\ 3141 & \text { S. A. Landenberger (5) } \\ 3151 & \text { W. I. Klein (3) } \\ 3154-1 & \text { C. L. Ward (8) } \\ 6000 & \text { V. Dugan, Actg. } \\ 6300 & \text { T. Hunter, Actg. } \\ 6320 & \text { R. E. Luna, Actg. } \\ & \text { Attn: TTC Master File } \\ 6320 & \text { TTC Library (25) } \\ 6321 & \text { M. G. Vannoni, Actg. } \\ 6322 & \text { G. F. Hohnstreiter } \\ 6323 & \text { D. R. Bronowski (3) } \\ 6323 & \text { T. L. Sanders } \\ 6323 & \text { W. L. Uncapher (3) } \\ 7541 & \text { V. Bateman } \\ 7543 & \text { T. G. Carne } \\ 7544 & \text { D. L. Gregory } \\ 8524 & \text { J. A. Wackerly }\end{array}$

